NBSIR 79-1623

\title{
FRACTURE CONTROL PRACTICES FOR METAL STRUCTURES
}

H.I. McHenry ${ }^{1}$

S.T. Rolfe ${ }^{2}$

${ }^{1}$ Fracture and Deformation Division

National Measurement Laboratory

National Bureau of Standards

Boulder, Colorado 803.03

${ }^{2}$ University of Kansas

Civil Engineering Department

Lawrence, Kansas 66044

Sponsored by:

David Taylor Naval Ship Research \& Development Center

Annapolis, MD 21402 



\title{
FRACTURE CONTROL PRACTICES FOR METAL STRUCTURES
}

\author{
H.I. McHenry ${ }^{1}$ \\ S.T. Rolfe ${ }^{2}$
}

${ }^{1}$ Fracture and Deformation Division

National Measurement Laboratory

National Bureau of Standards

Boulder, Colorado 80303

2 University of Kansas

Civil Engineering Department

Lawrence, Kansas 66044

Sponsored by:

David Taylor Naval Ship Research \& Development Center

Annapolis, MD 21402

January 1980

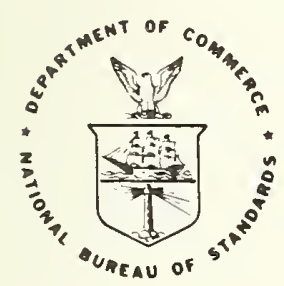

U.S. DEPARTMENT OF COMMERCE, Philip M. Klutznick, Secretary Luther H. Hodges, Jr., Deputy Secretary Jordan J. Baruch, Assistant Secretary for Science and Technology

NATIONAL BUREAU OF STANDARDS, Ernest Ambler, Director 

ADMINISTRATIVE INFORMATION---_-_-

1. INTRODUCTION --1

2. ELEMENTS OF FRACTURE CONTROL-_-_-

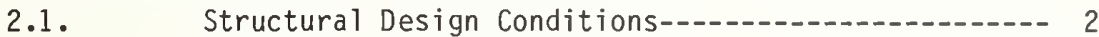

2.1.1. Design Life---_-_- 3

2.1.2. Loads---1

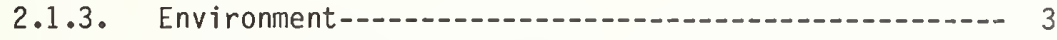

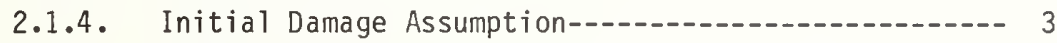

2.1.5. Safety Factors--.-_-_-_- 3

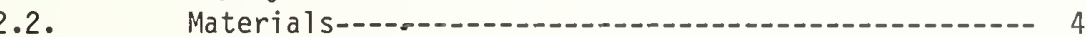

2.2.1. Selection---1.-- 4

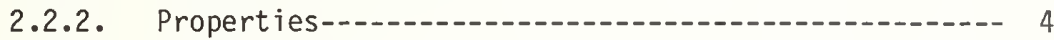

2.2.3. Specifications-_-_-_-_- 4

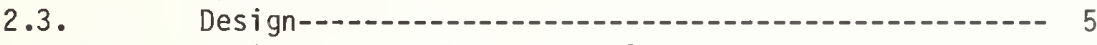

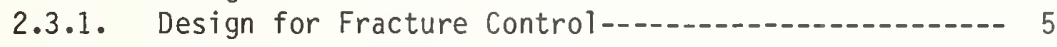

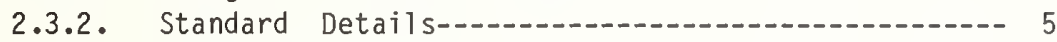

2.3.3. Joining Practices---1-_-_- 5

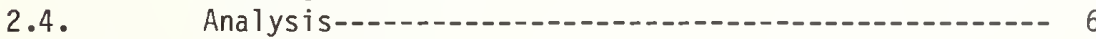

2.4.1. Stress Analysis-_-_- Fatigue Analysis-_- 6

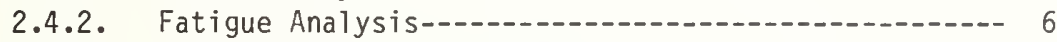

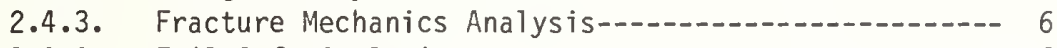

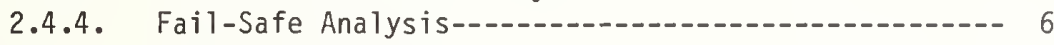

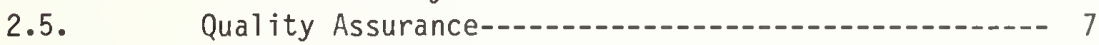

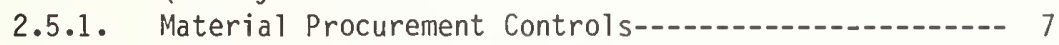

2.5.2. Fabrication and Processing Controls---_-_-_-_----- 7

2.5.3. Inspection--.-.- 7

2.5.4. Proof Testing-_-_-_-_._- 7

2.5.5. Traceability--------------------------------- 8

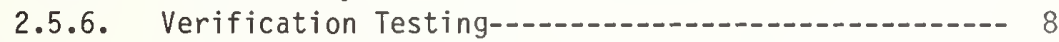

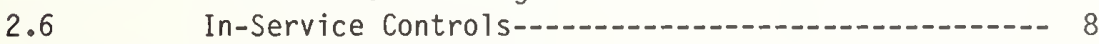

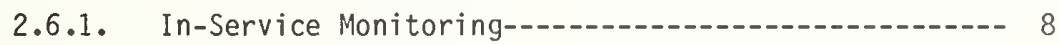

2.6.2. Periodic Inspection-...-- 8

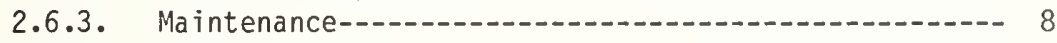

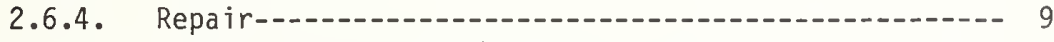

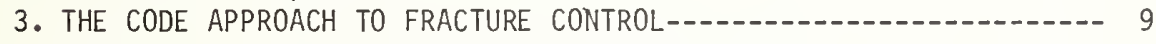

3.1 .

3.1.1. Design Life--_..- 10

3.1.2. Loads---

3.1.3. Environment--1-_-_-_-10 10

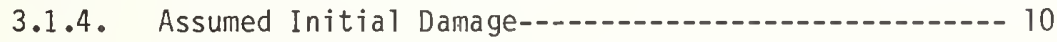

3.1.5. Safety Factors--

3.2

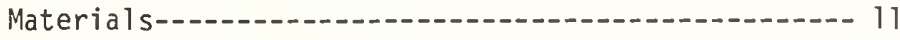

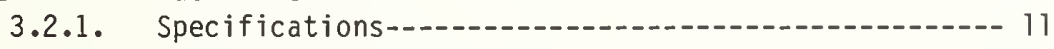

3.2.2. Properties--- Tount--- 12

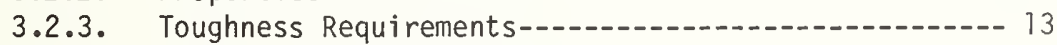

3.3 .

Design and Analysis-_...-.-1 14

3.3.1. Design for Fracture Control-_-_-_-_-_-_-_-_-_-_-- 14

3.3.2. Standard Details-_-_._-_._- 15

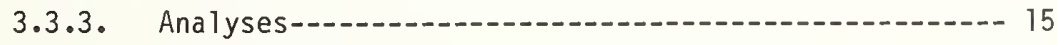

3.3.4. Fatigue Control--_-n-_- 16

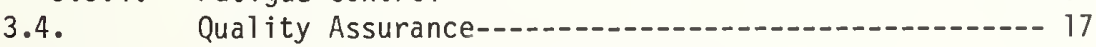

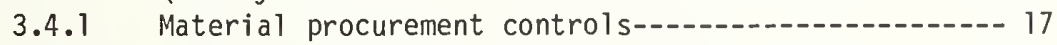

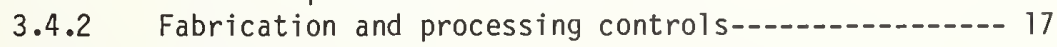

3.4.3 Inspection----

3.4.4 Verification testing--_- 18 
3.5. In-Service Controls 19

3.5.1. Periodic inspection-_... 19

3.5.2. Maintenance and repair-_..... 20

4. THE PERFORMANCE SPECIFICATION APPROACH TO FRACTURE CONTROL-- 20

4.1. Structural Design Conditons------ 20

4.2. Materials-- 21

4.3. Design and Analysis-_.- 21

4.4. Quality Assurance-1.- 22

4.5. In-Service Controls-_.

5. FRACTURE CONTROL CONCEPTS FOR NAVAL SYSTEMS-_.

5.1. Steel Toughness Requirements------ 23

5.1.1. The strain rate shift-_- 23

5.1.2. Metallurgical controls-- Toughness saturation-_- 24

5.1.3. Toughness saturation-_-_-_.-. 24

5.2. Weld Quality Standards-_-_- 24

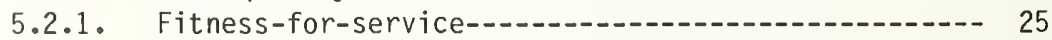

5.2.2. Assessment of flaws detected during in-service

5.3. Aerospace Practices for High Performance Structures 26

5.3.1. Loads-.-.-.- Ful]-scale testing- 26

5.3.2. Full-scale testing---10-- 26

5.3.3. Fracture critical parts-- 27

6. SUMMARY COMMENTS-_- 28

7. ABBREVIATIONS-_ 29

APPENDIX---1X-- 31

MERCHANT SHIPS-.._- 32

LNG SHIPS - CONTAINMENT SYSTEMS--10 36

FIXED OFFSHORE STRUCTURES---1-10 44

FLOATING NUCLEAR POWER PLANT---1-- 53

LNG STORAGE TANKS-- 56

STEEL BRIDGES--.-1 6 T

LARGE ROTATING EQUIPMENT---1-- 65

PRESSURE VESSELS-.-1- 68

NUCLEAR PRESSURE VESSELS-1- 72

GAS AND OIL PIPELINES-_-

PRESSURE PIPING--POWER AND CHEMICAL INDUSTRIES---------- 82

USAF AIRCRAFT--

NASA SPACE VEHICLES- 
1. The Effect of Strain Rate on the Fracture Toughness of a Structural Steel

2. Critical Crack Length as a Function of Charpy V-Notch Toughness for a Specific Type of Size of Line Pipe

A-1 Logic Diagram for the Selection of Fracture Critical Parts of the Space Shuttle system 

FRACTURE CONTROL PRACTICES FOR

METAL STRUCTURES

H. I. McHenry

S. T. Rolfe

Fracture control practices are the engineering procedures and requirements that contribute to the prevention of fracture in metal structures. These practices are identified as the elements of fracture control and each element is defined and described. The systematic application of these practices to the prevention of fracture in a particular structure is accomplished by either the code approach or the performance specification approach to fracture control. In these two approaches, the consideration given to each of the elements of fracture control is discussed and illustrated with examples for specific types of structures. Selected practices that may be of use in Naval systems are discussed. An Appendix contains detailed summaries of the fracture control practices used in each of thirteen classes of metal structures, including ships, offshore structures, bridges, cryogenic tanks, pressure vessels, piping, power generation equipment, and aerospace structures.

Key words: Fracture control; fracture mechanics; mechanical properties; quality assurance; stress analysis; structural safety.

Note on Units: Duplicate units are used throughout this document. SI units appear first followed by English units except when quotations from codes and specifications are given. In that case the first unit is a direct quotation and the second is a conversion.

\section{ADMINISTRATIVE INFORMATION}

This project was sponsored by the Naval Sea Systems Command (SEA 05R) under Program Element 62761N, Task Area SF54-591-506. The program manager is Dr. H. H. Vanderveldt (SEA 05R). The project monitor was John P. Gudas of the David W. Taylor Naval Ship Research and Development Center (Code 2814).

\section{INTRODUCTION}

In the fall of 1977, the Naval Sea Systems Command started a program entitled "Fracture Control Technology for Ships and Submarines". The initial tasks included the identification of Navy fracture control requirements and an assessment of fracture control practices used by U.S and foreign industries. As part of this program, NBS was requested to review fracture control practices used by American industry and by government agencies other than the Navy and to identify practices that may be useful to the Navy.

The approach used in this study was first to identify and define the elements of fracture control, and then to prepare detailed summaries of the fracture control practices used for thirteen classes of metal structures. Concurrently, Navy personnel were reviewing Navy practices and requirements relative to fracture control. Discussions with the Navy investigators led to the identification of fracture control concepts that are potentially useful to the Navy. 
The report consists of the review of fracture control elements and approaches, and the identification of innovative and cost-effective fracture control concepts that merit consideration for Naval systems. The detailed summaries of fracture control practices used for thirteen types of structures are presented in the Appendix.

\section{ELEMENTS OF FRACTURE CONTROL}

The objective in design of large complex structures such as ships, bridges, pressure vessels, aircraft, etc. is to optimize the desired performance requirements relative to cost considerations (i.e., the overall cost of materials, design, fabrication, and operation) so that the probability(and economic consequences)of failure are low. To achieve these objectives, engineers make predictions of service loads and conditions, calculate stresses in various structural members resulting from these loads and service conditions, and size the members such that the stresses are limited to values below the critical stresses for the potential failure modes of the structure, i.e., yielding, buckling, fatigue, creep, and brittle fracture.

The prevention of brittle fracture is an important consideration because of the sudden and uncontrolled nature of such failures. Experience gained from service failures of many engineering structures indicates that most brittle fractures are initiated by small flaws that grow, as cracks, to a critical size during service. Accordingly, there are three parts to the fracture problem: (1) The initial flaw size, (2) crack growth, and (3) crack tolerance. The initial flaw size is a function of material and weld quality, the workmanship during fabrication, and the inspection and quality control. The crack-growth behavior is controlled by the cyclic stress history, the thermal and chemical environment, and the design detail. The crack tolerance is governed by the material toughness, the crack size, and the maximum stress level.

A complete understanding of all these factors is obviously not possible for a complex structure. Thus, to assure safety, it is necessary to devise a plan to limit the uncertainties. Such a plan is a fracture control plan and consists of the systematic consideration of the numerous elements of the fracture problem. The elements of fracture control are all of the factors that must be considered during design, fabrication, and operation of a structure to assure satisfactory fracture resistance of the structure during its intended service life. The various elements of fracture control are listed and defined in this section.

\subsection{Structural Design Conditions}

The structural design criteria are the operational and performance standards against which the expected (or actual) behavior of the structure can be judged. They are based on the specified operating conditions that the structure must be designed to tolerate, and the analysis assumptions and safety factors used in design. Operating conditions relevant to fracture control include the design service life, the anticipated service load history, and 
the thermal and chemical environment. Analysis assumptions may include consideration of failed members, preexisting flaws, superimposed loads, and methods of combining stresses. Safety factors on loads or on material properties may be used to account for uncertainties in the loads and material properties.

\subsubsection{Design Tife}

Design life is the specific number of years of service (e.g., 20 years) or application of loads (e.g., 2,000,000 cycles) that a structure must withstand. A distinction should be made between total design life (useful service) and intermediate design life (time for replacement of critical parts or members to extend the total design life of the structure).

\subsubsection{Loads}

Loads are all the forces that the structure must withstand throughout its 1 ife, such as gravity, applied, displacement, natural (e.g., earthquake), repeated (e.o., fatiguc, wave action), etc.

\subsubsection{Environment}

The environment in which the structure must perform is the anticipated thermal and chemical exposure. Temperature extremes, time at temperature, and number of thermal cycles should be used to account for strength reductions due to thermal exposure and to analyze for creep and thermal fatigue. The chemical environment (e.g., sea water, fuel, ajr, etc.) should also be characterized in terms of duration and repetitions of exposure. For environmental considerations, the load vs. time profile also becomes important to properly account for environmentally enhanced fatigue crack growth.

\subsubsection{Initial damage assumption}

Flaws, deformation, the failure of members, etc. should be considered during design. In certain design codes, the designer is required to account for the possibility of flaws and to conduct a fracture mechanics analysis to insure the satisfactory behavior of the flaved structure.

\subsubsection{Safety factors}

Limit criteria (e.g., yield strength, $K_{I c}$, etc.) generally are reduced by factors, or applied loads increased by factors, to reach an allowable working stress that accounts for unexpected variations in loads or material properties. These factors are called safety factors. Increasing the factor of safety for a particular mode of failure, reduces the likelihood of failure by that particular mode. 
Probabilistic analysis is an emerging design concept that can be used instead of safety factors.

\subsection{Materials}

The fracture resistance of a structure is strongly dependent on the materials of construction. Controls on material procurement and subsequent processing (heat treatment, welding, etc.) must be implemented such that the material in the as-fabricated structure retains the properties assumed in design.

\subsubsection{Selection}

Often, the materiais for a particular class of structures are specified by codes, and the material selection process is automatic. That is, materials that have been used successfully in the past are selected for similar applications. However, for new systems or applications, material selection actually depends on an optimization of strength, ductility, toughness, fabricability, fatigue, environmental, and cost factors. Thus, material selection should be based on an understanding of the material response to all anticipated service loadings and environments.

\subsubsection{Properties}

Material properties used in design are generally based on the minimum values required in the material procurement specification such as yield strength, tensile strength, and in some cases, toughness properties such as CVN, NDT, or $K_{I C}{ }^{*}$ Alternatively, data compilations such as MIL Handbook-V may be used as the source of statistically derived property values. Properties such as fatigue behavior may be included in the code or code-approved handbooks.

Code-approved procedures, or in some cases, code-body approvals, generally are required to develop properties of materials needed for design but not available from approved sources.

\subsubsection{Specifications}

Material procurement specifications are used to provide assurance that the materials of construction do not have properties inferior to those assumed in design. Specifications generally are required for each material and product form. These documents specify the minimum acceptable values for the tensile properties and, in some cases, fracture properties. Requirements may also be established for melting and primary processing (such as in ABS* specifications), heat treatment, chemical composition, ultrasonic quality, and dimensional tolerances. Quality assurance provisions, testing procedures, and reporting requirements may be stipulated.

*Abbreviations defined in Section 7. 
Material processing specifications may be required for all processing operations that may alter the as-fabricated properties of the material. Examples are specifications for heat treatment, welding, and electroplating. These documents specify requirements for equipment control, processing procedures, acceptance standards, quality assurance provisions, and workmanship. Where applicable, tests may be required to measure mechanical properties, chemical composition, surface condition, and dimensional tolerances. Procedures are defined for surface preparation, rework and repair, temperature control, etc. Applicable testing procedures, subcontractor provisions, and reporting requirements may be stipulated.

\subsection{Design}

Design is the overall process of proportioning and arranging members into a structural configuration that will perform the intended functions under the specified design conditions. As part of a comprehensive fracture control plan, design responsibilities include the following: a) Minimize the probability of structural failure by using damage-tolerant design concepts and materials, b) reduce the incidence of fatigue cracking and corrosion problems by careful attention to design detail, and c) provide adequate accessibility for inspection and repair.

\subsubsection{Design for fracture control}

Certain codes require that damage in the as-fabricated structure or damage that occurs during service be considered during the initial design process. The methods most commonly used are the safe life and fail-safe approaches. The safe-life approach requires that a flaw will not grow to critical size during service due to the anticipated loads and environment. The fail-safe approach requires that the structure remaining after failure of any given member will not fail within a period of service sufficient to detect and repair the failed member.

\subsubsection{Standard details}

Standard details are those that are known to give satisfactory performance in other structures. Many codes stipulate that the standard details described in the code be used where applicable. For example, certain welded connections such as ground butt welds have better fatigue lives than partial-penetration butt welds. Hence these standard details can be specified with some assurance of the level of performance.

\subsubsection{Joining practices}

The design should require qualified joining practices to assure satisfactory reliability in welded and mechanically fastened joints. Most codes require qualification of each welding procedure, i.e., for each material (or class of materials), welding process, position, and thickness range. Similarly, codes for bolted or riveted structures such as aircraft may stipulate hole preparation and fastener installation procedures that assure satisfactory fatigue resistance. 
Analysis is the analytical evaluation of the design to determine the distribution and magnitude of the stresses and to determine if the design conforms to the structural design criteria relative to strength, deformation, fatigue, fracture, and safety.

\subsubsection{Stress analysis}

Stress analysis consists of the analytic determination of the stresses and deformations resulting from the external loads and temperature imposed on the structure. The results are compared with the specified design criteria to detemine margins of safety. Design iterations are required until there are adequate margins of safety throughout the structure.

\subsubsection{Fatigue analysis}

Fatigue analysis is the assessment of the expected behavior of the structure to assure that fatigue failure will not occur within the specified service life due to application of the anticipated loads. This may be accomplished by reducing the stresses below a level specified in the code for fatigue critical details (as is the case for bridges) or by calculating the fatigue damage in the structure using semiempirical methods. The calculated fatigue damage is compared with the specified design criteria to determine if the requirements are met. If the fatigue damage is too high, design iterations are required until the stress levels throughout the structure are sufficiently low to meet the fatigue requirements.

\subsubsection{Fracture mechanics analysis}

Fracture mechanics analysis is the analytical determination of the influence of loading, crack size, and structural geometry on the fracture resistance of materials containing cracks. When applied to design, the objective of the fracture mechanics analysis is to limit operating stresses such that a flaw of a specified initial size located anywhere in the structure will not grow to critical size during the service life of the structure. Service life for a given location is calculated on the basis of the specified initial flaw size, a stress analysis of the structure for the location in question, and experimental data describing the crack growth and fracture behavior of the material used. Fracture mechanics parameters are used to compare the stress field ahead of a crack $\left(K_{I}\right)$ with the critical material toughness $\left(K_{I C}\right)$, i.e., analogous to comparing a design stress ( 0 ) with a limiting stress $\left(\sigma_{y s}\right)$.

\subsubsection{Fail-safe analysis}

Fail-safe analysis is the stress analysis of the structure with one or more elements failed as specified in the criteria. Dynamic release of energy during failure of the element(s) 
must be taken into account. The stresses in the remaining structure must be sufficiently low to meet the design criteria for residual strength and fatigue life.

\subsection{Quality Assurance}

Quality assurance is the system of controls used to ensure that the as-fabricated structure conforms to the code requirements.

\subsubsection{Material procurement controls}

Receiving inspection verifies that the raw material meets the requirements of the applicable procurement specifications. This is accomplished by reviewing the records supplied by the vendor and, where applicable, by conducting acceptance tests. Al1 material should be clearly marked and allocated such that the correct material is used throughout the structure.

\subsubsection{Fabrication and processing controls}

Production processing and fabrication should be conducted by qualified personnel in accordance with documented work instructions, using adequate equipment.

Testing requirements invoked by the processing specification should be performed as required on a timely basis. Processing variables such as temperature, time, welding parameters, etc. should be monitored using calibrated equipment, and the variables should be controlled within acceptable ranges.

\subsubsection{Inspection}

Inspection should insure that the structure conforms to the material, dimensional, and installation requirements of the structural drawings and that defects which could cause premature failure are not present in the raw material or the as-fabricated structure. Inspection consists of the dimensional checks, nondestructive evaluation of specified areas such as the welds, and in some cases, destructive tests to verify conformance to standards generally specified on the drawing.

\subsubsection{Proof testing}

Some structures, e.g., pressure vessels, pipes, etc. are loaded to stress levels greater than the anticipated service loads to verify structural integrity. This loading, generally hydrostatic, is called proof testing, and is intended to be nondestructive. 


\subsubsection{Traceability}

Traceability refers to the ability to trace the history of the materials of construction through records indicating original manufacturing procedures, test results, fabrication sequence, etc. These records may be used to predict the remaining life of a structure, to help estabiish the reasons for any failures, and to determine if other similar structures have a potential problem.

\subsubsection{Verification testing}

Accelerated total-service-life testing of completed documents or entire structures is referred to as verification testing. It usually is only done when there are numerous identical structures such as small pressure vessels, automobiles, insulation panels, etc. in which actual service loads can be applied and the behavior verified by testing to failure.

\subsection{In-Service Controls}

Once the structure is put into service several controls should be implemented to prevent fracture. These controls include: Monitoring the severity of service usage, periodic inspection and maintenance, and approved repair procedures.

\subsubsection{In-service monitoring}

For certain structures, the time history of loads (and sometimes temperature) should be recorded to verify that the load history assumed in design is at least as severe as the actual load history. This is accomplished for USAF aircraft through the loads/environment spectra survey and for commercial aircraft by instrumenting representative aircraft with flight load recorders which monitor the principal load parameters, i.e., velocity, acceleration, and altitude. In other structures (such as nuclear pressure vessels), time, temperature, and pressure recorders are used to monitor service usage.

\subsubsection{Periodic inspection}

Many structures, particularly those susceptible to extensive fatigue and/or corrosion, are subjected to periodic inspection to assure that structural damage is detected prior to failure.

\subsubsection{Maintenance}

A maintenance plan should be developed for many classes of structures to prevent damage due to wear and corrosion that may enhance fatigue damage or otherwise lead to premature failure. 


\subsubsection{Repair}

When structural damage is detected, approved repair procedures should be used to assure the structural integrity of the repaired region. In general, the repair procedure should adhere to the code requirements governing materials and processes, such as welding consummables and post-weld thermal treatments.

3. THE CODE APPROACH TO FRACTURE CONTROL

Current approaches to fracture control vary widely from industry to industry. Consideration of the numerous practices summarized in the Appendix reveals two general approaches: 1) The design and fabrication codes, and 2) performance specifications. In the code approach to fracture control, the design and fabrication of a particular structure conform to a set of rules established for the general class of structures that includes the particular structure, e.g., bridges, pressure vessels, and ships. The performance specification approach, discussed in section 4 is applicable to high performance structures where the inefficiencies associated with general rules cannot be tolerated, e.g., airplanes and spacecraft.

The code approach to fracture control is used for general classes of structures where loading modes, design procedures, fabrication methods, and inspection procedures are fairly uniform. A code is a set of rules established for a general class of structures by committees of interested and knowledgeable engineers. Examples are the ABS Rules for Shipbuilding, the ASME Boiler and Pressure Vessel Code, and the AASHTO Standard Specifications for Highway Bridges. Sometimes these codes, combinations of code segments, and/or additional rules are incorporated into Federal regulations, e.g., the U.S. Coast Guard regulations for shipbuilding or the Office of Pipeline Safety Operations regulations for pipeline construction.

Each of the elements of fracture control is considered in the context of the code approach in the following subsections. The examples used to illustrate specific practices are taken from the detailed summaries of fracture control practices presented in the Appendix.

\subsection{Structural Design Conditions}

The design conditions, analysis assumptions, and safety factors on material properties used as the basis for structural design criteria vary from code to code depending on the severity of the design conditions, the scope of the structural analysis, and the complexity of the design. Variations from structure to structure within a code class are accounted for by stating the design and analysis requirements in general terms. For exanple, the code may require consideration of loads due to earthquakes, a negligible factor for most structures but a primary requirement for others. 


\subsubsection{Design 1ife}

Design life is not a specific requirenent in codes. Cenerally the procurement specification for a code structure specifies the design life. The number of fatigue cycles and the corrosion allowance are related to design life and accounted for by code rules.

\subsubsection{Loads}

Loads are conservatively estimated in the code approach. For many classes of structures, there is a dominant load source, c.g., internal pressure for pressure vessels and piping and centrifugal forces for steam turbine rotors. In more complex structures, the loads are estimated on a worst-case basis. For cxample, to cstimate bridge loads, it is assumed that each lane is occupied by a line of trucks that extends over the complete span. The most approximate treatment of loads is the case of merchant ships where design is based on scaling of known proportions of structural sections rather than on specific loadings. Superimposed on the primary loads are thermal stresses, dead loads due to structural weight and, where applicable, the loads due to wind, carthquakes, ice, and snow.

\subsubsection{Environment}

The anticipated service environment is an important consideration in the design of many structures. The minimum design temperature is particularly important for the selection of steels with satisfactory toughness. The API 620 code for storage tanks specifies minimum temperatures as a function of location. Elevated temperature exposure must be considered because of reduced strength and creep as temperature and time at temperature increase. Chemical environment is considered because of corrosion in containers for chemicals and for structures that operate in adverse environments such as offshore structures.

\subsubsection{Assumed initial damage}

Initial damage assumptions are not generally required in codes. For example, the AASHTO bridge code simply requires that all injurious defects be removed. Weld defects are permitted within acceptance limits defined by the codes, but the defects are sufficiently small so that they need not be considered in the design. In vicw of actual service experience with large welded structures, this assumption may not be realistic.

Structures where initial damage is assumed include LilG ships and cargo tanks and gas pipelines. LilG ships are required to have a double bottom, double side shells, and transverse bulkheads to localize hull damage to a portion of the ship. LIIG containment systems are designed to tolerate failure of the primary barrier either through the use of a secondary barrier or through a leak-before-break approach that has been approved for a specific pressure vessel design. An initial damage assumption is not explicitly required for gas pipclines but 
toughness requircments for the line pipc are gencrally cstablished by the owner company such that the material can arrest a running through-thickness crack.

\subsubsection{Safcty factors}

Safety factors in codes are generally applicd to matcrial properties to arrive at acceptable design stress levcls. For cxample, a factor of safety of 3 on burst strength is required in the AlISI B31.1 and B31.3 piping codes, ASME Pressure Vesscl Code Scction VIII Division 2, and the API 620 Storage Tank Code. This is achicved by spccifying that the allowable stress in tension is the lesscr of $1 / 3$ of the ultimate strength or $2 / 3$ of the yicld strength. Additional factors may be required for castings and weldments. In ccrtain codes. factors may depend on stccl quality, typc"of wclding, degrcc of inspcction, and production form. For example, in API 620 a factor is applied to allowablc stress that depcnds on steel quality. A factor of 1 on pressurc vesscl stccl, and a factor of .92 on structural stecl.

The magnitude of the safety factor varics with the scope of the structural analysis, the complexity of the design, and the possible consequences of failure. For pressurized components, some factors on burst strength arc. I for ASME Scction VIII, Division 1 Pressure Vessels; 3 for ASME Scction VIII, Division 2 Prcssure Vessels which require a more thorough analysis and inspcction than Division 1 vesscls, and approximatcly 2 (allowable stress is 72 percent of the yield strcngth) on $0 i 7$ pipelincs. For gas transmission pipelines, the allowable stresscs are based on the spccificd minimum yicld strength reduced by factors that range from 0.4 to 0.72 depending on the population density and degrec of development in the vicinity of the pipeline, i.c.; strcss levels are reduced as the conscquences of failure are incrcased.

\subsection{Matcrials}

In the code approach to fracturc control, matcrials that have been uscd successfulty for years in similar structures or that have undergone cxtcnsive testing gcnerally arc the only oncs used. Beforc ncw materials can be spccificd for structures that are dcsigned according to codes, the codc writing bodies must be satisficd (on the basis of material and structural tests) that thesc materials will indccd perform satisfactorily.

\subsubsection{Spccifications}

Matcrials of construction must conform to the requircments of material spccifications listed in the applicable code. In gcneral, unlistcd matcrials may be uscd providing the material is certified to mect all the requircments of a listcd material specification, and its usc is approved by either the cognizant code committec (c.g. ASME Prcssurc Vcsscl Code) or by the purchaser (e.g., API 620 Storage Tank Code). Materials arc listed by specification and by grade; i.c., not all grades for a given specification may be used. Usage is further restricted by notes to avoid improper application of the material. 
ASTM material specifications are used in many of the codes, including the ANSI B31 piping codes, the API 620 storage tank code, and the AASHTO bridge code. ASME material specifications are used in the ASME Boiler and Pressure Vessel Code. The ASME and ASTM specifications are often related and carry similar numbers, e.g., ASME SA-24C specification for stainless steels is similar to ASTM A 240. Other material specifications include the ABS ship steels, and the API specifications for steel line pipe.

Many of the ASTM and ASME material specifications are for product types and cover many grades. For example, ASTM A 240 is the Standard Specification for Heat-Resisting Chromium and Chromium-Nickel Stainless Steel Plate, Sheet, and Strip for Fusion Welded Unfired Pressure Vessels. It includes many types of stainless steel suitable for this application. Wherever possible, types are designated by numbers conforming to grade specifications put out by other organizations. In the case of A 240, grades are specified by the AISI designation such as 302, 304, 304L, etc. Grades not covered by the AISI designation system are given ASTM-designations such as XM17, a nitrogen-strengthened CR-Ni-Mn stainless steel. Similarly, ASTM A 131 is the standard specification for structural steel for ships and the grade designations are related to the ABS grades of ship steel.

Some codes, such as the API RP 2A code for offshore structures, use many types of material specifications. The approved materials list in API RP 2A includes Canadian (CSA), German (DIN), British (BS), and International (ISO) designations and several types of American Specifications--ASTM, API, and ABS.

\subsubsection{Properties}

The material specifications specify the minimum tensile properties that are used as the basis for determining allowable stress values. Usually minimum values for tensile strength, 0.2 percent offset yield strength and elongation are specified. Sometimes a range of tensile strength is specified to avoid brittle behavior associated with higher strength levels. other properties sometimes specified include minimum reduction of area, maximum hardness, and minimum bend ratios (bend diameter to thickness).

Properties used for fatigue and fracture analyses are included in certain codes which require these analyses. The ASME Section VIII, Division 2 Rules for Pressure Vessels require a fatigue analysis for vessels subject to fatigue cycling that exceeds specified conditions. The fatigue data used in the analysis are summarized in fatigue design curves applicable to broad classes of materials. The ASME Section XI, Division 1 Rules for Inservice Inspection of Nuclear Power Plant Components provide a fracture mechanics analysis procedure for determining the acceptability of flaws that have been detected during in-service inspection. The analysis is based on measured material properties applicable to the part of interest or on conservative representations of fracture toughness and fatigue crack-growth data. The material property data are applicable to the most common grades of nuclear vessel steels. 
The lower bound fracture toughness data are presented as a function of temperature indexed to the nil-ductility transition (NDT) temperature of the material and are referred to as the reference fracture toughness $\left(K_{I R}\right)$ curve. The NDT, measured at the time of purchase, is shifted to account for irradiation during service. Upper bound fatigue crack-growth data are given for buried flaws and for surface flaws where the growth rates are accelerated due to environmental effects.

\subsubsection{Toughness requirements}

To assure satisfactory fracture resistance, codes generally specify minimum levels of Charpy $V$-notch (CVN) impact toughness for 10 - and intermediate-strength steels. Nonferrous materials such as aluminum and copper alloys do not exhibit a ductile-to-brittle transition, and, thus, are not usually toughness tested. Toughness requirements for most types of structures are based on prior experience, however, an increasing number of fracture criteria are being derived on the basis of fracture mechanics considerations as is the case for bridges, gas pipelines, and nuclear pressure vessels. The various requirements are summrized below.

The toughness requirements for pressure vessels (ASME Section VIII) and piping (ANSI B31.1 and B31.3) are a function of strength 1eve1, deoxidation practice, and heat treatment. Minimum CVil values for carbon and low alloys steels are specified in terms of average absorbed energy at a specified temperature. $17.7 \mathrm{~J}$ (13 ft $1 \mathrm{~b}$ ) for strengths of $448 \mathrm{MPa}$ (65 ksi) and lower, $20.4 \mathrm{~J}$ (15 ft 1b) for strengths ranging from 448-517 $\mathrm{MPa}$ (65 to $75 \mathrm{ksi}$ ), and $27.2 \mathrm{~J}$ (20 ft 1b) for strengths ranging from 517-655 MPz (75 to $95 \mathrm{ksi}$ ). The toughness requirements for higher strength steels, steels heat treated to enhance strength, and stainless steels are specified in terms of notch ductility as measured in a CVN test; $.38 \mathrm{~mm}$ (.015 inch) lateral expansion is required. The test temperature for all grades is the design temperature or the minimum temperature at which pressure will be applied, whichever is lower. A lower test temperature must be used when subsize tests are conducted and the subsize width is less than 80 percent of the material thickness.

The toughness requirements on ship steel plates depend on the grade, plate orientation, and strength level. The steels used in low stress and moderate temperature locations, Grades $A, B$, and $A H$, do not have any fracture toughness requirements. Steels used for crack arrestor strakes, for low temperature applications, or for locations otherwise deemed critical must meet toughness requirements specified in the ABS rules. The CVN toughness requirements range from 19-34J (14 to $25 \mathrm{ft} \mathrm{1b)} \mathrm{depending} \mathrm{on} \mathrm{strength} \mathrm{1evel} \mathrm{and} \mathrm{orientation.} \mathrm{Test}$ temperature and frequency of testing depend on the grade. For example, grades $D$ and $D H$ are tested at $-200 \mathrm{C}, 3$ specimens from each $36.4 \mathrm{Mg}$ (40 tons); and grades $\mathrm{E}$ and EH are tested at -40 C, 3 specimens from each plate. For many applications, it is permissible to use grades DS or CS, which do not require testing, in place of grades D or $E$, respectively. 
Experience has shown that grades DS and CS consistently meet the toughness requirements for grades $D$ and $E$, respectively, due to the controls on chemistry, deoxidation practice, and heat treatment. The idea of using metallurgical controls to assure toughness in place of CVII requirements is unique to the ABS rules. This precedent has potential value for other codes because the metallurgical controls contribute directly to toughness whereas the charpy requirements simply measure toughness.

The CVII toughness requirements discussed above are conducted either at the minimum service temperature (e.g., the ASME approach) or at an arbitrarily low temperature (e.g., ABS grade E) under impact loading conditions. An alternative approach is to use actual loading rates and factor in the various design features pertinent to the particular design. This approach is used in the AASHTO bridge code. Here, the test temperature is increased by an amount equal to the shift in transition temperature as the loading rate is decreased from the impact rate used in CVII tests to the maximum loading rate expected in bridges. The resulting CVN impact toughness requirements are $34 \mathrm{~J}(25 \mathrm{ft} \mathrm{lb})$ at $21^{\circ} \mathrm{C}\left(70^{\circ} \mathrm{F}\right)$ above the minimum service temperature for 10 - and intermediate-strength steels.

\subsection{Design and Analysis}

Design is the arrangement and proportioning of structural members to withstand specified loads whereas analysis is the determination of the stress distribution in given structural members. Both procedures are based on analytical methods of stress analysis, ranging from strength of materials techniques to finite-element analysis using large computers. Obviously. the functions are closely related.

\subsubsection{Design for fracture control}

Good design practices are essential to fracture control. The most common methods of fracture control used in design are to lower the design stress, to improve the design of details, and to provide redundant load paths. Another design practice that is very helpful, but less formalized in the codes, is to provide the accessibility needed to facilitate fabrication, erection, and inspection.

The use of lower design stresses has evolved as a means of reducing the incidence of fracture in many codes. The approach was used in the boiler and pressure vessel industry where numerous failures occurred in the early 1900's. Through the years, the allowable stress was lowered (as a percentage of minimum tensile strength) thereby greatly decreasing the number of failures in succeeding years. The approach is basic to most codes. For example, the ASME code for pressure vessels limits the allowable stresses in welds in accordance with joint location, joint design, and degree of inspection. The API code for offshore structures requires lower stresses for waterline braces because of corrosion fatigue considerations. The ANSI gas pipeline code requires lower stress as a function of geographic location, i.e., lower stresses where the consequences of failure are greater. 
The elimination or reduction of stress concentrations and structural discontinuities is an effective means of fracture control. Cracks usually start at specific design details (e.g., connections, cutouts, stiffeners, etc.). Considerable improvement in fatigue behavior can be obtained in smoothing the flow of stress at details. The most notable examples to illustrate the significance of poor design details are the Liberty Ships of World War II. The majority of fractures in these ships started at the corners of square hatch cutouts at the top of the shear strake--design practices that were subsequently eliminated in the ABS rules.

Design detail has the greatest importance in fatigue critical structures. For example, the allowable fatigue stress range in the AASHTO bridge code varies from $110 \mathrm{MPa}$ (16 ksi) for butt welds ground flush to $17.2 \mathrm{MPa}(2.5 \mathrm{ksi})$ for an as-welded cover plate where there is an abrupt change in section. Similarly, the AWS fatigue curves for offshore structures vary by more than a factor of 10 on stress, depending on the particular structural detail.

The use of multiple load paths to provide structural redundancy is an effective means of preventing fracture in structures such as bridges, offshore structures, and ships. This practice is encouraged in the AASHTO bridge code by designating as fracture critical those tension components that are not redundant and whose failure might result in the collapse of the bridge. Ships are not normally fail-safe, but the IMCO code for LIIG carries (adopted by $A B S$ and USCG) requires double side shells, a double bottom, and transverse hull heads to separate the cargo spaces--provisions that provide multiple load paths.

\subsubsection{Standard details}

Standard design details and associated analysis procedures are specified in most codes to assure continued use of practices known to give satisfactory performance in other structures. Notable examples are weld joint designs, welded connections, and reinforcenent of openings. Standardized design practices are particularly well developed for design codes for pressurized containers such as the.ASME pressure vessel code, the AlISI piping codes, and the API storage tank code.

\subsubsection{Analyses}

Design codes for most classes of structures require the analytical determination of the stresses and deflections caused by the imposed loads and the determination of their significance with respect to strength, stiffness, and stability criteria. To perform satisfactorily the structure must withstand the service loads without yielding, deflecting excessively or buckling. After designing to these criteria, the code may require that the fracture and fatigue characteristics of the structure be evaluated. Because many failures of structures or structural members occur by fatigue or fracture, it is desirable to consider these failure modes during initial design when it is easier to make changes, e.g., in the geometry of certain details. 
Codes that require fatigue analysis include the ASME Pressure Vessel Code Section VIII, Division 2, the AWS Structural Welding Code (offshore structures), the AASHTO Bridge Code, and to a lesser extent, the ANSI B31.1 and B31.3 piping codes. Two types of structures may require a fracture mechanics analysis: 1) LNG shipboard containment systems designed to pressure vessel requirements and not requiring a secondary barrier, and 2) nuclear pressure vessels when in-service inspection reveals flaws that exceed original acceptance requirements.

\subsubsection{Fatigue control}

Fatigue control in the code approach generally is based on the prevention of crack growth by using $S-N$ curves to prevent initiation of a crack. The analysis is based on extensive testing, a conservative estimate of the loads, a fairly accurate stress analysis, and large factors of safety to account for material and fabrication variability. Design of details can affect the allowable stress range significantly, as was noted in section 3.3.1.

S-N curves usually are obtained in one of two ways:

a) Results of smooth polished test specimens are used to obtain the basic fatigue properties of the material. The stress range is divided by a fatigue stress concentration factor to estimate the fatigue lives for a particular local geometry (e.g., as received surface, notches, weldments, etc.). This "derived" $\mathrm{S}-\mathrm{N}$ curve is then used to estimate the life of a structure at a particular stress range, with appropriate factors of safety on life.

b) Results of actual fabricated members are used to obtain the fatigue properties of the material in the actual service condition. obviously there is no need to use any stress-concentration factors to further reduce these results because the geometrical factors (e.g., stress concentrations) are an integral part of the test specimens. The AASHTO bridge specifications follow this approach by categorizing details from $A$ to $E$. Category $A$ refers to smooth plates, category $B$ to butt welds with reinforcement ground smooth, and categories $C, D$, and $E$ refer to weldments with increasing severity of stress concentration. For each category from $A$ to $E$, the code allowable fatigue stress level for 2,000,000 load cycles is reduced from $110 \mathrm{MPa}(16 \mathrm{ksi})$ to $17.2 \mathrm{MPa}(2.5 \mathrm{ksi})$.

Conventional procedures for estimating structural fatigue-life expectancy are based on the establishment (through appropriate material or structural tests) of a life estimate as described above. After obtaining these results, a somewhat arbitrarily chosen factor (usually ranging from 2 to 5 ) is applied to reduce this estimate to a presumably safe service life. The size of this factor usually is based on judgment or probability analysis to account for the variability or scatter associated with fatigue testing. 


\subsection{Quarity Assurance}

Quality assurance is the system of controls used to ensure that the as-fabricated structure conforms to the code requirements. For many structures built to code requirements, the $Q / A$ system can be complicated by the use of different organizations to design, fabricate, erect, inspect, and use the structure. Many of the codes clearly define these responsibilities, as discussed below.

\subsubsection{Material procurement controls}

As discussed in section 3.2.1., a variety of material procurement specifications is used in the various codes. The most common types are the ASTM specifications. The ASTM specifications have requirements on manufacture, heat treatment, chemistry, mechanical properties, dimensional variations, test specimens and methods, quality, repair by welding, marking, inspection, and test reports.

For many products, including structural and pressure vessel steels, the purchaser has rights of inspection. For example, ASTM A6 (structural steels) and ASTM A2O (pressure vessel plates) specify: "The inspector representing the purchaser shall have entry, at all times while work on the contract of the purchaser is being performed, to all parts of the manufacturer's works that concern the manufacture of the material ordered. The manufacturer shall afford the inspector all reasonable facilities to satisfy him that the material is being furnished in accordance with the specification."

The manufacturer reports all test results, including the chemical analysis of the heat, to the purchaser when required and requested. Conformance to the applicable specification requirements is certified on the mill test reports. Subsequently, the purchaser may perform a product analysis on all or any part of the order and has the right to reject the material if it fails to meet the chemistry requirements of the procurement specification.

\subsubsection{Fabrication and processing controls}

The fabrication and processing controls comprise a major part of most codes. Good workmanship is essential to fracture control in code structures because of the uncertainties of inspection during fabrication and erection and because of the limited inspection most structures receive during service. Each of the codes establishes requirements and/or recommended practices for the major fabrication and processing operations applicable to that class of structures, e.g., welding, forming, and heat treatment.

Detailed consideration is generally given to welding and associated activities. The general approach used in most codes to assure weld integrity is to specify requirements for workmanship, for qualification of materials, procedures and welders, for weld quality, inspection and repair welding, and for post-weld heat treatment. 
In addition to the design and fabrication codes, there are codes that relate specifically to welding e.g., API Standard 1104--Standard for Welding Pipelines and Related Facilities, Section IX of the ASME Boiler and Pressure Vessel Code--Welding and Brazing Qualifications, and the AWS Structural Welding Code--Steel. The qualification requirements of ASME Section IX are used for many types of pressure-containing weldments, e.g., by the other sections of the ASME code, by the AIISI B31.1 and B31.3 pressure piping codes, and by the API 620 Storage Tank Code.

\subsubsection{Inspection}

Many of the codes distinguish between examination, a quality control tool, and inspection, a proof of compliance to code and contract requirements. Examinations are the quality control functions performed by personnel employed by the material supplier, fabricator, or erector. Inspections are the proof-of-compliance functions performed for the owner by the authorized inspector. Codes generally specify the qualifications of the authorized inspector. The inspector is permitted free access to all parts of the site where manufacture of the material or fabrication and erection of the structure takes place. The duty of the inspector. is to conduct all tests and inspections necessary to be satisfied that all code and contract requirements are met.

Inspections common to most codes include verifications that 1) materials conform to the applicable specifications, 2) welding procedures and welders are qualified, 3) heat treatments are properly performed, 4) nonconforming materials and welds are properly repaired and re-examined, 5) required NDE and tests are performed and the results are acceptable, and 6) dimensional tolerances and arrangement conform to the engineering drawings.

\subsubsection{Verification testing}

Proof testing is used as a quality control tool for many classes of structures, particularly pressure vessels and piping. For pressure containment structures, hydrotesting or pneumatic testing generally involves loading the completed assembly to a pressure level above that anticipated in service. The proof-stress factors (proof-pressure/design pressure) range from 1.1 to 1.4 , depending on the type of structure, the intended service, and the testing medium. Oil pipelines, LNG storage tanks, and pressure vessels are hydrotested to 1.25 times the design pressure. If a pressure vessel cannot be filled with water, it is pneumatically tested to 1.15 times the design pressure. The proof-stress factors for gas pipelines vary form 1.1 to 1.4 depending on location. Piping subject to low internal pressures is simply leak tested, e.g., gas pipelines with stresses below 30 percent of yield strength or oil pipelines with stresses below 20 percent of yield strength. 


\subsection{In-Service Controls}

Many of the codes are limited to the design and fabrication requirements and do not cover in-service controls. Notable examples are the ASME Section VIII Pressure Vessel Code, ANSI B31.1 and B31.3 Pressure Piping Codes, and the API 620 Storage Tank Code. Extensive coverage is given to in-service controls in the following cases: The ABS Rules for Shipbuilding, the ANISI B31.4 and B31.8 codes for 011 and gas pipelines, the API RP 2A Recommended Practice for Offshore Platforms and the ASME Section XI Rules for Nuclear Power Plant Components. In those cases where the codes do not cover in-service controls, the owner and in some cases, local authorities, may require periodic surveys and maintenance. When repairs are necessary, the materials and procedures may have to conform to the requirements specified in the code for initial construction.

In pressure containment structures, time histories of pressure and temperatures, when applicable, are generally recorded to monitor service usage. For complex structures such as bridges, ships, and offshore platforms, periodic surveys are preferred as discussed in section 3.5.2. Pressure monitoring for oil pipelines is required to assure that at any point in the piping system 1) the maximum steady-state operating pressure and static head pressure do not exceed the specified pressure ratings, and 2) the pressure rises due to surges do not exceed the internal design pressure by more than 10 percent. Similar requirements are generally involved in all pressure containment structures.

\subsubsection{Periodic inspection}

Periodic inspections are required for most classes of structures and are known as patrol programs, surveys, and in-service inspections. For pipelines, the operating company maintains periodic patrol program to observe surface conditions on and adjacent to the pipeline right-of-way, indication of leaks, construction activity other than that performed by the operator, and any other factors affecting the safety and operation of the pipeline. Patrols are required at relatively short intervals, e.g., two weeks for 011 lines and one week for LPG 1 ines in developed areas. Annual surveys are required for specified locations in offshore platforms (splash zone and critical above-water members), and ships (steering systems, specified valves, coamings, hatch covers, and locations particularly liable to rapid deterioration). Additional surveys are required for the remainder of the ship or offshore structure; special periodic surveys are scheduled for ships at four-year intervals and for offshore structures at five-year intervals or following exposure to severe loading conditions. In-service inspections of nuclear power plant components are scheduled at intervals ranging from 3 to 40 years, depending on the particular inspection program, the component class, and the operating experience. The scheduling generally coincides with plant outages due to refueling or maintenance. 


\subsubsection{Maintenance and repair}

The oil and gas pipeline codes (AlISI B31.4 and B31.8) are the only codes that explicitly treat maintenance. The pipeline operator is required to have detailed plans and instructions for maintenance of the system, including corrosion control, right-of-way maintenance, and procedures for maintenance and repair of the pipeline, including valves, pump stations, terminals, and tank farms.

\section{THE PERFORMANCE SPECIFICATION APPROACH TO FRACTURE CONTROL}

The performance specification approach to fracture and fatigue control is used for high-technology weight-critical structures where structural safety and reliability are essential. The main feature of this approach is the requirement that crack-like flaws of specified size must be assumed to exist in worst-case locations throughout the as-fabricated structure. Parts deemed susceptible to crack growth and fracture are identified as fracture-critical and are subject to the requirements of a comprehensive fracture control plan. The approach has been applied by the Air Force to aircraft, by NASA to spacecraft and missiles, and by the Navy to hydrofoils.

The performance specification approach is based on 1) a detailed knowledge of the anticipated operating conditions, particularly the service load history; 2) a thorough evaluation of the selected materials and of representative joints and components; 3 ) a complete structural analysis of the design, including stress, fatigue, and fracture analyses; 4) a comprehensive quality control program to assure that the as-fabricated structure has the properties and quality levels assumed in design; and 5) an effective in-service program of usage monitoring, maintenance, inspection, and repair. The following discussion emphasizes the approaches to each of the elements of fracture control taken by the Air Force in the Aircraft Structural Integrity Program, which is the outstanding example of the performance specification approach.

\subsection{Structural Design Conditions}

Structural design conditions are generally stipulated in the procurement contract. The conditions may be explicitly stated, as is generally the case for service life, e.g., "the design life shall exceed 20 years." More commonly, the conditions are stipulated indirectly through performance requirements (e.g., a $7 \mathrm{~g}$ aircraft at specified velocity and altitude), planned operational usage (e.g., 4000 flights of specified mission profiles), and referenced specifications. Early in the design stage, the contractor must develop explicit criteria consistent with the contract and specification requirements which are subject to approval by the contracting agency. 
Success of the performance specification approach is dependent upon a valid and complete set of structural design conditions. The basis for the structural design criteria for USAF aircraft is briefly summarized below and given in more detail in the Appendix. Maximum design loads are based on the specified performance requirements. The fatigue loads spectrum is based on planned operational usage and the load exceedance data of MIL-A-8866B. The chemical and thermal environment is characterized in terms of intensity, duration, and frequency-of-occurrence of all exposures based on planned operational usage. Initial damage assumptions are based on the requirements of MIL-A-83444. Safety factors on static strength, fatigue life, and safe crack-growth intervals are based on the applicable military specifications.

\subsection{Materials}

In the performance specification approach, materials and processes are selected by the contractor on the basis of prior experience, trade-off studies to optimize weight and cost, and requirements for system safety and reliability. There is not a set list of materials that limits material choice as in the code approach, but the need for extensive characterization of the mechanical properties tends to result in the choice of materials previously used. However, the selected materials and processes are subject to approval by the procuring agency .

The properties of the selected materials must be thoroughly characterized in the appropriate product forms and thickness ranges. The influence of processing on the material properties in the as-fabricated structure must be assessed. Several sources of data are available for most materials, including handbooks and data from previous programs available to the contractor and to the procuring agency. Gaps in the data base are filled by tests conducted by the contractor.

Material procurement and processing specifications are prepared for each material, product form, and material/process combination selected for usage in fracture-critical parts. These specifications should invoke controls that are sufficient to preclude the use of materials in the structure that have properties inferior to those assumed in design. The specifications are prepared by the contractor and approved by the procuring agency.

\subsection{Design and Analysis}

The role of the design and analysis functions is to integrate materials and structures technology into the design of safe, functional, and economical structures. The design should incorporate the results of the structural analyses of strength, rigidity, fatigue 1ife, and fracture resistance. Careful attention to design detail is essential because fatigue cracks initiating at stress concentrations are perhaps the most likely source of failures. 
The two principal design options for providing damage tolerance are the fail-safe and the safe-life approaches. In the fail-safe approach, fracture safety is provided by structural redundancy. Inspectability is essential to fail-safe design to assure detection of the initial failure before the damage spreads beyond control. In the safe-life approach, the stress levels are limited such that a flaw should not grow to critical size during the life of the structure. When sufficient inspectability exists, this latter approach can be modified to provide for a safe inspection interval--at which time the structure is inspected and certified for another interval of safe operation.

Extra caution is required in the design and analysis of structural joints--both mechanically fastened and welded. Joints are the areas of greatest uncertainty because of stress concentrations, fabrication defects, residual stresses, and questionable load paths. Design concepts should be evaluated and analysis procedures should be verified by conducting static strength and fatigue tests on representative joints. Care should be taken in locating joints to avoid high-load areas and compounding stress concentrations whenever possible.

A complete structural analysis of the design should be conducted on a timely basis to permit iteration of the design/analysis sequence and optimization of the design. Stress analysis is used to verify airframe strength, to provide stresses for fatigue and fracture mechanics analyses, to identify fracture critical components, and to select components and loading conditions for structural tests. Fatigue analysis is used to determine the stress limits that must be imposed throughout the structure to avoid fatigue failure during the specified service life. Fracture mechanics analysis is used to determine the stress limits necessary to assure that a preexisting flaw of assumed initial size will not grow to critical size during the specified service life, or in the case of inspectable structures, during the interval of service between inspections. Fail-safe analysis is used to verify that failure of a single member will not cause complete structural failure and further to verify that the fatigue life of the remaining structure is sufficient to permit detection and repair of the failed member before total structural failure occurs.

\subsection{Quality Assurance}

The quality-assurance program is the system of controls that ensures that the asfabricated structure conforms to the design requirements. The program should assure quality throughout the design, fabrication, installation, and service life of the structure. Each organizational element contributes to quality assurance e.g., engineering assures the correctness of drawings and specifications; inspection verifies dimensional and quality requirements, etc.

In the performance specification approach, the engineering drawing should be used to transmit the fatigue and fracture control requirements relative to materials, processing, fabrication, and inspection of specific parts. Fracture-critical parts should be so identified on the drawing. Notes on the drawing should be used to invoke the material procurement 
material processing specifications, fabrication controls, and inspection and corrosion protection requirements. Other elements of quality assurance such as traceability, proof testing, and verification testing should be applicable to the total system--instead of to individual parts.

\subsection{In-Service Controls}

An effective in-service program of usage monitoring, maintenance, inspection, and repair is essential to the success of the performance specification approach to fatigue and fracture control. The duration and severity of usage should be monitored to assure that service operations do not exceed design limits. Safe-usage intervals should be determined on the basis of fatigue, fracture mechanics, creep, wear, and corrosion control considerations. After completion of a usage interval, periodic inspection, maintenance, and repairs should be performed to the extent necessary to assure satisfactory performance during the next usage interval.

\section{FRACTURE CONTROL CONCEPTS FOR NAVAL SYSTEMS}

The purpose of reviewing fracture control practices used in a wide range of industries to identify promising concepts that could be developed for llaval use. In this section, selected concepts are discussed. The relative importance of the various concepts and the specific applicability are not addressed; the purpose is simply to identify those industry practices that merit consideration by the llavy for further development.

\subsection{Steel Toughness Requirements}

The establishment of toughness requirements is a difficult task for all structures where brittle fracture is a credible failure mode. Innovative approaches used in specific codes that may have broad applicability are described below.

\subsubsection{The strain rate shift}

The rate of loading (slow, intermediate, or impact) can have a significant effect on the fracture toughness of structural steels. This behavior is shown in figure 1 for a $345 \mathrm{MPa}$ (50 ksi) yield strength structural steel. Note that the toughness transition for intermediate-loading rate occurs over $80^{\circ} \mathrm{C}$ below that for impact loading. The transition temperature for slow-loading rate is even lower. If the service loading rates are intermediate (as has been shown to be the case for bridges) or slow, satisfactory notch-toughness levels can be obtained well below the dynamic transition behavior, i.e., below the NDT temperature.

For Navy structures subjected to slow or intermediate rates of loading, this approach may be viable. However it should be emphasized that other factors such as service experience, 
design and fabrication controls, and actual fatigue tests of welded beams were considered before AASHTO established their material specification on the basis of the loading rate shift.

\subsubsection{Metallurgical controls}

The ABS rules for ordinary strength steels include two grades that require toughness testing, grades $D$ and $E$. For most applications, it is permissible to use grades DS or CS, which do not require testing, and consequently cost less, in place of grades $D$ or $E$, respectively. The reason for deleting test requirements is that experience has shown that grades DS and CS consistently meet the toughness requirements for grades $D$ and $E$, respectively, due to controls on chemistry, deoxidation practice, and heat treatment. The idea of using metallurgical controls to assure toughness in place of Charpy impact requirements has potential applicability to Naval specifications. The metallurgical controls contribute directly to toughness whereas the test requirements simply measure toughness.

\subsubsection{Toughness saturation}

The toughness requirements for line pipe have been extensively studied by AISI, AGA, and British Gas. The results indicate that the notch toughness (e.g., as measured by Charpy $V$-notch or drop-weight tear tests) required to arrest a running crack is simply related to the hoop stress level and the pipe dimensions. Increasing the toughness to higher levels does not improve performance; i.e., the toughness is saturated. Similar relationships have been developed to control crack initiation. That is, above a certain toughness level, as shown in figure 2 , critical crack size is flow-stress dependent and independent of toughness.

Figure 2 shows the relationship between flaw size and toughness for a given pipe geometry and stress level using relationships developed by Battelle for the AGA. In this figure, increasing the toughness above $70 \mathrm{~J}$ (50 ft 1b) has no further effect on critical flaw size. similar curves can be drawn for any grade or size of pipe operations at the specified stress level. In summary, meaningful and quantitative toughness values can be specified above which failure is independent of toughness. Since the values vary with pipe dimensions and stress level, they are not included in the API pipe specifications, but are specified in procurement specifications for specific pipelines.

\subsection{Weld Quality Standards}

Weld quality standards are generally established on the basis of workmanship considerations, i.e., quality levels that a qualified welder can consistently meet when the proper consummables and equipment are used and the welding conditions (weather, joint accessibility, etc.) are satisfactory. Workmanship standards can be more restrictive than necessary to achieve structural integrity in the weld. Two approaches to weld quality based 
on fitness-for-service considerations have recently been developed: One for as-welded structures and the other for cases where defects have been found during periodic in-service inspection.

\subsubsection{Fitness-for-service}

In 1976, alternative weld quality standards were developed for the girthwelds of the trans-Alaska oil pipeline on the basis of a fitness-for-service evaluation. In this evaluation, allowable flaw size curves were calculated using fracture mechanics models that relate flaw size to applied stress and material toughness. Parameters for the analysis were the worst-case operating stresses and the lower bound material properties. In addition, safety factors were applied to the calculated flaw sizes to conservatively account for uncertainties in the analytical models and the inspection methods. The end results of the evaluation were curves of allowable flaw length plotted as a function of the flaw depth estimated from radiographic inspection records. Flaw sizes above the curve required repair, and those below the curve were acceptable.

The al ternative standards permitted acceptance of weld defects that were considerably longer than those permitted in the API 1104 code. As a result of this work, the code writing body and the regulatory authorities (Office of Pipeline Safety Regulation) have been considering revisions to the code (API 1104) and the regulations (49CFR192 and 49CFR195) to permit use of the fitness-for-service approach in the future.

\subsubsection{Assessment of flaws detected during in-service inspection}

Section XI of the ASME Boiler and Pressure Vessel Code provides procedures for determining the acceptability of flaws detected during in-service inspection that exceed the size limits applicable to the as-fabricated vessel. The procedures, summarized in Appendix A of Section XI, "Analysis of Flaw Indications," are based on the principles of linear elastic fracture mechanics. They are applicable to ferritic steels in thick sections $1 \geq 102 \mathrm{~mm}$, 4 inch) with specified minimum yield strengths less than $50 \mathrm{ksi}$ ( $345 \mathrm{MPa}$ ) and to structural configurations that have simple geometries and stress distributions. Procedures are given to size the flaw, represent the flaw as an elliptical (or semi-elliptical) crack, calculate the stress intensity, estimate material toughness including irradiation effects, account for fatigue crack growth and conduct the analyses for the various operating conditions. The results of the analyses are minimum critical flaw sizes for normal and upset conditions. The calculated flaw sizes and flaw evaluation criteria are used to determine if continued operation without repair of the observed flaw indication is acceptable. 


\subsection{Aerospace Practices for High Performance Structures}

Several practices commonly used in the design and evaluation of airplanes and spacecraft may be useful for high performance llaval structures.

\subsubsection{Loads}

The USAF has a continuing effort to characterize the loads encountered by aircraft during service. The detailed consideration given to loads is essential to the design of aircraft because stress levels throughout the airframe are limited by fatigue; i.e., higher stresses could lead to fatigue failure. In contrast, Naval ships are designed to withstand massive overloads due to combat operations or extreme sea states. Consequently, the routine cyclic loads are of lesser importance. Exceptions occur in advanced systems that are subjected to severe cyclic loading during normal operations, e.g., siruts and foils in hydrofoil systems and the load-transfer components in controllable-pitch propellers. For these exceptional cases, detailed knowledge of the operational loads is essential to rational design.

Maneuver loads are statistically characterized in terms of exceedance curves for each mission segment, i.e., ascent, cruise, air-to-air combat, etc. Each exceedance curve indicates the number of times a given level of acceleration is exceeded. Airframe loads can then be computed for the velocity, altitude, gross weight, and configuration of the airplane during that mission segment. The number and magnitude of loads for each mission segment are computed on the basis of the planned operational usage of the aircraft. The grand total of all the loads is the maneuver loads spectrum for the aircraft.

The gust loads spectrum is derived from the continuous turbulence model specified in MIL-A-8861. The atmospheric turbulence environment is simulated as a continuous random process. A power spectrum of the turbulence represents the forcing function in the frequency domain and a dynamic analysis is used to determine the load response of the flexible airframe. The response characteristics are a function of the velocity and configuration of the aircraft. The severity of the turbulence is primarily a function of altitude. The sum of all the loads due to the airframe response to the power spectrum for each mission segment is the gust loads spectrum of the aircraft.

Additional loads analyses are conducted to account for cabin pressurization, taxi and ground handling loads, operation of control surfaces, and combined gust and maneuver loads during low-level contour operations.

\subsubsection{Full-scale testing}

Fu11-scale testing is an essential part of the USAF Airframe Structural Integrity Program. Similar tests are not normally required for ships because of obvious practical 
limits. Normally, ships are simply too big, too expensive, and too few to justify testing a complete unit to destruction. However, there are some ships and, more commonly, subsystens that may benefit from full-scale testing. Notable examples are, again (as in subsection 5.3.1.), the struts and foils of hydrofoil ships and the controliable pitch propeller system. The full-scale tests generally conducted by the USAF on a new aircraft are described below.

Static tests are tests conducted on an instrumented airframe that simulates the loads resulting from critical flight and ground handling conditions. The tests are used to verify the stress analysis results by correlating strain survey results with analytical predictions and to verify that the design ultimate -strength of the airframe exceeds specification requirements.

Fatigue tests are tests conducted to evaluate the capability of the airframe to withstand repeated applications of the fatigue loads spectrum. Cycling is continued for a minimum of two service lifetimes or until the economic life is exceeded, i.e., until repairs are so frequent or so major that the airframe is not worth fixing. The results are used to verify that the economic life exceeds the design service life, to identify fatigue critical components, and to provide a basis for establishing special inspection and maintenance requirements.

Damage-tolerance tests are a relatively new requirement for USAF aircraft. A series of tests are conducted on full-scale articles with specified levels of induced damage, usualiy fatigue cracks in critical locations. The size of the induced damage and the applied loads approximate the initial damage conditions and residual strength requirements used in design. The results verify the damage tolerance of the fracture critical parts and the ability of the analysis to predict structural performance.

Additional tests are conducted in operating aircraft that verify airframe safety without requiring destruction of the airframe. These include loads surveys, dynamic response tests, sonic response tests, flight vibration and flutter tests, and rigidity tests. The test philosophy and certain of the techniques may be applicable to llaval ships during sea trials.

\subsubsection{Fracture critical parts}

In the performance specification approach, only parts designated as fracture-critical must conform to the requirements of the fracture control plan that exceed normal design requirements. For the space shuttle program, NASA requires that fracture-critical parts be identified on the basis of criticalness to structural flightworthiness and susceptibility to cracking or fracture. For USAF aircraft, fracture-critical parts are defined as those menbers whose failure could result in loss of the aircraft and whose stress levels are limited by the fracture mechanics analysis requirements. In summary, fracture-critical parts are identified on the basis of the consequence and likelihood of fracture. 
Identification of fracture-critical parts is a useful exercise to limit over-application of fracture control requirements and to focus attention on those parts most likely to cause fracture problems. Drawing on the two llaval examples cited previously the performance specification approach may be limited to the controllable-pitch propeller instead of the entire frigate, or to the struts and foils instead of the complete hydrofoil.

\section{SUMMARY COMMENTS}

The prevention of fracture has always been a primary consideration in engineering design. The many practices used in a variety of industries to prevent fracture have been reviewed. Two general approaches are used: The code approach and the performance specification approach. The code approach is used for nearly all commercial construction and is based on minimum requirements on design, materials, fabrication, and quality assurance that are applicable to a wide variety of configurations within a general class of structures, e.g., bridges, pressure vessels, and merchant ships. The performance specification approach is used for high performance structures where the inefficiencies associated with general codified rules cannot be tolerated, e.g. aircraft and space vehicles.

Certain practices associated with the two approaches may be of potential value to the Navy. The codes, which are continuously updated to incorporate potential improvements in industry practice, contain many fracture-control concepts that may be less costly than the practices used for Naval systems. The performance specifications used by the Air Force and NASA include fracture-control practices that may be useful for high performance Naval systems.

Fracture-control practices used by industry that offer potential cost reductions for Naval systems are related to the establishment of steel toughness requirements and weld quality standards. Alternative concepts for establishing steel toughness requirements include the strain-rate shift approach developed for bridges, the metallurgical-controls approach used for merchant ships, and the toughness-saturation approach developed for line pipe. Weld quality standards based on fitness-for-service considerations have been used in place of more stringent workmanship standards for inspection of pipelines and offshore structure and for in-service inspection of nuclear pressure vessels.

Fracture-control practices used for aerospace structures may improve the reliability of certain Naval systems, particularly those advanced systems where the experience base is limited. Practices worthy of consideration include loads characterization, full scale testing, and formalized designation of fracture-critical parts. 
7. ABBREVIATIONS

AASHTO

ABS

AGA

AIAA

AISC

AISI

ANSI

API

ASIP

ASME

ASM

ASTM

AWS

CFR

CSA

ECP

ENSIP

FAA

IMCO

I SO
American Association of State Highway and Transportation officials

American Bureau of Shipping

American Gas Association

American Institute of Aeronautics and Astronautics

American Institute for Steel Construction

American Iron and Steel Institute

American National Standards Institute

American Petroleum Institute

Aircraft Structural Integrity Program

American Society of Mechanical Engineers

American Society for Metals

American Society for Testing and Materials

American Welding Society

Code of Federal Regulations

Canadian Standards Association

Engineering Change Proposal

Engine Structural Integrity Program

Federal Aviation Administration

International Maritime Consultive Organization

International Standards Organization 


\author{
Acknowledgment
}

The authors gratefully acknowledge the contributions of Peter W. Marshall of the Shell $0 i 1$ Company, Houston, Texas, who contributed the appendix section of Fracture Control for Fixed Offshore Structures; and James A Begley of the Westinghouse Electric Corporation, Pittsburgh, Pennsylvania, who contributed the appendix section on Large Rotating Equipment for Electric Power Generation. 
APPENDIX

SUMMARIES OF FRACTURE CONTROL PRACTICES

USED FOR METAL STRUCTURES

CONTENTS:

Page

Ships and Sea Systems

Merchant Ships - - - - - - - - - - - - - - - - - 32

LNG Ships - Containment Systems - - - - - - - - - - - - - - 36

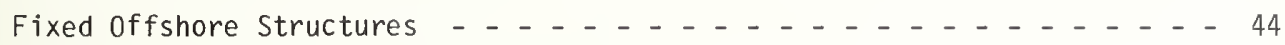

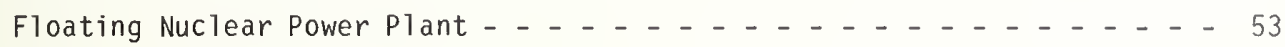

Steel Structures

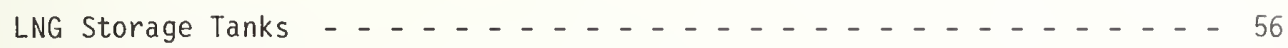

Steel Bridges - - - - - - - - - - - - - - - - - 61

Large Rotating Equipment for Electrical Power Generation - - - - - - - - 65

Pressure Vessels and Piping

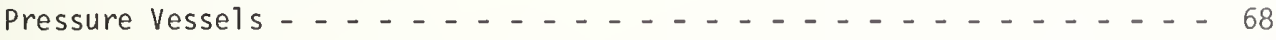

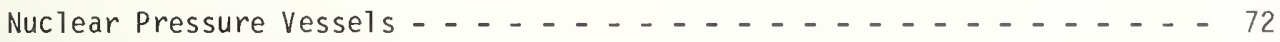

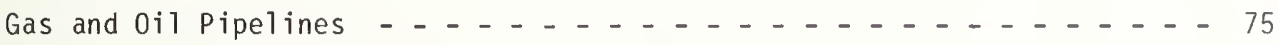

Pressure Piping - Power and Chemical Industries _ - - - - - - - - 82

Aerospace

USAF Aircraft - - - - - - - - - - - - - - - 88

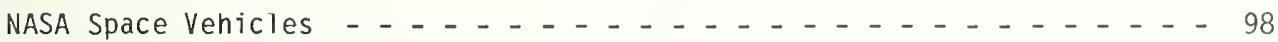




\section{MERCHANT SHIPS}

1. Overview

A. Codes and regulations

a. ABS Rules for Building and Classing Steel Vessels [1]

b. U.S. Coast Guard Inspection Regulations [2]

B. Historical

a. World War II ship failures [3]

b. Toughness considerations [4]

c. Principles of fracture--safe design [5]

d. Fracture-control guidelines for welded steel ship hulls [6]

2. Structural Design Conditions

A. Design life--not specified

B. Loads--complex combination of bending (1ongitudinal and horizontal) and torsional loadings for various sea states. Loads can be rationally determined from analysis of ship response to wave motions. ABS rules do not require this approach, but sets minimum standards for sizing hulls based on past experience.

a. Allowable design stresses not specified--rather section modulus is "proportioned" as a function of the length squared, as well as the breadth, according to empirical relations. Above certain length (about $1000 \mathrm{ft}$ ) section modulus is increased in proportion to the length, not the length squared.

b. Empirical relations based on satisfactory prior experience also are used to determine hull plate thicknesses as a function of overall ship length.

c. Hull deflection from still-water bending moment and wave-induced bending moment is restricted by ABS Rules.

d. Using the hull-girder section modulus, a loading manual that shows effects of various loaded and ballasted conditions on the longitudinal bending moments is calculated for review by ABS.

e. Safety factors--not specified because of large variation in sea states.

3. Materials and Processes

A. Specifications

a. Ordinary strength steels, ABS Grades A to E. Al so covered by ASTM A131 Standard Specification for Structural Steel for Ships.

b. Higher strength steels--ABS grades AH, DH, and EH. Also covered by ASTM 131

c. Steels for low temperature service--ABS Rules, Section 24 
B. Properties

a. Ordinary strength steels

$\sigma_{y s} \geq 34 \mathrm{ksi}(234 \mathrm{MPa})$

$58 \mathrm{ksi}(400 \mathrm{MPa})<\sigma_{\mathrm{tu}}<71 \mathrm{ksi}(489 \mathrm{MPa})$

b. Higher strength steels

AH32, DH32, and EH32: $\sigma_{y s} \geq 45.5 \mathrm{ksi}(313 \mathrm{MPa}$ )

$68 \mathrm{ksi}(469 \mathrm{MPa})<\sigma_{\mathrm{tu}}<85 \mathrm{ksi}(586 \mathrm{MPa})$

AH36, DH36, and EH36: $\sigma_{y s} \geq 51 \mathrm{ksi}(351 \mathrm{MPa})$

$71 \mathrm{ksi}(489 \mathrm{MPa})<\sigma_{\mathrm{tu}}<90 \mathrm{ksi}(620 \mathrm{MPa})$

c. Low temperature steels

V-039, V-051, V-062: $35 \mathrm{ksi}(241 \mathrm{MPa})<\sigma_{t y}<80$ percent $\sigma_{t u}$

$58 \mathrm{ksi}(400 \mathrm{MPa})<\sigma_{\mathrm{tu}}<90 \mathrm{ksi}(620 \mathrm{MPa})$

Ni steels and stainless steels

Strength per applicable ASTM specification

C. Minimum toughness

a. Ordinary strength steels

Grade D: $14 \mathrm{ft} 1 \mathrm{~b}(19 \mathrm{~J})$ at $-20^{\circ} \mathrm{C}$ transverse, $20 \mathrm{ft} 1 \mathrm{~b}(27 \mathrm{~J})$ at $-20^{\circ} \mathrm{C}$

longitudinal

Grade E: $14 \mathrm{ft}(19 \mathrm{~J}) 1 \mathrm{~b}$ at $-40^{\circ} \mathrm{C}$ transverse, $20 \mathrm{ft} 1 \mathrm{~b}(27 \mathrm{~J})$ at $-40^{\circ} \mathrm{C}$

longitudinal

Others--not specified. Toughness controlled by chemistry and processing requirements.

b. Higher strength steels

Grades DH32 and DH36: $25 \mathrm{ft} 1 \mathrm{~b}(34 \mathrm{~J})$ at $-20^{\circ} \mathrm{C}$ longitudinal

$17 \mathrm{ft} 1 \mathrm{~b}(23 \mathrm{~J})$ at $-20^{\circ} \mathrm{C}$ transverse

Grades EH32 and EH36: $25 \mathrm{ft} 1 \mathrm{~b}(34 \mathrm{~J})$ at $-40^{\circ} \mathrm{C}$ Tongitudinal

$17 \mathrm{ft} 1 \mathrm{~b}(23 \mathrm{~J})$ at $-40^{\circ} \mathrm{C}$ transverse

Grades AH32 and AH36--not specified

c. Low temperature steels

$30 \mathrm{ft} 1 \mathrm{~b}(41 \mathrm{~J})$ longitudinal and $20 \mathrm{ft} \mathrm{lb}(27 \mathrm{~J})$ transverse at $5^{\circ} \mathrm{C}$ below minimum design temperature

4. Design

A. Members are proportioned using empirical guidelines as a function of the ship length squared (up to about $1000 \mathrm{ft}(305 \mathrm{~m})$--beyond that member sizes are proportional to the length). 
B. Standard details

Rules specify minimum requirements for all the main structural sections of ships, thus leading to use of standard configurations.

c. Joining practices

a. Specified in Section 30--Welding--of ABS Rules

b. New procedures and methods to be approved by $A B S$

D. Analysis

a. Strength and stability using classical and computer analyses

b. Fatigue analysis--none

c. Fracture analysis--none

5. Quality Assurance

A. Material procurement controls

ABS Rules Sections 43 and 24 (10w temperature service)

B. Welding controls--ABS Rules Section 30

a. Qual ified welders

b. Qualified welding procedures

c. Workmanship provisions stated in rules for joint preparation and welding with various processes and procedures

C. Inspection

Rules for MDE of hull welds [6]

D. $A B S$ personnel survey design and fabrication

E. Surveys after construction--annual and periodic

6. Operational Control

Wave forces can be reduced as much as 50 percent by speed reduction or change in heading. This is controlled at sea by the captain and obviously can have a large effect on the safety and reliability of the ship, which is completely out of control of the designer.

References

1. Rules for Building and Classing Steel Vessels (American Bureau of Shipping, 45 Broad Street, New York, Annual). 
2. Shipping, Chapter 1, Title 46 (Code of Federal Regulations).

3. Wheatcroft, M. F., Toughness considerations for merchant ship hulls, Fifth Annual Forum on Prevention of Failure in the Transportation Industry (June 1977).

4. Pellini, W. S., Principles of fracture-safe design, Parts I and II, The Welding Journal (March-Apri1 1971).

5. Rolfe, S. T., Rhea, D. M., and Kuzmanovic, B. 0., Fracture control guidelines for welded steel ship hulls, Ship Stucture Committee Report No. SCC 244 (1974).

6. Rules for Non-Destructive Evaluation of Hul 1 Welds (American Bureau of Shipping, 45 Broad St., New York). 
1. Overview

A. Codes and regulations

a. International Maritime Consultive Organization (IMCO) Code [1]

b. U.S. Coast Guard (USCG) Regulations [2]

c. American Bureau of Shipping (ABS) Rules [3]

B. Designs built in the U.S.

a. Avondale Shipyards, Inc.

Conch containment system [4]*

Free-standing, prismatic tanks

5083 aluminum plates and extruded shapes

b. Newport News Shipbuilding

Techniqaz containment system [5]

Membrane, prismatic tanks

304L stainless steel sheet

c. General Dynamics

Kvaerner-Moss, containment system $[6,7]$

Free-standing, prismatic tanks

5083-0 aluminum plates

2. Structural Design Conditions

A. Design life: 20 years

B. Loads: summarized in SSC-258 [8]

a. Static pressure: cargo weight

b. Vapor pressure: pressure relief value setting

c. Dynamic effects due to ship motions roll, pitch and heave conditions defined [9]

d. Thermal streses: $\Delta \mathrm{T}=190^{\circ} \mathrm{C}$

e. Flooding: applicable to free-standing tanks

f. Self weight: applicable to free-standing tanks (lifting required)

g. Fatigue loads [10]

C. Initial damage assumptions

a. Hull damage: IMCO Section 2.3 [1]

b. Prismatic design $[4,5]$

Secondary barrier required

Primary barrier assumed to be failed for hull temperature determination

* Commercial equipment is mentioned in this document to adequately identify certain LNG containment systems. In no case does this imply endoresement or recommendation by the National Bureau of Standards. 
c. Spherical design [1]

Leak-before-break required

Assume through-thickness crack of length $2 \times$ thickness

Safe crack growth for 15 days under worst-cast storm conditions

D. Safety factors

See section $3 C$ on allowable stresses and $4 B$ on fatigue analysis.

3. Materials and Processes

A. Selection, specifications -

a. Steel alloys

9 percent $\mathrm{Ni}$ : ASTM A353 and ASTM A553

36 percent $\mathrm{Ni}$ (Invar): ASTM A658

Austenitic stainless steels: ASTM A240

b. Aluminum a 11 oy

5083-0 sheet and plate: ASTM B209

5083-H 111 extrusions: ASTM B221

B. Properties

a. Room temperature guaranteed minimum properties used [4]

b. Exception is Conch design where allowables are based on strength at LNG temperatures [4]

C. Allowable stresses

a. Membrane tanks [1]--not specified (membranes not structural).

Tests and analyses must show compatibility of hull and containment system.

b. Free-standing-prismatic tanks [1] (independent tanks--type A)

Maximum stress is lesser of $\sigma_{t u} / 2.66$ or $\sigma_{t y} / 1.33$

where $\sigma_{t u}=$ tensile ultimate strength at room temperature

$\sigma_{\text {ty }}=$ tensile yield strength at room temprature

Hote: Weld metal values for $\sigma_{\text {tu }}$ and $\sigma_{\text {ty }}$ are used when the weld is weaker than the base metal.

c. Free-standing--spherical tanks $[1,12]$ (independent tanks--type B)

$$
\begin{aligned}
& \sigma_{\mathrm{m}} \leq \mathrm{f} \\
& \sigma_{\mathrm{L}} \leq 1.5 \mathrm{f} \\
& \sigma_{\mathrm{b}} \leq 1.5 \mathrm{~F} \\
& \sigma_{\mathrm{L}}+\sigma_{\mathrm{b}} \leq 1.5 \mathrm{~F} \\
& \sigma_{\mathrm{m}}+\sigma_{\mathrm{b}} \leq 1.5 \mathrm{~F}
\end{aligned}
$$


where

$$
\begin{aligned}
& \sigma_{\mathrm{m}}=\text { equivalent primary general membrane stress } \\
& \sigma_{\mathrm{L}}=\text { equivalent primary local membrane stress } \\
& \sigma_{\mathrm{b}}=\text { equivalent primary bending stress } \\
& f=\text { the lesser of } \sigma_{\mathrm{tu}} / \mathrm{A} \text { or } \sigma_{\mathrm{ty}} / \mathrm{B} \\
& \mathrm{F}=\text { the lesser of } \sigma_{\mathrm{tu}} / \mathrm{C} \text { or } \sigma_{\mathrm{ty}} / \mathrm{D}
\end{aligned}
$$

Equivalent stresses $\sigma_{C}$, are calculated by the Von Mises yield criterion:

$$
\sigma_{c}=\sigma_{x}^{2}+\sigma_{y}^{2}-\sigma_{x} \sigma_{y}+3 \tau_{x y}
$$

where $\sigma_{x}$ and $\sigma_{y}$ are normal stresses and $\tau_{x y}$ is the shear stress. The safety factors A, B, C, and D specified by the USCG [10] are as follows:

$9 \mathrm{Ni}$ Steel

Factor

\begin{abstract}
A
\end{abstract}
B

C 3

D $\quad 1.5$
Austenitic steels

$$
\begin{array}{r}
4^{* *} \\
1.6 \\
3 \\
1.5
\end{array}
$$

5083-A1

4
1.5
3
1.5

* 3 specified in IMCO

**3.5 specified by IMCO

Allowable stresses may be further limited by fatigue analysis, crack propagation analysis, and buckling criteria.

D. Minimum toughness
a. $9 \mathrm{Ni}$ steel

$30 \mathrm{ft} 1 \mathrm{~b}(41 \mathrm{~J})$ longitudinal and $20 \mathrm{ft} 1 \mathrm{~b}(27 \mathrm{~J})$ transverse at $-196 \mathrm{C}$

b. Fe-36Ni and $5083 \mathrm{Al}$ : none required

c. Austenitic steels: not required by USCG, optional to IMCO

d. $9 \mathrm{Ni}$ welds

$20 \mathrm{ft} 1 \mathrm{~b}(27 \mathrm{~J})$ at $-196^{\circ} \mathrm{C}$ for the following notch locations:

(weld parallel to rolling direction, specimens perpendicular to weld, notch perpendicular to surface)

Weld metal

Fusion line

Heat affected zone: 1,3 , and $5 \mathrm{~mm}$ from fusion line 
4. Design

A. Design for damage tolerance

Double-side shell and double bottom required for hull structure

Fail safe provisions

a. Secondary barrier required for prismatic tank designs

b. Leak-before-break and safe crack growth after leak required for spherical tank design. Fatigue spectrum for safe crack growth calculations is equivalent to 15 days of worst-case storm conditions.

B. Standard details

Each containment system design must be approved by the U.S. Coast Guard if the ship is to enter U.S. coastal waters.

C. Joining practices

a. Production weld procedures must be qualified for each base material, each type of consumable and welding process, and each welding position. Tests are as follows:

Cross-weld tensile test

Transverse bend tests

Charpy impact tests (if required for base material)

llacrosection, microsection, and hardness survey

b. Free-standing tank shells: full penetration butt welds and full penetration nozzle welds required.

5. Analysis

A. Stress analysis

a. Limits set by stress allowables, buckling criteria, fatigue, and crack propagation

b. Finite-element and closed-form methods used

E. Fatigue analysis

a. Membrane: fatigue testing of models required

b. Free-standing prismatic. fatigue analysis not required

Insulation and secondary barrier system models subjected to fatigue testing.

c. Free-standing spherical: cumulation damage fatigue analysis required 


$$
\frac{n_{i}}{N_{i}}+\frac{10^{3}}{N_{j}} \leq C_{w}
$$

where

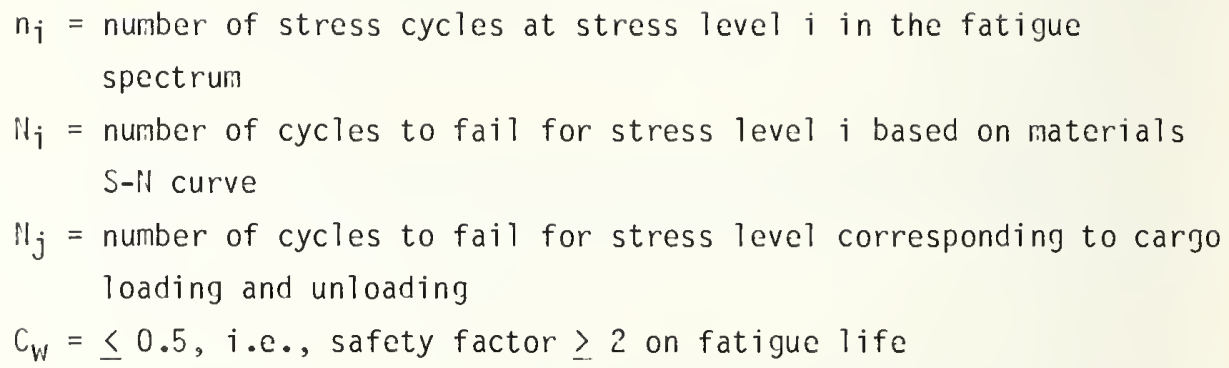

C. Fracture mechanics

a. Membrane and free-standing prismatic: not required

b. Free-standing-spherical

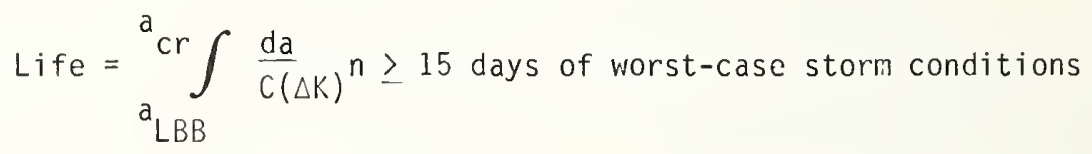

where $\mathrm{C}$ and $\mathrm{n}$ are crack growth rate parameters

$a_{L B B}=$ crack size for leak before break $=2 \times$ thickness

${ }^{a} C R=$ critical crack size

6. Quality Assurance

A. Material procurement and controls

ASTM requirements and IMCO minimum toughness requirements

B. Fabrication and processing controls

a. Weld procedure qualificaions required (See 2-D) 
b. Production weld tests: free-standing tanks only

Frequency: every $50 \mathrm{~m}$ of butt weld

Type: bend tests and Charpy impact test (if required for procedure test)

Notch location:

9lli steel: alternately in weld metal and HAZ

(worst location identified in procedure tests).

Austenitic steels: in center of weld

c. Inspection (NDE) $[11,13]$

a. Butt welds: 100 percent radiography

b. Ultrasonics, dye penetiant, and magnetic particle inspection sometimes required

D. Hydrotesting

a. Membrane tanks

Coferdams and spaces adjacent to cargo tanks must be tested.

b. Free-standing tanks

1) Hydrotest to approximate as nearly as possible the design stresses

2) Pressure in dome must at least equal the maximum allowable relief value setting.

3) For spherical tanks, at least one tank per ship must be instrumented with strain gages to verify stress levels [13].

4) For prismatic tanks, stresses in primary members must not exceed 90 percent of $\sigma_{t y}$. Strain gage verification required if stresses greater than 75 percent of $\sigma_{\text {ty }}$ are anticipated [4].

E. Verification testing

a. Membrane [14]

Component tests on:

"Waffle" panels (primary barrier)

Insulation system

Test boxes: $5 m^{3}$ specimens with full-size waffle panels

b. Free-standing prismatic [4]

Fatigue tests on insulation panels with secondary barrier

c. Free-standing spherical

Leak-before-break tests $[11,15]$

\section{References}

1. Code for the Construction and Equipment of Ships Carrying Liquified Gases in Bulk (International Maritime Consultive Organization, London, 1975). See also: Proceedings of the Maritime Safety Council 33 , No. 3 (1976). 
2. Liquified Flammable Gases, Code of Federal Regulations, Title 46, Part 38 (1977). See also: Liquified Natural Gas, Views and Practices, Policy and Safety (U.S. Coast Guard, CG-478, Feb. 1976).

3. Vessels intended to carry liquified gases (sec. 24 of Rules for Building and Classing Steel Vessels, American Bureau of Shipping, llew York, 1977).

4. Potts, W. K., and Cuthbert, W. L., LNG carriers using the conch containment system, Paper presented at the SNAME meeting, Vancouver, B. C., Canada, May 1975, Society of Naval Architects and Marine Engineers, New York, 1975.

5. Three stainless steel membrane LNG tankers first of type made in U.S.A., Nickel Topics 30, No. 1 (1977).

6. Howard, J. L., LNG marine carrier construction, Marine Technology 9, No. 3 (1972).

7. Glasfeld, R. D., Design of spherical shipborne LIIG cargo tanks, Marine Technology 13 , No. $3(1976)$.

8. Bass, R. L., Hokanson, U.C., and Cox, P. A., A study to obtain verification of liquid natural gas (LNG) tank loading criteria, Ship Structures Committee Report SSC-258 (1976).

9. Thomas, W. D., and Schwendtner, A. H., LNG carriers: The current state of the art, Oceanology International I, No. IA (1972).

10. Construction and Classification of Ships for Transport of Liquid Cargoes and Liquified Gases (Det Norske Veritas, HØvik, Norway, 1973). For specific examples, see Norwegian Maritime Research 1, No. 2 (1973) or ASTM STP 579, 238-260 (1973).

11. Tenge, P., and Solli, 0., Application of fracture mechanics for design and construction of liquified natural gas tanks in ships, Book, Materials Engineering in the Arctic (American Society for Metals, Metals Park, Ohio, 1977).

12. Henn, A. E., and Dickey, T. R., New regulations for liquified gas carriers, presented in GASTECH 75, Paris, 1975.

13. Howard, J. L., Kvamsdal, R. S., and Naesheim, K., Building and operating experience of spherical-tank LIIG carriers, Marine Technology 14, No. 2 (1977).

14. Jackson, R. G., and Kotcharian, M., Testing and technology of models of integrated tanks for LNG carriers (Proc. Ist International Conf. on LNG, Chicago, 1968). 
15. Kelsey, R. A., Wygonik, R. H., and Tenge, P., Crack growth and fracture of thick 5083-0 plate under liquified natural gas ship spectrum loading, ASTM STP 579, 44-79 (1975). 


\section{Overview}

A. Codes and regulations

a. USCS OCS Order 8 [1]

b. $\quad A P I \quad R P 2 \wedge[12]$

B. Historical failures

a. Blowout, fire, and collision [3]

b. Overload by storms [3]

c. Fatigue [4]

d. Brittle fracture [5]

e. Lamellar tearing and hydrogen-induced cracking during fabrication $[5,6]$

2. Structural Design Conditions

A. Design life

a. Platform life is governed by economic depletion of the hydrocarbon reservoir, and is generally in the range of 10 to 30 years. Fixed platforms are rarely salvaged for re-use at another location.

b. Fatigue calculations for modern, shallow-water platforms in the Culf of Mexico generally indicate an allowable fatigue life of 100-200 years using AWS criteria [7]. Deep-water platforms for which a fatigue design is made generally aim for 90-100 years. Median fatigue life is estimated to be 5 to 8 times Aws allowable.

B. Loads

a. Static loads based on self-weight, buoyancy, equipment, supplies, fluids, and drilling loads; corresponding nominal stresses limited to 60 percent of yield or buckling

b. Design wave load based on most probable maximum wave in the nominal 100-years storm, combined with wind and static loads, with allowable stresses at 80 percent of yield

c. Strength level earthquake having 5 to 40 percent probability of exceedance at platform sites during economic life, with stresses permitted to reach 100 percent of yield or buckling. In addition, structure must demonstrate survival for ductility requirement motions twice as severe.

d. Other conditions sometimes encountered include ice loads, sea-floor instability, and current-induced flutter.

e. Installation forces include lifting forces, loadout forces, launching forces, upending forces, hydrostatic pressure, and soil bearing pressures. 
C. Environment

a. Bulk of structure submerged in seawater with cathodic protection. Temperature above freezing with minimum generally in the $35^{\circ}-50^{\circ} \mathrm{F}$ $\left(2^{\circ}-10^{\circ} \mathrm{C}\right)$ range, depending on geographical location

b. Splash zone subjected to accelerated corrosion attack, alternating wet-dry salt spray

c. Air zone generally protected by paint. Lowest anticipated service temperature as follows:

$\begin{array}{lr}\text { Gulf of Mexico } & 14^{\circ} \mathrm{F}\left(-10^{\circ} \mathrm{C}\right) \\ \text { Southern California } & 32^{\circ} \mathrm{F}\left(0^{\circ} \mathrm{C}\right) \\ \text { Gulf of Alaska } & -13^{\circ} \mathrm{F}\left(-25^{\circ} \mathrm{C}\right) \\ \text { Cook Inlet } & -20^{\circ} \mathrm{F}\left(-29^{\circ} \mathrm{C}\right) \\ \text { Georgia Embayment } & 15^{\circ} \mathrm{F}\left(-9^{\circ} \mathrm{C}\right) \\ \text { Baltimore Canyon } & 5^{\circ} \mathrm{F}\left(-15^{\circ} \mathrm{C}\right) \\ \text { Georges Bank } & -5^{\circ} \mathrm{F}\left(-21^{\circ} \mathrm{C}\right)\end{array}$

d. Interior of tubular members and exterior of piling below midlines exposed only to stagnant, oxygen-depleted fluids

e. Where structural members are used for oil storage, these may be exposed to $\mathrm{H}_{2} \mathrm{~S}$ generated by bacterial action; however, this is unusual.

D. Initial damage assumption

a. API RP $2 X$ relates permissible discontinuities in welds to the level of notch toughness provided and to the fatigue $S-N$ curve assumed in design [8]. The commonly used class "C" criteria include the following:

--Tubular T-4- and K-connection welds made from the outside only typically have large discontinuities at the root up to $1 / 8$ in $(3 \mathrm{~mm})$ $x 2$ in $(51 \mathrm{~mm})$.

--Internal discontinuities el sewhere are limited to less than $1 / 8$ in $(3 \mathrm{~mm}) \times 1$ in $(25 \mathrm{~mm})$ or $1 / 10$ in $(2.5 \mathrm{~mm}) \times 2$ in $(51 \mathrm{~mm})$.

--Limitations are also placed on external weld profile--i.e., the weld metal shall merge smoothly with adjoining base metal, with no undercut over .01 in $(.25 \mathrm{~mm})$.

--These requirements are consistent with the observation that fatigue cracks in tubular connections usually start on the outside surface at the toe of the weld, with large root discontinuities rarely propagating.

b. Structures which suffer significant damage (e.g., during construction or due to overload) or deterioration (e.g., fatigue cracks or loss of section due to corrosion) may be reanalyzed for the actual conditions found. 
A. Selection criteria [5]

a. In recent frontier areas structures, critical deck members, e.g., main girders or truss chords, have been provided with pop-in protection; that is, drop weight NDTT plus $20^{\circ} \mathrm{F}\left(7^{\circ} \mathrm{C}\right)$ or comparable Charpy requirements (50 percent shear fracture) at the lowest anticipated service temperature. This is comparable to recently proposed Federal criteria for fracture-critical members in bridges.

b. For deck members whose sole failure would not be catastrophic, e.g., parallel multiple deck beams, ordinary mild steel is used.

c. For redundant tubular bracing in the underwater jacket structure subjected to nominal stresses less than yield, dependences on the initiation barrier at slow to moderate loading rates [9] permit the use of ordinary mild steel. Where higher strength steels are used, modest Charpy requirements similar to ASTM A709 are specified.

d. The requirements for piling are similar to those cited above for jacket bracing.

e. At tubular joints, or nodes, high local stresses occur at the toe of the weld--typically 3 to 5 times nominal on the main member's side, and 1.5 to 2.5 times nominal on the branch member side. Typically a "joint can" of increased thickness is provided in the main member, having a pop-in protection (NDTT plus $20^{\circ} \mathrm{F}, 7^{\circ} \mathrm{C}$ ) or better. This also provides tolerance to extremely large fatigue cracks at the anticipated wave loading rates. In addition, a "stub-end" piece in the branch member is sometimes used to provide enhanced notch toughness and weldability in the node area.

f. Consideration of these high local stresses (hot spot stresses) in fatigue generally precludes effective use.

g. Comparable notch toughness criteria are also applied to weld metal and heat affected zones.

B. Specifications

a. Fracture critical members and joint cans

Shel1 FCM

API Spec $2 \mathrm{H}$

ASTM A 537 class I

ASTM A 633 grades $A, B, C, D$,

BS 4360 grade 50D

DIN St $52-3$ N

b. Redundant bracing, piling, etc.

--Plate and shapes

ASTM A-36 
ASTM A 572 grade 42

ASTM A 709 grade 50T2

ASTM A 633 grade E

-Mil1 pipe

ASTM A 53

API $5 \mathrm{~L}$ grade $B$

API $5 L X$ grades 42 and 52

--Fabricated pipe using API Spec $2 B$ and plate listed above.

\section{Processing}

a. Structural quality ASTM A6; some plates are normalized; some are low sulfur with inclusion shape control.

b. Cold forming into pipe involves 2-5 percent strain. Subsequent strain aging when welded may cause significant loss of notch toughness--e.g., 20-40 $\mathrm{F}$

$\left(-7\right.$ to $\left.4^{\circ} \mathrm{C}\right)$ shift in transition temperatures.

c. Welding processes

$$
\begin{aligned}
& \text { SMAW--low hydrogen manual } \\
& \text { SAW--multi-pass submerged arc } \\
& \text { GMAW--short arc and spray arc } \\
& \text { FCAW--open arc }
\end{aligned}
$$

4. Design and Analysis

A. Damage and tolerance--typical jackets are multiple load path, fail-safe

structures. Fatigue or brittle failure is generally localized to one brace. The remaining structure exhibits sufficient strength and further deterioration is

sufficiently gradual to permit survival until. the next periodic inspection. This behavior has been investigated in a case study [10] but is not analyzed for every structure.

B. Joint design

a. Strength design of simple tubular joints utilizes API-AWS punching shear requirements.

b. Strength design of more complex joints utilizes the lower bound theorem of ultimate strength, commonly known as the cut-and-try approach [11].

c. Initial fatigue design is in terms of reduced allowable stresses, to be used with the cyclic part of the design wave load--for example, as shown in the following table: 


$\begin{array}{ccc}\text { AWS } & \text { Typical } & \text { Waterline } \\ \text { Category } & \text { Braces } & \text { Braces }\end{array}$

$\begin{array}{llll}\text { Hot spot stress } & X & 47 \mathrm{ksi}(324 \mathrm{MPa}) & 34 \mathrm{ksi} \text { (234 MPa) } \\ \text { nominal } \mathrm{f}_{\mathrm{a}}+\mathrm{f}_{\mathrm{b}} & \mathrm{D}^{\prime} & 19 \mathrm{ksi}(131 \mathrm{MPa}) & 15 \mathrm{ksi} \text { (103 MPa) } \\ \text { punching shear } & \mathrm{K} & 7.5 \mathrm{ksi}(52 \mathrm{MPa}) & 5 \mathrm{ksi} \text { (34 MPa) } \\ & \mathrm{T} & 5 \mathrm{ksi}(34 \mathrm{MPa})\end{array}$

These allowable stresses are derived from preliminary generic analysis (e.g., [12]). Category $X$ is used with empirical formulas for hot spot stress concentration factors [13].

C. Standard details

These are given in Section 10 of AwS.

5. Analysis

A. Stress analysis

a. Global-scale analysis of elastic static or dynamic space frame program yields nominal member stresses and AISC ratio checks.

b. Local-scale analysis of critical tubular joints may be performed using twin shell or isoparametric solid finite elements, or model tests.

c. Microscopic effects at toe of weld are built into empirical $S-N$ curves for hot spot stress on practical as-welded hardware.

B. Fatigue analysis [14]

a. Stress analysis tools described above used to develop transfer functions for. hot spot stress at 4 points at each end of each brace for various wave frequencies and directions.

b. Wave climate is described in terms of directional scatter diagram. Each sea state is represented by Pierson-Moskowitz spectrum.

c. Short-term stress statistics are computed for each sea state at each hot spot. These are accumulated to yield long term (annual) statistics.

d. Cummulative damage is computed using Miners Rule and AWS-X-modified S-N curve.

C. Fracture mechanics

Used mainly as a research tool to evaluate engineering procedures 
6. Quality Assurance

A. Material procurement controls

Steel ordered by fabricator to ASTM, API, or AWS specifications. Structural practice per ASTM A6. Mill reports checked by owner's inspector.

B. Fabrication and processing controls

a. Major fabricators have independent, in-house quality control organization. In addition, owner provides resident inspector and third-party non-destructive testing.

b. Welding procedures are qualified per AWS D1.1, with additional Charpy requirements.

c. Welders are qualified per AWS D1.1, with GAR required for tabular connections.

d. Fabricators are evaluated by visiting team using AISC quality certification program checklist.

C. Inspection

a. All welds are visually inspected.

b. Radiographic examination

Girth welds in jacket legs, piling, and structural braces--100 percent

Longitudinal seams in fabricated pipe--spotcheck except that joint cans are checked 100 percent

Butt welds in truss members and girder tension flanges--up to 100 percent as directed by inspector

c. Uttrasonic examination in fabrication yard

Tee welds in major tubular connections--100 percent

Deck truss joints and crane base tie-ins--up to 100 percent as directed by inspector

d. Ultrasonic examinations during offshore erection

Piling splices--up to 100 percent

Deck leg base connections--100 percent

Deck field splices--up to 100 percent

D. Proof testing

Members used to provide buoyancy or fluid storage are leak tested.

E. Traceability

Fabricator usually keeps track of the numbers used on a given job. Exact identity of individual pieces depends on finding mill heat stamp. 
F. Verification testing [15]

a. As research, selected platforms are instrumented to record sea state, wave forces, deck motions member stresses, etc.. permitting comparisons between predicted and measured response.

b. llethods for periodic monitoring of structure natural frequencies hold promise for detecting major loss of strength and stiffness. However, nonlinear foundation or operational changes in deck mass can cause similar shifts. Being used on a very limited trial basis.

6. Failure llitigation Strategies [15]

A. Surveys

a. Yearly surveys include visual inspection for collision damage, splash zone corrosion, condition of deck, and effectiveness of cathodic protection.

b. More detailed surveys are conducted following exposure to severe loading conditions, or every 5-10 years. This involves checking the condition of all underwater braces, and spot checks in which marine growth is removed to permit detailed color photography for surface pitting, cracks at nodes, etc. Atterpts at using oversold, undercalibrated, nondestructive techniques have led mainly to false alarms.

B. Fail safe while manned

a. In the Gulf of Mexico, there is sufficient warning for hurricanes that offshore platform personnel can be evacuated, and the wells secured against leakage in the event of structural collapse. This is done as a practice of long standing. For periods while the platforms are manned and the wells are flowing, the maximum expected winter storm produces only 40 percent of the design hurricane load. This leaves a considerable margin for undetected damage.

b. In other areas like the llorth Sea, de-manning may not always be possible, and a strategy comparable to the above remains to be developed.

c. Repairs

a. Techniques for underwater welding, hyperbaric chamber welding, and internal grouting are available for repairing or upgrading members in offshore structures when justified.

b. When structural deficiencies are found, the decision on whether or not to undertake repair attempts to make a rational trade-off between the cost of repair and the benefits in terms of risk reduction. 
References

1. United States Department of the Interior, Geological survey, Conservation Division, Gulf of Mexico Area, OCS Order No. 8, Platforms, Structures, and Associated Equipment, effective October 1, 1976.

2. Recommended Practice for Planning, Designing, and Constructing Fixed Offshore Platforms, API RP2A, 9th Edition (American Petroleun Institute November 1977).

3. Marsha11, P. W., and Bea, R. G., Failure modes for offshore structures (Proc. BOSS'76, 2, Trondheim, Norway, August 1976)."

4. Marshall, P. W., Design considerations for tubular joint design in offshore construction, URC Bulletin 193 (April 1974).

5. Carter, R. M., et. al., Materials problems in offshore platforms (Proc. OTC, Mo. 1043, May 1969).

6. Harrison, J. D., The selection of material to avoid fracture in large offshore structures (Proc. OTC, No. 1909, May 1973).

7. Structural Welding Code, AWS D1.1-75 (American Welding Society, 1975 edition with revisions).

8. American Petroleum Institute, Recommended Practice for U1trasonic Examination of Offshore Structural Fabrication and Guideline for Qualification of Ultrasonic Technicians, API RP 2X, draft approved for letter bal1ot, June 1978.

9. Rolfe, S. T., and Barsori, J. M., Fracture and Fatigue Control in Stuctures (Prentice-Hal1, 1977).

10. Marsha11, P. W., Failure modes for offshore structures--part II--fatigue, Methods of Structural Analysis (ASCE Specialty Conference, Madison, Wisc., August, 1976).

11. Marshal1, P. W., Sherman, D. R., and Groff, W. J., Limit State Design of Tubular Connections, Ibid., separate preprint.

12. Marshal1, P. W., et al., Preliminary dynamic and fatigue analysis using directional spectra, Journal of Petroleum Technology (June 1977).

13. Marshal1, P. W., A review of stress concentration factors in tubular connection, Shell CE-32 Report (April 1978). 
14. Marshal1, P. W., and Kinva, R. K., Dynamic and fatigue analysis for deep water fixed platform (paper presented at ASCE-EMD Specialty Conference, Raleigh, North Carolina, May 1977).

15. Marshal1, P. W., Philosophy for monitoring inspection and repair of fixed offshore platforms (Proc. of MTS-IEEE Oceans '78, September 1978). 
1. Overview

A. Codes and regulations

a. Nuclear Regulatory Commission (NRC) Regulations - Power Plant

b. U.S. Coast Guard Regulations - Support Barge

c. ABS Rules for Building and Classing Steel Vessels

d. American Welding Society Qualification and Certification Program

B.

Scope

This summary is limited to the requirements for the support barge as discussin in [1].

2. Structural Design Conditions

A. Design 1 ife $=40$ years

B. Loads

a. Dead load + live load

b. Wave action

c. Tornado

d. Earthquake

e. Fatigue

C. Service conditions
a. Water temp., $28.6^{\circ} \mathrm{F}\left(-2^{\circ} \mathrm{C}\right)$
b. Air temp., $-5^{\circ} \mathrm{F}\left(-21^{\circ} \mathrm{C}\right)$
c. Water depth at site, 40-70 ft (12-21 m)
d. No drydocking

D. Safety factors

a. Stresses at extreme loading (dead, live, tornado, etc.) $<0.9 \sigma_{\text {ys }}$

b. Fracture Control Plan developed to obtain very high level of structural integrity

c. Crack arrestors 
A. ABS-CS steel

$$
\begin{array}{ll}
\text { a. } & \sigma_{y s}=34 \mathrm{ksi}(234 \mathrm{MPa}) \\
\text { b. } & \sigma_{\text {tu }}=58-71 \mathrm{ksi}(400-489 \mathrm{MPa}) \\
\text { c. } & \text { Percent elong. }=24 \text { percent in } 2 \text { in }(51 \mathrm{~mm})
\end{array}
$$

B. Fracture toughness requirements

$$
\begin{array}{ll}
\text { a. } & N D T=-30^{\circ} \mathrm{F}\left(-34^{\circ} \mathrm{C}\right) \\
\text { b. } & D T=250 \mathrm{ft} \mathrm{lb}(340 \mathrm{~J}) \text { transverse at }+30^{\circ} \mathrm{F}\left(-7^{\circ} \mathrm{C}\right) \text { concepts such that } \\
\mathrm{K}_{\mathrm{ID}} / \sigma_{\mathrm{yD}} \geq 1.5 \text { at } 30^{\circ} \mathrm{F}\left(-7^{\circ} \mathrm{C}\right) .
\end{array}
$$

4. Quality Assurance

A. Welding procedure and performance

a. Section IX - ASME Code

b. Secton 30 - ABS Rules

c. USCG Marine Engineering Regulations, Subchapter F, Code of Federal Regulations 46 CFR57

B. Material procurement controls

a. Supplier qualification

Produce CS per $A B S$ requirements and NDT $\geq-30^{\circ} \mathrm{F}\left(-34^{\circ} \mathrm{C}\right)$

Establish dynamic tear transition curve.

b. Supplier quality controls

ABS requirements for grade CS

2 dynamic tear tests (transverse) per heat

2 NDT tests per plate, NDT $\geq-30^{\circ} \mathrm{F}\left(-34^{\circ} \mathrm{C}\right)$

C. Weldment testing

a. Prequalification investigation (for each process)

Chemical and mechanical properties per ABS rules

Establish dynamic tear and Charpy $V$-notch transition curves for the weld, $H A Z$, and base metal.

Weld metal NDT $<-30^{\circ} \mathrm{F}\left(-34^{\circ} \mathrm{C}\right)$

b. Procedure qualification (in addition to ASME Section IX)

Dynamic tear energy $>250 \mathrm{ft} 1 \mathrm{~b}(340 \mathrm{~J})$ at $30^{\circ} \mathrm{F}\left(-1^{\circ} \mathrm{C}\right)$ in the weld and $H A Z$

NDT $<-30^{\circ} \mathrm{F}\left(-34^{\circ} \mathrm{C}\right)$ in the weld metal

c. Production tests

Toughness tests every 10001 inear feet $(305 \mathrm{~m})$ of weld by each process Dynamic tear (weld and $\mathrm{HAZ}$ ) > $250 \mathrm{ft} \mathrm{lb}(340 \mathrm{~J})$ at $+30^{\circ} \mathrm{F}\left(-\mathrm{T}^{\circ} \mathrm{C}\right)$ NDT (weld and $\mathrm{HAZ}$ ) $<-30^{\circ} \mathrm{F}\left(-34^{\circ} \mathrm{C}\right.$ ) 
D. Mondestructive examination

Comprehensive in-house program approved by Coast Guard

\section{References}

1. Chazel, E. A., Deck, J., Rolfe, S. T., and Thompson, T. E., The structural requirements including fracture control for the halls of the proposed coating nuclear power plants. 
1. Overview

A. Codes applicable to storage tanks

a. API Standard 620: Recommended Rules for Design and Construction of Large, Welded, Low-Pressure Storage Tanks [1]

b. API Standard 650: Welded Steel Tanks for 0 il Storage [2]

B. Code applicable to LNG storage tanks

a. API Standard 620, Appendix Q: Low-Pressure Storage Tanks for Liquefied Hydrocarbon Gases

c. Regulations

a. Federal none

b. State and local: may require conformance to API 620

\section{Structural Design Conditions}

A. Design life not specified

B. Loads

a. Pressure $<15$ PSIG $(0.1 \mathrm{MPa})$. Tanks are pressure rated and relief valves are set at or below the pressure rating.

b. Weight of liquid $29.31 \mathrm{~b} / \mathrm{ft}^{3}\left(.47 \mathrm{~g} / \mathrm{cm}^{3}\right)$ minimum for methane

c. Partial vacuum if probable

d. Supporting systems

Localized and general loads

Foundation conditions factored in

e. Superimposed loads

Attached equipment, piping, etc.

Snow loads where applicable

Insulation and lining

Wind

Earthquake

c. Temperature

a. Parts exposed to LNG: $-270 \mathrm{~F}\left(-168^{\circ} \mathrm{C}\right)$

b. Parts not exposed to LNG: lower of lowest one-day mean ambient temperature plus $15^{\circ} \mathrm{F}\left(8^{\circ} \mathrm{C}\right)$, or vapor temperature if exposed to LNG vapor 
D. Initial damage assumptions--none

3. Materials and Processes

A. Selection specifications

a. LNG containment materials

$5 \mathrm{Ni}$ and $9 \mathrm{Ni}$ steels

AISI grade 304 and $304 \mathrm{~L}$ stainless steels

$3003-0,5052-0,5083-0,5086-0,5154-0,5456-0$, and 6061-0, T4 and T7

al uminum alloys

b. Parts not exposed to LNG -

Various ASTM, ISO, and CSA grades selected according to minimum temperature, thickness, and product form

B. Allowable design stresses

a. Tension

Lesser of $1 / 3$ tensile strength or $2 / 3$ yield strength for $5 \mathrm{Ni}$ and $9 \mathrm{Ni}$ steels

The weld strength $(95,000 \mathrm{psi}, 655 \mathrm{MPa})$ sets the tensile allowable for $5 \mathrm{Ni}$

and $9 \mathrm{Ni}$ steel welds.

Lesser of $1 / 3$ tensile strength or $3 / 4$ yield strength for $304,304 \mathrm{~L}$, and aluminum alloys

b. Compression

Allowable stress for uniaxial compression in relatively thick wal1, smal1 diameter tanks ( $t-c / R>.0175$ ) is $15,000 \mathrm{psi}$ (103 MPa) for steel, where $\mathrm{t}=$ thickness, $\mathrm{c}=$ corrosion allowance, and $\mathrm{R}=\mathrm{tank}$ radius. For al uminum, factor 15,000 by the ratio of the yield strength for the Al-alloy to 30,000.

Allowable stress for biaxial compression (again for tanks where $\mathrm{t}-\mathrm{c} / \mathrm{R}>.0175)$ is $8,340 \mathrm{psi}(57 \mathrm{MPa})$. For aluminum, factor 8,340 by the ratio of the yield strength for the Al-alloy to 30,000 .

For tanks with $t-c / R \leq .0175$, allowable stresses are established on the basis of stability considerations in accordance with formulas in API 620.

c. Combined stresses

Tension tension--treat as tension

Tension compression--use biaxial stress chart in API 620 to compute stress reduction factor

d. Shear

Less than 80 percent of the maximum allowable tensile stress 
d. Shear

Less than 80 percent of the maximum allowable tensile stress

e. Welded joints

Maximum allowable efficiencies of arc-welded joints specified 70 percent to 100 percent for butt welds and 35 percent to 70 percent for filled welds depending on joint configuration and extent of radiographic inspection.

C. Minimum toughness requirements for $5 \mathrm{Ni}$ and $9 \mathrm{Ni}$ steels

a. Test temperature: $77 \mathrm{~K}\left(-320^{\circ} \mathrm{F}\right)$

b. Plates: 3 specimen set for each plate, transverse direction, $20 \mathrm{ft} 1 \mathrm{~b}(27 \mathrm{~J})$ minimum average, $16 \mathrm{ft} 1 \mathrm{~b}(22 \mathrm{~J})$ minimum, $.015 \mathrm{inch}(3.8 \mathrm{~mm})$ minimum lateral expansion

c. Structural shapes: 3 specimen set for each different shape in each heat treatment 1ot, longitudinal direction from the thickest part of the shape, 25 $\mathrm{ft} \mathrm{lb}(34 \mathrm{~J})$ minimum average, $20 \mathrm{ft}$ lb $(27 \mathrm{~J})$ minimum, .015 inch $(3.8 \mathrm{~mm})$ minimum lateral expansion

d. Forgings, piping, tubing: 3 specimen set for each heat included in any heat treatment 1ot, $25 \mathrm{ft} 1 \mathrm{~b}(34 \mathrm{~J})$ minimum average, $20 \mathrm{ft}$ 1b $(27 \mathrm{~J})$ minimum, .015 inch $(3.8 \mathrm{~mm})$ minimum lateral expansion

e. Subsize Charpy specimens. Impact energy requirements reduced by a factor equal to the thickness reduction factor.

D. Minimum toughness requirements for welds

a. $5 \mathrm{Ni}$ and $9 \mathrm{Ni}$ steel weld metal

Not required for the common, high nickel electrodes if deposited by the SMAW or GMAW processes. For other processes, plate toughness requirements must be met on Charpy specimens taken from weld procedure qualification test plates.

b. 304 and 304 L stainless steel weld metal Not required for austenitic welds deposited by the SMAW or GMAW processes. For other processes, $77 \mathrm{~K}$ tests, $15 \mathrm{ft} 1 \mathrm{~b}(20 \mathrm{~J})$ minimum average, $12 \mathrm{ft} 1 \mathrm{~b}$ $(16 \mathrm{~J})$ minimum and .011 inch $(2.8 \mathrm{~mm})$ minimum lateral expansion on Charpy specimens taken from weld procedure qualification test plates.

c. $5 \mathrm{Ni}$ and $9 \mathrm{Ni}$ Heat Affected Zone (HAZ)

Plate toughness requirements must be met on Charpy specimens taken from weld procedure qualification test plates. Notch located approximately normal to the plate surface such that as much HAZ material as possible is in the resulting fracture.

4. Design

A. Design for damage tolerance--not required 
B. Standard details

a. Tanks have single vertical axis of revolution.

b. Design procedure given for tank walls, roofs, bottoms, knuckle regions, ring grades, openings and reinforcements, structural members, bolted flange connections, cover plates, and flush shell connections

c. Reinforcement of single openings, welded nozzles and other connections, flush type shell connections

C. Joining practices

Welding practices, procedure qualification, and welder qualification per ASME, Section IX

5. Analysis

A. Stress analysis

a. Standard formulas for sizing sidewalls, roofs, bottoms, knuckle regions, and compression ring girders

b. Unit forces determined by statics using strength-of-materials approaches or numerical methods

B. Fatigue-none

C. Fracture mechanics-none

6. Quality Assurance

A. Material procurement controls

ASTM, ISO and CSA specifications

B. Fabrication and processing controls

a. Welding procedure and welders qualified to ASME IX

b. Welds identified by welder

c. Weld fitup, edge preparation, and cleaning requirements per API 620

d. Weather conditions for welding limited

Welding not done on wet surfaces

Welding not done in rain, snow, or high winds

Base metal temperature greater than $0 \mathrm{~F}\left(-18^{\circ} \mathrm{C}\right)$

Preheat required for temperatures between 0 and $32 \mathrm{~F}\left(-18\right.$ to $\left.0^{\circ} \mathrm{C}\right)$

c. Weld quality requirements

a. Butt welds must be full penetration welds with complete fusion for the full length and free from undercuts, overlaps, and abrupt ridges or valleys. 
b. Reinforcement Timits specified

c. Radiograph acceptance standards per ASME, Section VIII, Division 1 (UW-51(b))

d. U1trasonics-acceptance standards agreed to by purchaser and manufacturer

e. Liquid penetrant-acceptance standards per ASME, Section VIII, Division 1 (UA94,95)

D. Inspection

a. Qualified inspectors per API 620 requirements

b. Inspector assures compliance with engineering design and with the provisions of API Standard 620

c. Radiography requirements

Complete for joints thicker than $11 / 4$ inch (32 mm)

Complete for butt welds where the increased joint efficiency factor is used in design except for circumferential welds in cylindrical or conical tanks where only the intersections are radiographed $(3$ inches, $76 \mathrm{~mm}$, on each side of intersection)

Spot radiographing is required on intersections at various locations in the tanks.

E. Hydrostatic and pneumatic tests

a. Tanks are filled with water to the design liquid level and pressurized to 1.25 times the design pressure. Due to the low specific gravity of LNG, exceptions to the procedure to avoid overloading the foundation or overstressing the tank are permissible. Allowable stresses during test are based on 80 percent of the yield strength for $5 \mathrm{Ni}$ and $9 \mathrm{Ni}$ steels and 90 percent of the yield strength for 304, 304L, and aluminum alloys.

b. Outer tanks in double-wall tanks are leak tested.

c. Proof tests are required for novel designs.

\section{References}

1. Recommended Rules for Design and Construction of Large, Welded, Low-Pressure Storage Tanks, API Standard 620, American Petroleum Institute, Washington, D.C., Sixth Edition, 1978.

2. Welded Steel Tanks for $0 \nmid 1$ Storage, API Standard 650, American Petroleum Institute, Washington, D.C., 1978. 
1. Overview

A. Codes

Standard Specifications for Highway Bridges-American Association of State Highway and Transportation Officials (AASHTO)

2. Structural Design Criteria

A. Design life-50-70 years

B. Loads-AASHTO Code (truck and lane)
a. Dead load
b. Live load (HS trucks)
c. Impact factor, wind

C. Initial damage assumption-none

D. Fracture critical members are designated as those tension components of a bridge whose failure would be expected to result in the collapse of the bridge. These members have special toughness requirements as noted below.

3. Materials and Processes

A. Selection specifications

AASHTO Materials Table (ASTM steel grades A36, A572, A588, A514)

B. Properties

a. ASTM tensile properties

b. Toughness values-see attached table of Charpy $V$-notch requirements for fracture critical members. For $\mathrm{A} 36\left(\sigma_{\mathrm{ys}}=36 \mathrm{ksi}, 248 \mathrm{MPa}\right)$ steel at $0^{\circ} \mathrm{F}\left(-18^{\circ} \mathrm{C}\right)$ service temperature, the minimum CVN impact requirement is $25 \mathrm{ft} 1 \mathrm{~b}(340 \mathrm{~J})$ at $70^{\circ} \mathrm{F}\left(21^{\circ} \mathrm{C}\right)$. Values are based on intermediate loading rate and temperature shift. Similar values are specified for other steels.

C. Allowable stresses
a. Tension: $\sigma_{\mathrm{T}} \sim .55 \sigma_{\mathrm{ys}}$
b. Compression: $\sigma_{\mathrm{c}} \sim .55 \sigma_{\mathrm{ys}}$ or buckling 
4. Design

A. Damage tolerance-structural redundancy encouraged

B. Standard details-fatigue categories A, B, C, D, E, F based on standard details shown in AASHTO Specification

C. Joining Practices-AWS Structural Code [2]

5. Anatysis and Design

A. Stress analysis-stress allowables, buckling criteria to withstand given truck and wind loading fatigue curves $(S-N)$

B. Fatigue analysis-based on categories of details and $S-N$ curves when essentialiy $\mathrm{a}_{0} \sim 1 / 8$ in $(3.2 \mathrm{~mm})$ and $10 \mathrm{w} \mathrm{da} / \mathrm{dN}$

C. Fracture mechanics--not required

Concepts used in establishing toughness requirements

6. Quality Assurance

A. Material procurement--per applicable ASTM specification

B. Fabrication and processing

a. AWS Structural Welding Code [2]

b. AISC requirements [3]

c. AASHTO Fracture Control PIan [4]

C. Quality of workmanship required by AASHTO Code "workmanship and finish shall be equal to the best general practice in modern bridge shops."

D. Inspection

a. Butt welds-100 percent radiography

b. AWS Specifications

E. Proof testing-none

References

1. Standard Specifications for Highway Bridges, American Association of State Highway and Transportation Officials, Washington, D.C., 12th Edition, 1977. 
2. Structural Welding Code - Steel, AWS D1.1-78, American Welding Society, Miami, FL, . 1978.

3. AISC

4. Fracture Control Plan, Draft developed by the Structual Steel Design and Welding Technical Committees of the AASHTO Subcommittee on Bridges and Structures in consort with the Bridge Division of the Federal Highway Administration, April 1978. 
Charpy V-notch Requirements(a) for Fracture-Critical Members

ASTM

Designation Thickness, inches

$$
\frac{\text { Zone } 1^{(a)}}{\mathrm{ft}-1 \mathrm{~b}(\mathrm{~J})} \quad \frac{\text { Zone } 2^{(\mathrm{b})}}{\mathrm{ft}-1 \mathrm{~b}(\mathrm{~J})} \quad \frac{\text { Zone } 3^{(\mathrm{d})}}{\mathrm{ft}-\mathrm{lb}(\mathrm{J})}
$$

A36

A572

Up to 4 in $(102 \mathrm{~mm})$

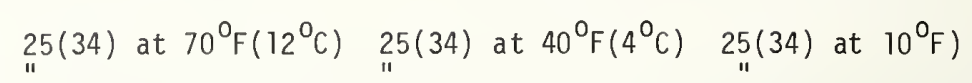

Up to 4 in $(102 \mathrm{~mm})$
mechanically fastened

" Up to 2 in $(51 \mathrm{~mm})$

A588 Up to 4 in (102 mm)

mechanically fastened

Up to 2 in (51 m)

welded

Over 2 in to 4 in

(51-102 mm) welded

$30(41)$ at $70^{\circ} \mathrm{F}\left(21^{\circ} \mathrm{C}\right) \quad 30(41)$ at $40^{\circ} \mathrm{F}\left(4^{\circ} \mathrm{C}\right) \quad 30(41)$ at $10^{\circ} \mathrm{F}\left(-12^{\circ} \mathrm{C}\right)$

A514 Up to 4 in (102 mm) mechanically fastened

Up to $2-1 / 2$ in

(64 mm) welded

$35(48)$ at $0^{\circ} \mathrm{F}\left(-18^{\circ} \mathrm{C}\right) 5(48)$ at $0^{\circ} \mathrm{F}\left(-18^{\circ} \mathrm{C}\right) 35(48)$ at $-30^{\circ} \mathrm{C}\left(-34^{\circ} \mathrm{C}\right)$

$35(48)$ at $0^{\circ} \mathrm{F}\left(-18^{\circ} \mathrm{C}\right) 35(48)$ at $0^{\circ} \mathrm{F}\left(-18^{\circ} \mathrm{C}\right) 35(48)$ at $-30^{\circ} \mathrm{C}\left(-34^{\circ} \mathrm{C}\right)$

Over $2-1 / 2$ in to

4 in $(64-102 \mathrm{~mm})$

$45(61)$ at $0^{\circ} \mathrm{F}\left(-18^{\circ} \mathrm{C}\right)$ 45(61) at $0^{\circ} \mathrm{F}\left(-18^{\circ} \mathrm{C}\right)$

NOT PERMITTED

welded

(a) The CVN-impact testing shall be "P" plate frequency testing in accordance with AASHTO T-243 (ASTM A673). When more than one flange or web is stripped from a larger plate, only the larger plate need be tested. The Charpy test pieces shall be coded with respect to heat/plate number and that code shall be recorded on the mill-test report of the steel supplier with the test result. If requested by the Engineer, the broken pieces from each test (three specimens, six halves) shall be packaged and forwarded to the Quality Assurance organization of the State. Use the average of three (3) tests. If the energy value for more than one of three test specimens is below the minimum average requirements, or if the energy value for one of the three specimens is Tess than two thirds $(2 / 3)$ of the specified minimum average requirements, a retest shall be made and the energy value obtained from each of the three retest specimens shall equal or exceed the specified minimum average requirement.

(b) Zone 1:

(c) Zone 2:

(d) Zone 3:

Minimum Service Temperature $0^{\circ} \mathrm{F}\left(-18^{\circ} \mathrm{C}\right)$ and above

Minimum Service Temperature from $-1^{\circ}\left(-19^{\circ} \mathrm{C}\right)$ to $-30^{\circ} \mathrm{F}$ $\left(-34^{\circ} \mathrm{C}\right)$.

Minimum Service Temperature from $-31^{\circ}\left(-35^{\circ} \mathrm{C}\right)$ to $-60^{\circ} \mathrm{F}$ $\left(-51^{\circ} \mathrm{C}\right)$.

If the yield strength of the material exceeds $65 \mathrm{ksi}(448 \mathrm{MPa})$, the temperature for the CVN value acceptability shall be reduced by $15^{\circ} \mathrm{F}\left(8^{\circ} \mathrm{C}\right)$ for each increment of $10 \mathrm{ksi}$ (69 $\mathrm{MPa}$ ) above $65 \mathrm{ksi}(448 \mathrm{MPa})$. The yield strength is the value given in the certified "Mill Test Report." 


\author{
for \\ Electrical Power Generation
}

1. Overview
A. Codes and regulations
Design practices are proprietary to the equipment manufacturers. There are no design codes or federal regulations applicable.
B. Equipment
a. Steam turbine rotors and shafts
b. Generator rotors
c. Steam and land-based gas turbine
d. Discs and wheels
C. Scope
Due to the absence of design codes for large rotating equipment, this summary is limited to general information of a non-proprietary nature.

2. Structural Design Conditions

A. Design life: 40 years

B. Loads
a. Centrifugal stresses due to rotation
b. Thermal stress
c. Bending of large shafts from dead weight
d. Shrink-fit stresses for discs
e. Stop-start fatigue cycle
f. Small amplitude vibration

c. Initial damage assumptions
a. Company specific
b. Generally based on operating experience, backed up by fracture mechanics analysis

D. Safety factors
a. Company specific
b. Factor of 2 on yield strength is typical 
A. Selection, specifications

a. Generator rotors--ASTM A 469

b. Turbine rotors and shafts--ASTM A 470

c. Turbine rotor disks and wheels ASTM A 471

d. Proprietary company specifications, more rigorous than the ASTM specifications, may be the procurement requirements.

B. Processes

a. Basic eletric furnace melting

b. Vacuum treated prior to or during pouring to remove objectionable gases, particularly hydrogen

c. Forged using equipment with sufficient power to hot work the metal throughout its section. The axial center of the forging is maintained common with the axial center of the ingot.

d. Heat treatment--quench and tempered (A469 and A 471) or double normalized (A47C)

c. Stress relief--required after rough machining

C. Properties

a. Minimum tensile and impact requirements in accordance with procurement specification (ASTM or company)

b. Companies have ongoing material cvaluations to qualify suppliers and to assess material variability.

D. Allowable stresses

Company specific

4. Design Practices
A. Based on successful operating history
B. Quality materials
C. Specified operating stresses
D. Minimal stress concentrations 
5. Analysis

A. Stress analysis

a. Closed form methods

b. Finite element analysis

c. Photo elastic stress analysis

B. Fatigue analysis

a. Mainly conventional S-ll approach

b. Low cycle fatigue used to analyze discs

c. Fracture mechanics analysis--back up analysis and for in-service inspection

6. Quality Assurance

A. Material procurement controls

a. ASTM and company material specifications

b. In-house material evaluation--check test not receiving inspection

B. Inspection

a. Ultrasonics (bore is critical region)

b. Magnetic particle

c. Defect limits are company specific

d. $X$ ray where applicable, but generally parts are too big for $x$ ray

C. Verification testing

a. Overspeed rotation tests

b. 20 percent overspeed--increases stresses 40 percent 
1. Overview

A. Codes

a. American Society of Mechanical Engineers (ASME) Boiler and Pressure Vessel Code, Section VIII, Pressure Vessels

Division 1-applicable to vessels designed for pressures not exceeding 3,000 psi (21 MPa)-Factor of Safety against burst $=4$

Division 2-Alternative Rules-more precise design and inspection procedures are required than for Division 1-Pressures greater than 3,000 psi (21 MPa) are allowed-Factor of Safety against burst $=3$

2. Structural Design Criteria

A. Design life-not specified

B. Loads

a. Internal or external pressure

b. Impact, including rapidly fluctuating pressures

c. Weight of vessel and contents

d. Superimposed loads from other equipment

e. Wind loads, and earthquake loads where required

$f$. Reactions of supports

g. Effect of temperature gradients

C. Initial damage assumption-none

"All injurious flaws shall be removed"

D. Safety factors

3 or 4 on burst, depending on Division 1 or Division 2 rules

3. Materials and Processes

A. Only certain materials permitted as given by Code Material

Specifications, Section II

Part A-Ferrous Materials

Part B-Nonferrous Materials

Part C-Welding Rods, Electrodes, and Filler Metals 
B. Properties

Minimum tensile values as specified in Code

c. Special toughness reuirements

a. Carbon and 1ow-alloy steels

Minimum Charpy $V$-Notch Impact Test Requirements for these steels vary from 10 to $20 \mathrm{ft} 1 \mathrm{~b}$ (14 to $27 \mathrm{~J}$ ) (depending on deoxidation) at minimum service temperature. (Section VIII,Division 2,AM-210)

b. Quenched and tempered ferritic steels

Minimum lateral expansion of 0.015 in $(3.8 \mathrm{~mm})$ at minimum service temperature. (Section VIII,Division 2,AM-310) For service temperatures below $-20^{\circ} \mathrm{F}\left(-29^{\circ} \mathrm{C}\right)$, drop-weight NDT tests shall be made with NDT (no-break) to be at or below that temperature.

D. Allowable stresses

a. Section VIII, Division 2, Alternate Rules

Referred to as design stress intensity values, $S_{m}$. Design allowable values are given in Section VIII, Division 2, Article M-6, "Material Design Data," for materials as a function of temperature. For example, SA-372 steel with a specified minimum yield of $35 \mathrm{ksi}$ (241 MPa) and tensile of $60 \mathrm{ksi}$ (413 MPa) has a design stress allowable ranging from $20\left(\sigma_{T} / 3\right) \mathrm{ksi}(138 \mathrm{MPa})$ at $100^{\circ} \mathrm{F}\left(38^{\circ} \mathrm{C}\right)$ to $17 \mathrm{ksi}(117 \mathrm{MPa})$ at $650^{\circ} \mathrm{F}\left(349^{\circ} \mathrm{C}\right)$.

b. Section VIII, Division 1 Design allowable stress values given in UG-23--"Maximum A1lowable Stress Values." For example, Table UCS-23 gives maximum a1lowable stress for SA-36 steel as $12.7 \mathrm{ksi}(88 \mathrm{MPa}$ ). Minimum yield strength is $36 \mathrm{ksi}$ (248 MPa) and minimum tensile strength is $58 \mathrm{ksi}(400 \mathrm{MPa})$. The allowable stress is less than $\sigma_{T} / 4$ because $\mathrm{SA}-36$ is a structural grade.

4. Design and Analysis

A. Design requirements specified in Code.

B. Thickness of vessel parts are established by formulas given in Code using the most severe combination of loadings and allowable stress intensities (also given in Code for each material) expected to occur.

C. Formulas are based on maximum shear stress theory of failure.

D. Standard details

Acceptable transition details presented in Code--Design Requirements 
E. Fatigue evaluation

a. Specific rules are established for conditions when fatigue analyses are mandatory (Conditions A and B, Section VIII, Division 2, Alternate Rules, $A D-160)$.

b. Fatigue analysis based on S-N curves that have factor of safety of 20 on life or 2 on stress.

c. Stress ranges for fatigue analyses are based on startup and shutdown, number of operating pressure cycles, thermal stresses, and mechanical loading, e.g., piping reactions.

F. Experimental stress analysis shall be conducted to substantiate analysis of critical parts for which theoretical stress analysis is inadequate.

\section{Quality Assurance}

A. Material procurement

Section II, Material Specifications-same as ASTM material specifications

B. Fabrication and processing control

General fabrication requirements given in Section VIII, Article F-1, General

Fabrication Requirements and Section IX, Welding and Brazing Qualifications.

C. Inspection

Section $V$, Nondestructive Examination

Various methods (radiographic, ultrasonic, magnetic particle, liquid penetrant, visual, eddy current, and leak testing) are specified to detect both surface and internal discontinuities.

D. Hydrotest

a. After all required heat treatments have been performed, the completed vessel shall be sujected to either a hydrostatic test (Article T-3) or a pneumatic test (Article T-4).

b. Hydrostatic test pressure to be not less than 1.25 times the design pressure times the lowest ratio of design stress at the test temperature of the vessel to the design stress at design temperature.

c. Pneumatic test can be used only if vessel cannot be filled with water. Required pneumatic test pressure shall be not less than 1.15 times the design pressure times the lowest ratio of design stress at test temperature to design stress at design temperature.

E. Safety valves set approximately 10 percent above the operating pressure. 
6. Fracture Mechanics Analysis

Not used in Section VIII, Pressure Vessels. Fracture mechanics is used in Section III, Nuclear Power Plant Components. 
NUCLEAR PRESSURE VESSELS

1. Overview

A. Codes and Regulations

a American Society of Mechanical Engineers (ASME) Boiler and Pressure Vessel Code - Section III - Nuclear Power plant Components

b. Nuclear Regulatory Commission (NRC)

2. Structural Design Criteria

A. Design life - not specified (fatigue curves $\sim 25$ years)

B. Loads

a. internal and external pressure

b. impact loads, including rapidly fluctuating pressures

c. weight of the component and contents

d. superimposed loads such as other components, operating equipment, etc.

e. wind loads, snow loads, earthquakes

f. reactions of supporting lugs, rings, etc.

g. temperature effects

C. Maximum shear stress theory

$$
\begin{aligned}
& \sigma_{\max }=1 / 2\left(\sigma_{1}-\sigma_{3}\right) \\
& \text { Generally } \sigma_{\max } \leq \frac{\sigma_{u 1 t}}{3} \text { at operating temperatures } \\
& \text { Example: carbon steel }-\sigma_{y s}=24 \mathrm{ksi}(165 \mathrm{MPa}), \sigma_{u 1 t}=45 \mathrm{ksi}(310 \mathrm{MPa}) \\
& \max =15 @ 100^{\circ} \mathrm{F}\left(38^{\circ} \mathrm{C}\right) \\
& 14.2 @ 300^{\circ} \mathrm{F}\left(149^{\circ} \mathrm{C}\right) \\
& 12.9 @ 500^{\circ} \mathrm{F}\left(260^{\circ} \mathrm{C}\right) \\
& 11.5 @ 700^{\circ} \mathrm{F}\left(371^{\circ} \mathrm{C}\right)
\end{aligned}
$$

D. Detailed stress report showing stress analysis is required for normal stress, shear stress, bending stress, secondary stress, thermal stress, and fatigue stresses. 
E. Safety factors:

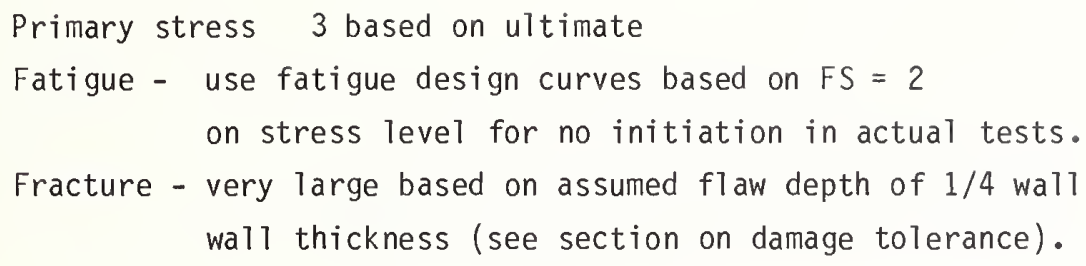

3. Materials and Processes

A. ASTM and SA grades.

B. Properties - Minimums specified by Code and tested by manufacturer according to ASME Code - NB-2000, Material

C. Fracture Toughness Requirements

a. Drop weight tests to determine NDT according to ASTM E-208-60 standard

b. Charpy $V$-notch tests according to ASTM SA-370

c. Requirements for toughness levels described in Article G-2000 (copy attached)

1. Establish RT ${ }_{\text {NDT }}$ (reference NDT temperature)

2. Establish $K_{I R}$ - reference critical stress intensity factor for dynamic loading for all operating temperatures

3. Use CVN impact test results to verify RT

4. Assume surface $f l a w$ depth of $1 / 4$ wall thickness

5. Calculate applied stress intensity factors at all operating levels

1) $K_{\text {Im }}=$ stress intensity factor due to membrane stress

2) $\mathrm{K}_{\mathrm{It}}^{\mathrm{Im}}=$ stress intensity factor due to thermal stress

6. To establish allowable pressure at any operating temperature,

$$
2 \mathrm{~K}_{\text {Im }}+\mathrm{K}_{\text {It }} \mathrm{K}_{\text {IR }}
$$


4. Quality assurance

A. ASTM and SA material requirements

B. Actual tension, CVN, NDT tests by manufacturer

C. Preparation of Materials Report and Stress Report

D. ASME Fabrication Requirements NB-4000 includes procedure qualification tests, radiography, ultrasonic, and magnetic particle testing, weld production tests of weld metal and heat affected zone, specified repair procedures, etc.

5. Verification testing

A. Hydrotesting at 1.25 times system design pressure

B. Use of pressure gages

C. Periodic in-service inspection according to ASME Section XI - Division 1 -

D. a. Owners responsibility

b. NRC control

c. Examination and inspection

d. Standards for Examination Evaluation

e. Repair Procedure

f. System pressure tests

g. Records and reports

h. Replacements 
1. Overview

A. Codes

a. Liquid Petroleum Transportation Piping Systems ANSI B31.4 [1]

b. Gas Transmission and Distribution Piping Systems ANSI B31.8 [2]

c. Standard for Welding Pipe Lines and Related Facilities API Std. 1104 [3]

B. Regulations

a. Transportation of Liquids by Pipeline 49 CFR 195 [4]

b. Transportation of Natural and Other Gas by Pipeline: Minimum Federal Safety Standards, 49 CFR 192 [5]

C. Practices

a. Material procurement specification: Requirements on line pipe quality specified by owner companies frequently exceed the minimum requirements of the applicable codes and regulations.

b. Nondestructive testing of field welds: Federal regulations require inspection of from 10 to 100 percent of each day's field butt welds, the percentage depending on location (e.g., 10 percent in isolated locations, 100 percent under highway crossings). In practice, 100 percent inspection is frequently required by the owner company and/or by federal regulatory authorities.

c. Crack arrest: Although not required by codes and regulations, many owner companies require crack arrest capabilities in gas pipelines. This is generally achieved by specifying minimum toughness requirements sufficient to avoid long running cracks or by specifying use of mechanical crack arrestors at intervals along the line.

D. Scope

Fracture control practices are summarized for large diameter ( 12 inch, $.3 \mathrm{~m}$ ) steel pipelines for transportation of $0 i l$ and gas. Codes and regulations have additional provisions for non-ferrous and plastic pipe, and for small idameter pipe.

2. Structural Design Conditions

A. Design life: not specified. Determined by size of oil/gas reservoir. Trans-Alaska Pipeline has a design life of 30 years. Other pipelines have been in operation longer than 30 years. 
B. Loads

a. Internal design pressure

b. External design pressure

c. Fluid expansion effects

d. Dynamic effects

Impact

Wind

Earthquake

Vibration

Subsidence

Waves and Current

e. Weight effects

Live loads--1iquid transported plus ice and snow

Dead loads--weight of pipe, components, coatings, backfi11, and unsupported attachments.

f. Thermal expansion and contraction

g. Relative movement of connected components

h. Surge pressure--surge pressure has less than 20 percent design pressure.

C. Initial damage assumptionsd

a. $0 i 1$ pipelines: none

b. Gas pipelines: Frequently owner specifications require crack arrest capability. Thus, the pipeline is designed to arrest a through-thickness crack that exceeds critical size at design pressure.

D. Locations

Design pressures (gas lines only) and inspection frequency are functions of location. For gas lines, the class location unit is an area that extends 400 yards $(366 \mathrm{~m})$ (B31.8) or 220 yards $(201 \mathrm{~m}$ ) (49 CFR 192) on either side of the centerline of any

continuous one-mile length of pipeline. For gas lines, four classes are defined as a function of population density and degree of development. For oil lines, pollution potential is also considered.

E. Design temperature

a. 0i1: Design stress constant for $-20^{\circ} \mathrm{F}<\mathrm{T}<+25^{\circ} \mathrm{F}\left(29^{\circ} \mathrm{C}<\mathrm{T}<-4^{\circ} \mathrm{C}\right)$.

b. Gas: Temperature derating factor used for $\mathrm{T}>250^{\circ} \mathrm{F}\left(121^{\circ} \mathrm{C}\right)$

Gas Temperature

T $\quad 250^{\circ} \mathrm{F}\left(127^{\circ} \mathrm{C}\right)$

$300^{\circ} \mathrm{F}\left(149^{\circ} \mathrm{C}\right)$

$350^{\circ} \mathrm{F}\left(176^{\circ} \mathrm{C}\right)$

$400^{\circ} \mathrm{F}\left(204^{\circ} \mathrm{C}\right)$

$450^{\circ} \mathrm{F}\left(232^{\circ} \mathrm{C}\right)$
Derating factor

1.000

.967

.933

.900

.867 
For immediate temperatures, the derating factor is determined by interpolation.

c. Low temperature service: cautionary notes regarding brittle fracture

3. Materials and Processes

A. Selection, specifications

a. Line pipe generally conforms to API specifications.

API $5 \mathrm{~L} \quad$ Steel (seamless and welded) line pipe

API 5LS Steel (special welded) line pipe

API 5LU Steel (seamless and welded) ultrahigh test heat treated line pipe

API 5LX Steel (seamless and welded) high test line pipe

b. Materials for components generally conform to ASTM specifications.

B. Properties

Allowable stresses for design based on the specified minimum yield stress (SMYS).

C. Allowable stresses

$S=($ SMYS) $\times F \times E \times T$

where $S=$ allowable stres

$\mathrm{F}=$ design factor

$E=$ weld joint factor

$T$ = temperature derating factor for gas lines (see 2.E.b.)

a. F-values

0il pipelines: $F=.72$ unless pipe has been cold worked to meet SMYS and subsequently heated, other than by welding, to $600^{\circ} \mathrm{F}\left(315^{\circ} \mathrm{C}\right)$ or more.

For latter case, $F=0.54$.

Gas pipelines: $F$ is a function of location.

Class $1 \quad F=0.72$

Class $2 \quad F=0.60$

Class $3 \quad F=0.50$

Class $4 \quad F=0.40$

b. E-values

For al1 commonly used API $5 \mathrm{~L}, 5 \mathrm{LS}$, or $5 \mathrm{LX}$ pipe, $E=1.00$. For API $5 \mathrm{~L}$ pipe

that is furnace butt welded, $E=0.65$ and furnaced 1 ap welded, $E=0.80$.

c. Surge pressures must not raise the stress more than 10 percent.

d. Allowable stresses--other than tension

Compression $=$ tension allowable

Shear $=45$ percent SMYS

Bearing $=90$ percent SMYS 
e. Structural supports

Tension (and compression) 66 percent SMYS

D. Minimum toughness

a. API requirements depend on specifications and strength level, e.g.,

API 5LX-65--base metal requirements, none on welds or HAZ. Transverse shear

energy: 50 percent ave, 35 percent min at $0^{\circ} \mathrm{C}$ or $+10^{\circ} \mathrm{C}, 2 / 3$ size

specimens

b. Specific pipelines have more stringent requirements, e.g., Trans-Alaska

Pipeline system.

Toughess on $5 \mathrm{LX} 65$ pipe (full-size specimens longitudinal)

Base metal $50 \mathrm{ft} 1 \mathrm{~b}(68 \mathrm{~J})$ at $-10^{\circ} \mathrm{C}$ (Ave of 3 ), $35 \mathrm{ft} 1 \mathrm{~b}(48 \mathrm{~J}) \mathrm{min}$,

50 percent shear

Weld $30 \mathrm{ft} 1 \mathrm{~b}(41 \mathrm{~J})$ at $0^{\circ} \mathrm{C}$ (Ave of 3), $20 \mathrm{ft} 1 \mathrm{~b}(27 \mathrm{~J})$, min

HAZ $30 \mathrm{ft} 1 \mathrm{~b}(41 \mathrm{~J})$ at $-{ }^{\circ} \mathrm{C}$ (Ave of 3 ), $20 \mathrm{ft} 1 \mathrm{~b}(27 \mathrm{~J})$, min

4. Design

A. Design for damage tolerance

0 il--none

Gas--crack arrest

B. Standard details

a. Straight pipe

Dimensional limits specified to assure good joint fit-up

b. Curved pipe

Pipe bending limits specified

c. Intersections, closures, ranges, reducers, and elbows

Design procedures standardized

d. Fittings, valves, and flanges

Standard components used

c. Joining practices

a. Acceptable butt-welded joint designs are standardized.

b. Attachment details for flanges recommended in B31.4

C. Details for reinforcement of openings specified 
5. Anatysis

A. Straight pipe and bends

$$
\begin{aligned}
t=P_{i} D / 2 S \quad \text { where } t & =\text { wall thickness } \\
P_{i} & =\text { internal pressure } \\
D & =\text { pipe diameter (nominal outside diam.) } \\
S & =\text { allowable stress value. }
\end{aligned}
$$

B. Expansion and flexibility

$$
\begin{aligned}
& S_{L}=E \alpha\left(T_{2}-T_{1}\right)-\nu S_{h} \\
& S_{L}=\text { longitudinal compressive stress } \\
& E=\text { Young's modulus } \\
& \alpha=\text { Linear coefficient of thermal expansion } \\
& \nu=\text { Poisson's ratio }=0.30 \text { for steel } \\
& T_{1}=\text { Temperature at time of installation } \\
& T_{2}=\text { Operating temperature } \\
& S_{h}=\text { Hoop stress due to internal pressure }
\end{aligned}
$$

\section{Quality Assurance}

A. Material procurement controls

API and supplemental owner-company requirements on strength, toughness, hardness, chemistry, dimensional tolerances, and inspection

B. Fabricating and processing controls (per API 1104)
a. Weld procedure qualifications
b. Welder qualifications
c. Controls on repair and removal of defects
d. Controls on weld joint design, preparation, and alignment

c. Inspection
a. Methods: commonly visual and radiography
b. Frequency: function of location (see 2.D).
c. Standards of acceptability (per API 1104)
d. Qualified inspectors and procedures required

D. Pressure testing

a. $0 i 1$ pipelines

For operating stresses < 20 percent SMYS, pneumatic leak test at 100 psig(0.7 $\mathrm{MPa}$ ) is satisfactory. 
For operating stress $>20$ percent SMYS, hydrotesting equivalent to not less than 1.25 times the internal design pressure at that location is required.

b. Gas pipelines

For operating stresses < 30 percent SMYS but > 100 psig $(0.7 \mathrm{MPa})$, leak tests required

For operating stresses $>30$ percent SMYS, hydro or pneumatic testing required at test pressures specified as a function of location:

Class 1: Test pressure exceed $1.1 \times$ m.0.p. (maximum operating pressure)

Class 2: Test pressure exceeds $1.25 \times \mathrm{m} .0 . \mathrm{p}$.

Class 3 and 4: Test pressure exceeds $1.40 \times \mathrm{m} .0 . \mathrm{p}$

7. Operation and Maintenance Procedures

A. Written plan for operating, maintenance, and emergency

a. Operate and maintain facilities in accordance with the plan.

b. Keep records necessary to administer the plan properly.

c. Modify the plan as required by changes in population density or operating conditions.

B. Elements of the plan

a. Surveillance and patrolling

b. Repair procedures

c. Testing of repairs

d. Leak records

e. Failure analysis

f. Procedures for abandoning facilities

g. Changes in class location

h. Valve maintenance

i. Corrosion control

j. Emergency plans

$k$. Review procedure for proposed changes in operating conditions.

1. Liaison with local authorities

m. Pipeline markers

n. Maintenance of pressure limiting and pressure regulating stations

References

1. Liquid Petroleum Transportation Piping Systems, American National Standards Institute, ANSI B31.4, American Society for Mechanical Engineers, New York, 1974.

2. Gas Transmission and Distribution Piping Systems, ANSI B31.8, American Society for Mechanical Engineers, New York, 1975. 
3. Standard for Welding Pipelines and Related Facilities, API Standard 1104, American Petroleum Institute, Washington, D.C., 13th Edition, 1973.

4. Transportation of Liquids by Pipeline, Part 195, Title 49, Code of Federal Regulations, 1978.

5., Transportation of llatural and Other Cas by Pipeline: Minimum Federal Safety Standards, Part 192, Title 49, Code of Federal Regulations 1978. 
1. Overview

A. Codes

a. Power Piping, ANSI B31.1 [1]

b. Chemical Plant and Petroleum Refinery Piping, ANSI B31.3 [2]

B. Regulations

a. Federal: none

b. State and local: may require conformance to B31 codes

2. Structural Design Conditions

A. Design life--not specified

B. Loads

a. Internal pressure

Static head plus sustained fluid operating pressure

b. External pressure

Maximum differential pressure

c. Ambient effects

Fluid expansion/contraction due to heating/cooling

d. Dynamic effects

Impact (e.g., water hammer effect)

Wind--same as specified for buildings

Earthquake--not concurrent with wind

Vibration

Discharge reactions

e. Weight effects

Life load: medium plus snow, ice

Dead load: system weight and permanent loads

f. Thermal expansion and contractoin

Due to reactions, temperature gradients, and differential thermal expansion

g. Effects of support, anchor, and terminal movements

C. Initial damage assumption: none

D. Temperature--B31.1

a. Fluid temperature unless shown to be lower

b. Heat exchanger piping: highest temperature expected in that section of the 
c. Piping from fired equipment: design temperature based on continuous (not peak) operating condition

E. Temperature--B31.3

a. Design temperature: most severe condition of coincident pressure and temperature (i.e., not peak)

b. Uninsulated piping, $T<100^{\circ} \mathrm{F}\left(38^{\circ} \mathrm{C}\right)$

Piping temperature equals fluid temperature

c. Uninsulated piping, $T \geq 100^{\circ}\left(38^{\circ} \mathrm{C}\right)$

\section{Component}

Thin wall components

Flanged fittings and flanges

Lap joint flanges

Bolting

Nonmetallic piping
Metal Temperature

(percent of fluid temperature)
d. Insulated (internal) piping
Based on heat transfer calculations
e. Insulated (external) piping
100 percent of fluid temperature

3. Materials and Processes

A. Selection specifications

a. Materials specifications listed in respective codes

b. Unlisted materials

B31.1--allowable stress must be assigned by B31.1 prior to use.

B31.3--allowable stress must be established in accordance with the allowable stress basis of the B31.1 code.

B. Limitations on materiats

a. Steels

Temperature limits to avoid graphitization

Carbon content limits ( $C \leq 0.35$ percent) to improve weldability

b. Cast irons

Specific limits placed on usage of cast iron, malleable iron, ductile iron, and high silicon iron regarding temperature, pressure, and impact

c. Nonferrous metals

Cautionary note regarding fire hazard and galvanic corrosion 
d. Welding

Not permitted in ductile iron or on aluminum alloy castings

c. Allowable stress basis--basic allowable stress values at temperature shall not exceed the lowest of the following (property $x$ factor):

Factor

Property

Specified minimum tensile strength at room temperature

Tensile strength at temperature

Specified minimum yield strength at room temperature

Ferrous

Nonferrous

Yield strength at temperature

Ferrous

Nonferrous

Average stress for a creep rate of .01 percent/1000 $\mathrm{h}$

Average stress for rupture at $100,000 \mathrm{~h}$

Minimum stress for rupture at $100,000 \mathrm{~h}$
B31.1 B31.3 B31.3 - Bolts

$\begin{array}{lll}1 / 4 & 1 / 3 & 1 / 4 \\ 1 / 4 & 1 / 3 & 1 / 4\end{array}$

$5 / 8 \quad 2 / 3 \quad 5 / 8$

$2 / 3 \quad 2 / 3$

$5 / 8 \quad 2 / 3 \quad 5 / 8$

$2 / 3 \quad 2 / 3$

$1.0 \quad 1.0 \quad 1.0$

$2 / 3 \quad 2 / 3 \quad 2 / 3$

$4 / 5 \quad 4 / 5 \quad 4 / 5$

Notes: 1. For austenitic stainless steels and certain nickel alloys allowable stresses up to 90 percent of the yield strength at temperature may be used if the added deformation is not deleterious.

2. For heat treated bolting materials, a factor of $1 / 5$ is used on specified minimum tensile strength at room temperature.

D. Properties

a. Strength vs. temperature: Trend curves are from ASME Boilder and Pressure Vessel Code. These curves are factored in accordance with Part $C$ above to derive allowable stresses. Section VIII, Division 1 factors are used for ANSI B31.1 and Section VIII, Division 2 factors are used for ANSI B31.3.

b. Minimum toughness requirements: 


$$
\begin{array}{ll}
\text { Charpy Impact Energy, } & \text { ft } 1 \mathrm{~b}(\mathrm{~J}) \\
\text { Killed Steels } & \text { Other Steels }
\end{array}
$$

Specified Minimum Tensile

Strength $\sigma_{\text {ts }}$

Carbon and low alloy steels

$\sigma_{\mathrm{ts}} \leq 65 \mathrm{ksi}(448 \mathrm{MPa})$

$65(448 \mathrm{MPa})<\sigma_{\mathrm{ts}}<75 \mathrm{ksi}(517 \mathrm{MPa})$

$75(517 \mathrm{MPa})<\sigma_{t s}<95 \mathrm{ksi}(655 \mathrm{MPa})$

$\sigma_{\mathrm{ts}} \geq 95 \mathrm{ksi}(655 \mathrm{MPa})$

Stainless steels
Ave Min Ave Min

$13(18) 10(14)$

10 (14) $7(10)$

15 (20) $12(16)$

$13(18) 10(14)$

$20(27) 15(20) \quad--\quad \ldots$

$\frac{\text { Lateral Expansion, inch }(\mathrm{mm})}{0.015(3.8)}$

$0.015(3.8)$

4. Design

A. Design for damage tolerance--formalized procedure not specified, however, B31.3 states: "Provisions shall be made to contain or safely relieve any excessive pressures to which the system may be subjected, e.g., ambient influences, improper operation, and failure of control devices."

B. Standard details--code or ASTM specification requirements for:

a. Reinforcements

b. Closures

c. Flanges and blanks

d. Reducers

e. Valves, fitting, etc.

c. Joining practices

a. Welding: practices, procedure qualification, and welder qualification per ASME, Section IX

b. Brazing: qualification per ASME, Section IX, Part QB

5. Analysis

A. Stress analysis--standard formula for:

a. Straight pipe under internal pressure

b. Intersections

c. Piping components

d. Sustained loads, thermal expansion, flexibility

e. Reinforcements 
B. Fatigue analysis--the allowable stress range for expansion stresses is reduced by a factor, $f$, for cyclic conditions, where $f$ is a function of the numer of full temperature cycles:

$\begin{array}{lc}\begin{array}{l}\text { Stress range reduction factors, } f \\ \text { Temperature cycles, } N\end{array} & \text { Factor } f \\ N<7000 & 1.0 \\ 7000 \text { to } 14,000 & 0.9 \\ 14,000 \text { to } 22,000 & 0.8 \\ 22,000 \text { to } 45,000 & 0.7 \\ 45,000 \text { to } 100,000 & 0.6 \\ \text { Over } 100,000 & 0.5 \\ & \\ & \end{array}$

6. Quality Assurance

A. Material procurement controls--ASTM specifications

B. Fabrication and processing controls Weld procedure and welder qualifications per ASME IX

C. Inspection--to assure compliance with engineering design and with the requirements of B31.1

Responsibility of the owner

Code compliance verified by authorized code inspector

Certified inspectors

D. INDE of welds--acceptance standards given

Visual

Magnetic particle per ASME $V$, Article 7

Liquid penetrant per ASIIE $V$, Article 6

Radiography per ASME $V$, Article 3

Ultrasonic per ASME V', Article 5 
E. Leak testing--boiler external piping to be in compliance with ASME I requires hydrotest per ASME I, Section PG-99

Leak testing per requirements of owner

$\sigma \leq 90$ percent $\sigma_{y s}$ in a11 leak tests

\section{References}

1. Power Piping, American Nlational Standards Institute, ANSI B31.1, American Society of Mechanical Engineers, llew York 1977.

2. Chemical Plant and Petroleum Refining Piping, ANSI B31.3, ASME, New York, 1977. 
1. Overview

Source: AIAA Workshop on Analysis of USAF Aircraft Structural Durability and Damage

Tolerance, Washington, D.C., April 1978.

A. Standards and specifications

a. Aircraft Structural Integrity Program

MIL-STDI-1530A

b. Specifications for Airplane Strength and Rigidity

MIL-A-8860 series

c. Airplane Damage Tolerance Requirements

MIL-A-83^44

B. Systems experience with fracture mechanics

a. Hew aircraft

Contract-specific requirements

$A-10$ and $B-1$

MIL-STDII-1530A requirements

F-15: by contract modification (ECP)

F-16. original contract requirement

b. Fleet aircraft--for inspection and modification planning

Evaluations completed

F-4 C/D, F-4E, A-7, C-5A, C141 A/B, F-111, and B-52

Evaluations in progress

T-38, E-3A, F-5E/F, KC-135, SK-71, T-39, F-5A/B

Evaluations being started

C- $130, \mathrm{~B}-52 \mathrm{G} / \mathrm{H}$

c. Engine Structural Integrity Program (ENSIP)

ElISIP still under development

Tentative EHSIP requirements being used to evaluate F-100 engines

C. Sumary of pre-1970 approach

a. Design and analysis

Fatigue analysis used to evaluate both durability and damage tolerance. Mean

life was predicted using conventional S-il data, Miner's rule for damage accumulation, and a block spectrum. A scatter factor of 4 was used to predict minimum 7 ife, i.e., mean $1 \mathrm{ife} / 4$. The scatter factor was assumed to account for the influences of initial quality level, environment, and material variability. 
b. Full scale testing

A production airplane was fatigue tested using a block spectrum for the equivalent of 4 service lives. Completion of the test without failure constituted proof of compliance to the aircraft structural integrity requirements. Test scheduling was not related to aircraft production schedules. Tear-down inspection of the test article was not generally required.

c. Force management--inspection and modification

The basic premise of force management was that safe 1 ife $=1 / 4$ of test 1 ife . Inspections, modifications, and repairs were scheduled for $1 / 4$ of test failure time. Inspection and maintenance times were adjusted for aircraft usage based on service life monitoring programs.

D. Problems with pre-1970 approach

a. Safe-life approach didn't always work for safety and durability.

b. High strength, flaw sensitive, stress corrosion susceptible materials not precluded

c. High stress levels not precluded

d. Full scale testing did not:

reflect developmental nature of test, include damage tolerance tests, use flight-simulation loading profiles, ensure timely data acquisition, and ensure critical data area identification by tear-down inspection.

e. Force management procedures need updating, i.e., fracture mechanics approach

f. Poor correlation between test and service

E. Summary of problems with pre-1970 aircraft

a. Severe usage

TAC T-38, F-5A/B

b. High stress levels--general

C-5A wing, KC-135 wing

C. High stress levels--1ocal

TAC T-38, F-5A/B, F-4C/D

d. Poor material toughness

B-52 D wing, F-111 wing fittings, KC-135 wing

e. Marginal initial quality

TAC T-38, F-5A/B, C-5A wing, F-111 wing fittings

f. Lack of damage tolerance

TAC T-38, F-5A/B, B52D wing, F-111 wing fittings, F-4C/D

g. Late testing

C-5A, F-111 
h. Test spectrum problems

KC-135, F-4C/D

2. Structural Design Conditions

A. Design life

a. Stipulated in contract established by force planners

b. Typical values

$\begin{array}{lccc} & \text { Fighters } & \text { Bombers } & \text { Cargo/Transport } \\ \text { Years of service } & 20 & 25 & 25-30 \\ \text { Flight hours } & 8,000 & 15,000 & 30,000 \\ \text { Number of flights } & 6,000 & 3,000 & 6,000 \\ \text { Number of landings } & 8,000 & 5,000 & 5-10,000 \\ \text { Fuselage pressurizations } & 8,000 & 5,000 & 5-10,000 \\ \text { B. Loads } & & \\ \text { a. Exceedance data in Mil-A-8866B specification } & \\ \text { b. Mission profiles and mission mix in contract, per force planners } \\ \text { C. Specifications for airplane strength and rigidity } \\ 8860 . & \text { General specification for ... } \\ 8861: & \text { Flight loads } & \\ 8862: & \text { Landing and ground handling loads } \\ 8865 . & \text { Miscellaneous loads } & \\ 8866: & \text { Repeated loads and fatigue } \\ 8867: & \text { Ground tests } & \\ 8869: & \text { Nuclear weapons effects } \\ 8870: & \text { Flutter, divergence, and other acroelastic instabilities } \\ 8892: & \text { Vibration } & \end{array}$

C. Environment

a. MIL A 8866B--design chemical/thermal environment spectra

The chemical and thermal environment anticipated during aircraft service is

characterized during aircraft design. Intensity, duration, frequency of

occurance of all exposures to chemicals, and temperatures are included.

b. MIL A 8867B--environment simulation requirements for tests

Material and joint allowables tests--evaluate chemical and thermal effects

Full scale tests--simulate chemical and thermal environment as deemed

necessary based on allowables tests 
D. Initial damage assumptions

Specified in MIL-A-83444 (2 July 1974) Airplane Damage Tolerance Requirements

a. Durability requirements (assumed initial quality level)

Cracks equivalent to an .005 inch $(.13 \mathrm{~mm})$ radius corner flaw are asssumed to exist at each location in the structure.

A larger initial flaw size may be required by the USAF if warranted by the initial quality data for the fastener holes in question. To establish inspection and maintenance schedules for aircraft in service, it is frequently necessary to establish the initial quality level by using fractographic methods to track flaw growth back to time zero.

b. Damage tolerance requirements (rogue flaw)

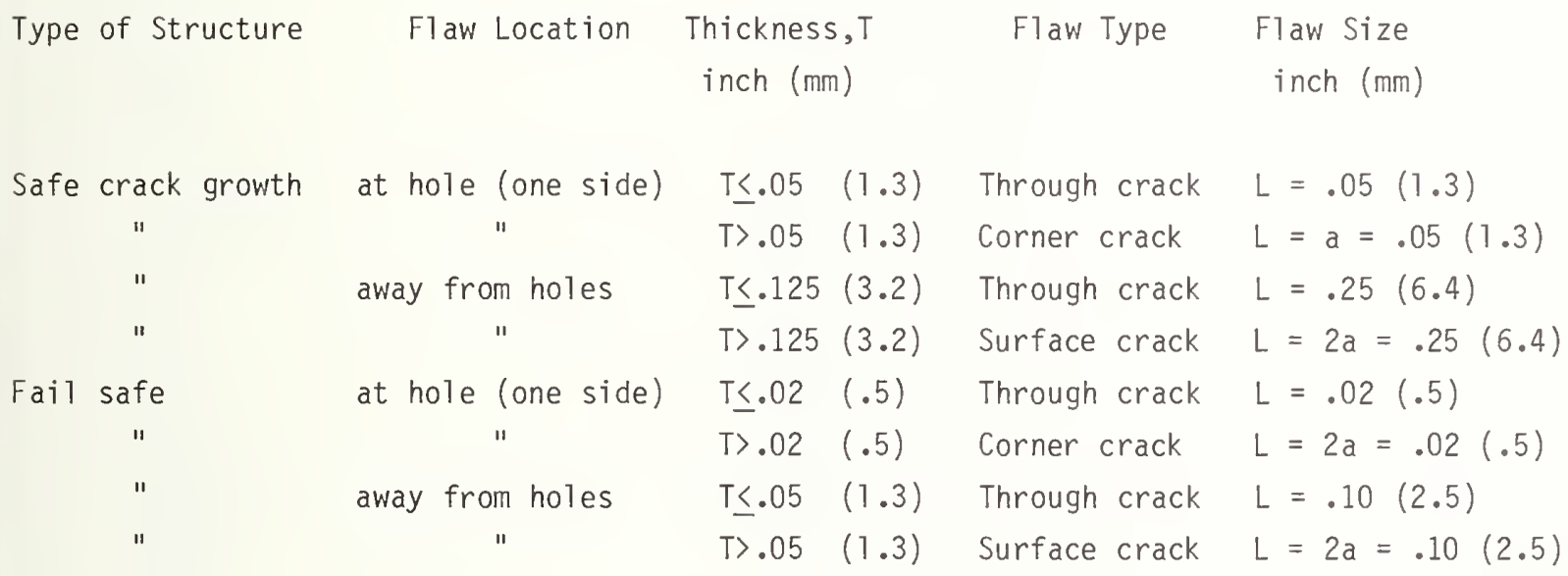

Corner cracks are quarter circular; surface cracks are semi-circular.

$L=$ crack length

$a=$ crack depth

c. Continuing damage

When crack growth terminates due to structural discontinuities or element failure, cracking is assumed to proceed at the most critical location of the remaining structure. The initial flaw size at this location is a .005 inch $(.13 \mathrm{~mm})$ radius corner crack at the edge of a hole or a .10 inch $(2.5 \mathrm{~mm})$ deep semicircular surface flaw, whichever is worst. Since this flaw is assumed to exist in the initial structure, it has grown by an increment, $\Delta a$, prior to termination of crack growth in the adjacent structure.

d. Remaining structure damage--fail-safe structures

Dependent configurations (structure where a common source of cracking exists in adjacent elements due to the nature of the fabrication procedures). The 
flaw size at the time of element failure is the initial rogue flaw size of 2.D.b. plus the increment of crack growth, $\Delta a$, prior to element failure. Independent configurations (structure where common source of cracking unlikely). The flaw size at the time of element failure is the continuing damage flaw size of 2.D.c.

Crack arrest structure (structure where unstable rapid crack propagation is arrested within a continuous area of structure and subsequent growth is slow enough to permit detection prior to complete failure). Flaw size in remaining structure depends on configuration. Two examples are: 1) for conventional skin-stringer structure, 2 panels and the central stringer are assumed to be totally cracked, and 2) for tear-strap configurations, the crack extends to the tear strap on each side of the stringer plus the stringer is broken.

e. Flaws assumed to exist after in-service insection

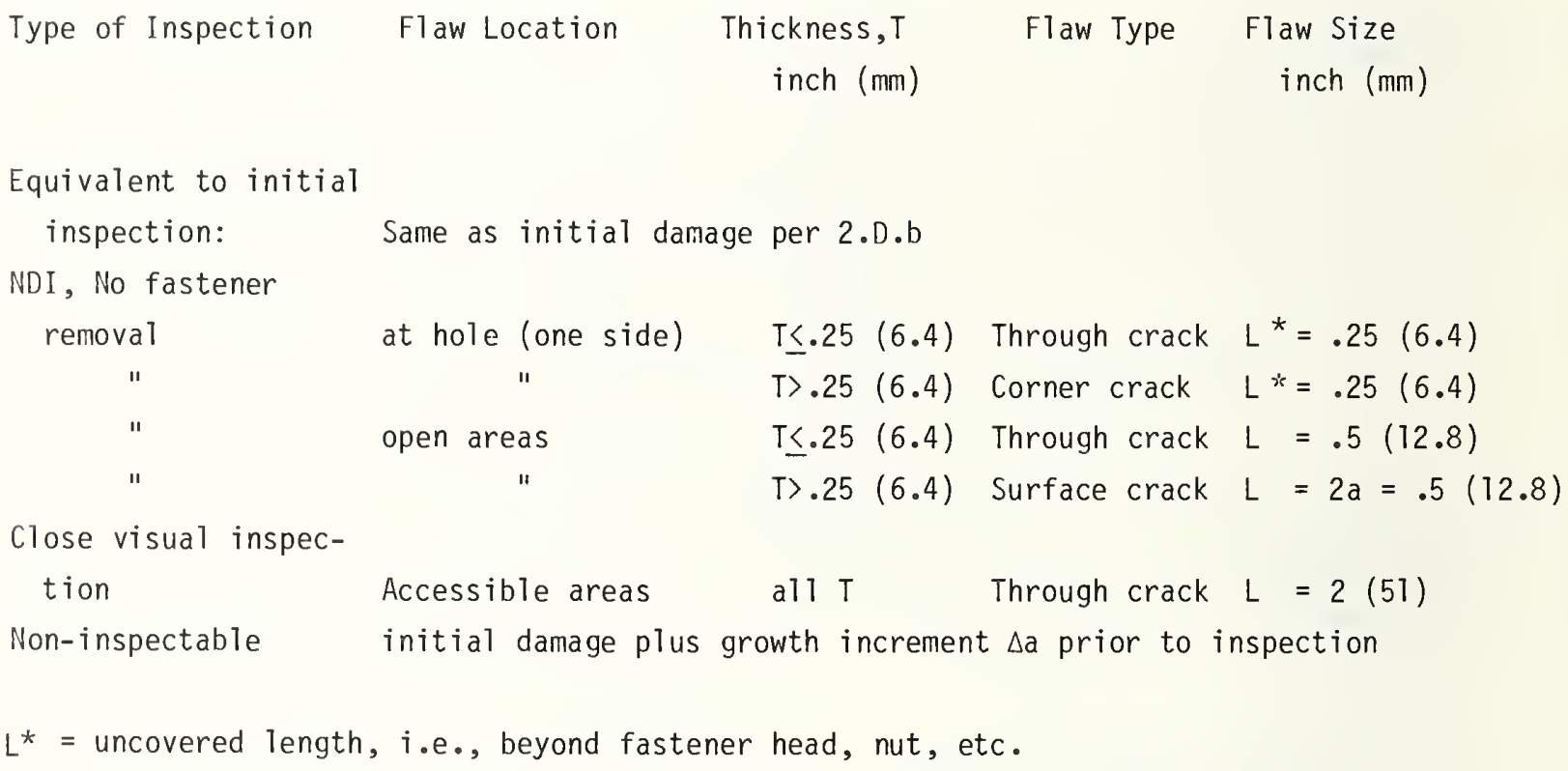

E. Safety factors

a. Static strength: factor of 1.5 on load

b. Fatigue (durability): None, formerly a scatter factor of 4 on life. Currently, economic life of the airframe must exceed the design service life.

c. Safe crack growth: factor of 2 on inspection interval Due to the damage assumptions required after inspection, it is sometimes easier to qualify structure as non-inspectable, which requires a factor of safety of 2 on design life. 
3. Materials and Processes
A. Selection
Based on concept/weight/material/cost trade studies, i.e., not a set list as in some codes
B. Properties
a. $\quad$ IIL-HDBK-5 (also-17 and-23 for plastics and composites)
b. Fracture mechanics properties. MCIC-HDBK-01
c. Contractor data: additional tests as required
d. Other sources: require approval by USAF

\section{Specifications}
Developed by contractor. Approved by USAF

4. Design and Analysis

A. Design for damage tolerance

a. Slow crack growth structure: Design concepts where stress levels are linited to assure that cracks will not grow to critical size during specified periods of usage which depend on degree of inspectability.

b. Crack-arrest fail-safe structure: Structure designed such that unstable, rapid propagation is stopped within a continuous area of structure and subsequent growth is slow enough to permit detection prior to complete failure.

c. Multiple load-path, fail-safe structure: Structure designed in segments such that localized damage is contained within one or two segments and the remaining structure exhibits slow crack growth and provides sufficient strength to the subsequent inspection.

B. Joints

a. Design development and joint allowables tests are conducted on representative joints (mechanically fastened and welded) to establish static strength and to verify crack growth analysis models that will be used for durability and damage tolerance evaluations.

b. The beneficial effects of interference fasteners, cold expanded holes, joint clamp-up, and other specific joint design and assembly procedures may be used in achieving compliance to the flaw growth requirements of MIL-A-83444. 
C. Stress analysis

a. Consists of the analytical determination of the stresses, deformations, and margins of safety resulting from the external loads and temperatures imposed on the airframe.

b. Used to verify airframe strength, provide stresses for fracture mechanics analysis, identify critical components for fracture control and for design development tests, and to select loading conditions for structural testing. It is also used as the basis for material review actions, for determination of the adequacy of structural changes, and for assessing the significance of new loads due to changed service requirements.

D. Fatigue (durability) analysis

a. Consists of the semi-empirical determination of the growth behavior of small flaws assumed to exist at critical locations throughout the structure due to application of the design service loads spectra. The analysis must account for load sequence and environmental interactions, material property variations, and analytical uncertainties.

b. Used to verify that the economic 1 ife of the airframe exceeds the design service life. This is accomplished by conducting the analysis between the limits of $f l a w$ sizes representative of the initial quality level (the minimum allowable initial flaw size is a .005 -inch $(.13 \mathrm{~mm})$ radius corner crack on one side of a hole) and flaw sizes that are readily repaired during depot level inspections. Generally the limiting flaw size is the maximum growth that can be eliminated by oversizing the hole to the next fastener size, generally about .030 inch $(.76 \mathrm{~mm})$.

E. Fracture mechanics (damage tolerance) analysis

a. Consists of the same flaw growth analysis used in 4.D.a except the initial flaw sizes are relatively large (rogue flaws) as summarized in 2.D.b. Initial flaws sizes and residual strength requirements are specified as a function of design concept (fail-safe or not) and inspectability.

b. Used to verify the safety of the airframe from potentially deleterious effects of initial defects caused by material manufacturing or processing malfunctions. The analyses are used to calculate critical flaw sizes, residual strengths, safe crack growth periods, and inspection intervals.

F. Fail-safe crack-arrest analysis

a. Consists of the analytical determination of the stress intensity factor as a function of crack length for a stress level corresponding to the lesser of design limit load or the maximum credible load multiplied by a dynamic factor $(D F=1.15$ unless test or analytical data indicate otherwise). 
b. Used to verify that crack arrest will occur in the configuration being evaluated for the specified level of initial damage and further to verify that subsequent fatigue crack growth will be slow enough to permit detection prior to failure.

C. Fail-safe multiple-1oad-path analysis

a. Consists of the analytical determination of the stresses and deformations caused by failure of a load path under specified loading conditions

b. Used to verify that load path failure will not cause complete structural failure and further to verify that fatigue crack growth in the remaining structure will be slow enough for specified initial flaw conditions to permit detection prior to failure

5. Quality Assurance

A. Material procurement controls

a. Material specifications prepared by contractor and approved by USAF

b. Minimum fracture toughness requirements are specified for materials to be used to manufacture fracture-critical parts. The specified toughness must equal or exceed the value used in design and analysis.

B. Fabrication and processing controls

a. Fastener installation procedures must be qualified to demonstrate that the assumed initial quality levels and that the beneficial effects of fatigue resistant fastener systems are valid.

b. Processing specifications are required to assure the processing conditions do not degrade material toughness to a level below that used in design.

c. Inspection

a. $\quad$ HDT demonstration program: Exceptions to the initial flaw size requirements of 2.D.b must be justified by an NDT demonstration program which verifies that all flaws equal to or greater than the design flaw size will be detected to the specified reliability and confidence levels. The demonstration shall be conducted using production conditions, equipment, and personine1; and the procedures employed must subsequently be used as production inspection requirements.

b. For each fracture-critical part, a specific inspection plan must be approved by the USAF and used in production.

D. Traceability

Traceability is required for all fracture-critical parts that receive processing and fabrication operations that could degrade the design material properties. 
A. Static tests

a. Consists of a series of laboratory tests conducted on an instrumented airframe that simulates the loads resulting from critical flight and ground handing conditions.

b. Used to verify the design ultimate strength of the airframe and to verify the stress analysis results by correlating strain survey results with analytical predictions

c. Scheduled to be completed such that the flight test program can be conducted on schedule, i.e., until test completion, flight test aircraft are restricted to 80 percent of limit load.

B. Fatigue (durability) tests

a. Consists of the repeated application of the flight-by-flight design service loads/environment spectra. Cycling is continued for a minimum of two lifetimes or until the economic life is reached. Subsequently the test article may be subjected to a teardown inspection, may be used for the damage tolerance tests, or may be cycled more to establish life or usage extension limits.

b. Used to verify that the economic life of the airframe exceeds the design service life, to identify fatigue critical components (hot spots) and to provide a basis for establishing special inspection and maintenance requirements.

c. Scheduled such that one lifetime of testing is completed prior to the full production go-ahead decision and two lifetimes are completed prior to delivery of the first production airplane.

C. Damage tolerance tests

a. Consists of a series of tests on full-scale articles with specified levels of induced damage that approximate the initial damage conditions and residual strength requirements used in design. Test articles include component test specimens and the static and durability test articles. Generally a separate test article specifically for damage tolerance testing is not required.

b. Used to verify the damage tolerance (and the analysis thereof) of the fracture critical parts

c. Scheduled to follow other major test programs in order to use the same test articles. 
D. Flight and ground operations tests

A series of tests are conducted on early aircraft, usually RDT and E aircraft to verify the airframe safety. These include.

a. Flight and ground loads survey

b. Dynamic response tests

c. Sonic durability tests

d. Flight vibration tests

e. Flutter tests

f. Ground vibration tests

g. Structural rigidity tests. 
General Sources. "Structural Design Criteria Applicable to a Space Shuttle," I:ASA SP-E057, January 1971.

E. M. Ehret, "Material Control and Fracture Control Planning for the Space Shuttle Orbiter Program," in Structural Integrity Technology, ASME, 1979.

1. Overview

A. Scope

This review is limited to the fracture control plan for the Space Shuttle required by the "Space Shuttle Flight and Ground System Specification," Document JSC 007700, Volume X, Revision B, Johnson Space Center, Houston, Texas. This document covers fracture control in a single paragraph which is shown below:

3.2.2.1.8 Fracture Control. In addition to the ultimate factors of safety presented in paragraph 3.2.2.1.5.2., designs for primary structure, windows, glass components of other subsystems, and tanks shall consider the presence of sharp cracks, crack-like flaws, or other stress concentrations in determining the life of the structure for sustained loads and cyclic loads coupled with environmental effects. Parts determined to be fracture critical, including all pressure vessels*, shall be controlled in design, fabrication, test, and operation by a formal, IIASA-approved fracture control plan as specified in SE-R-006, "JSC Requirements for Materials and Processes."

* For the purpose of this paragraph, a pressure vessel is defined to be a component designed primarily for the storage of pressurized gases or 1 iquids.

The Fracture Control section (2.4) of "Ceneral Specification, MASA USC Requirements for Materials and Processes," Document SE-R-0006, Revision B, March 29, 1976, is also reproduced less examples of organizational responsibilities below:

FRACTURE CONTROL REQUIREMENTS

Structural failures due to crack-like flaws shall be prevented on parts designated as critical to vehicle and crew survival by the application of fracture conirol to these parts. The identification of fracture critical 
based on the parts function, load, environment, life analysis material, and accessibility for inspection during fabrication and operation of the vehicle. Typical characteristics of a fracture control part are

a. Failure of the part will cause loss of the vehicle or crew.

b. Predicted operational stresses are a significant fraction of critical stress considering the load, environment, and life requirements of the part.

c. The part is not routincly accessible for preflight inspection.

FRACTURE CONTROL PLAN

A fracture control plan shall be developed to provide for the following.

a. Identification of components selected for fracture control on the basis of critically to structural flightworthiness and susceptibility to cracking or fracture.

b. Definition of organization responsibilities and procedure relevant to fracture control.

c. Maintenance of a continuing quality assurance activity.

d. Appropriate review, performance appraisal, and control by management.

The fracture control plan shall treat all organizations and disciplines which affect fracture control, and shall be approved by NIASA prior to implementation.

The two IIASA documents that cover the fracture control requirements for the entire Space Shuttle system are quoted because of their importance, brevity, and limited availability. These few paragraphs indicate how NASA implements fracture control for an incredibly complex system. In the NASA approach, the details of the fracture control plan for each major subsystem are prepared by the contractor for that subsystem and must be approved by NASA prior to implementation.

A further limitation on this review is that NASA treats fracture control as part of an overall systems specification that includes many other requirements that contribute to structural integrity. Fracture control is simply the set of extra requirements needed to assure that "structural failures due to crack-like flaws shall be prevented in parts designated as critical to vehicle and crew survival." 
Overall structural integrity of the Space Shuttle is primarily assured by analysis supplemented by tests to verify the analysis methods. Some full-scale testing is required to demonstrate capability to withstand the design loads and environment. IIASA's requirements for structural certification of the Space Shuttle system are specified in the Shuttle Master Verification Plan, IIASA Johnson Space Center, Report JSC-07700-10-MVP-01, May 15, 1973.

B. Subsystem fracture control plans

a. Space Shuttle Orbiter

Rockwell International, Space Revision Report SD73-SH-0082A, September 1974

b. Space Shuttle, Main Engine

Rockwell International, Rocketdyne Report RSS-8589-2, September 1977

c. Space Shuttle External Tank Martin Marietta, Michond Assembly Facility Report MMC-ET-SE13-C, Decenber 1, 1976

d. Space Shuttle Solid Rocket Motor Thioka1, Wasatch Division Report TUR-10184(DC), Revision B, May 18, 1977 IIASA, llarshall Space Flight Center Report SE-020-002-2H, June 17, 1974.

C. Fracture critical parts

The requirements of the fracture control plan are applicable to parts identified as fracture critical. The selection logic for fracture-critical parts is shown in figure $A-1$.

2. Structural Design Conditions

A. Design life--100 missions

B. Loads

Al1 static and dynamic loads and pressures acting on the structure are determined and distributed throughout the structure by rational analysis. Loads encountered in each of the operational phases (launch, space, reentry, atmosphere, flight, etc.) must be accounted for.

C. Environment

The structure must meet all the required design characteristics after (or during, as applicable) exposure to all credible environments. Thermal, chemical, and natural (rain, hail, blowing sand, etc.). 
D. Initial damage assumptions

a. Initial crack-like flaws are assumed to exist throughout the structure. The initial flaw size assumed in analysis is a function of the inspection method.

b. Standard NDE flaw sizes

Flaw sizes detectable with a 90 percent probability of detection and a 95 percent confidence level by inspectors certified to Level II of MIL STD 410 working to applicable aerospace industry and military standards. These flaw sizes are assumed in routine fracture mechanics analyses.

c. Special NDE flaw sizes

Flaw sizes detectable (again with $90 / 95$ statistics) by most-qualified inspectors using part-specific inspection procedures. These flaw sizes are assumed in the fracture mechanics analysis of specified parts where special NDE procedures are used.

d. NDE capabilities

\begin{tabular}{|c|c|c|c|}
\hline Inspection method & Flaw type & $\underline{\text { Standard NDE }}$ & Special IIDE \\
\hline $\begin{array}{l}\text { Penetrant or magnetic } \\
\text { particle }\end{array}$ & $\begin{array}{l}\text { Surface flaw } \\
\text { (Depth } \times \text { length) }\end{array}$ & $\begin{array}{l}0.19 \times 0.38 \mathrm{~cm} \\
(0.075 \times 0.150 \mathrm{in.}) \\
\text { or equivalent area }\end{array}$ & $\begin{array}{l}0.063 \times 0.127 \mathrm{~cm} \\
(0.025 \times 0.050 \mathrm{in} .) \\
\text { or equivalent area }\end{array}$ \\
\hline Ultrasonics & $\begin{array}{l}\text { Embedded flaw } \\
\text { (diameter) }\end{array}$ & $0.254 \mathrm{~cm}(0.100 \mathrm{in.})$ & $0.12 \mathrm{~cm}(0.047$ in.) \\
\hline Radiographic & $\begin{array}{l}\text { Surface or embedded } \\
\text { (depth } \times \text { length) }\end{array}$ & $\begin{array}{l}0.7 \times 1.4 \mathrm{t} \\
\text { Min length }=0.38 \mathrm{~cm} \\
(0.150 \text { in. })\end{array}$ & $\begin{array}{l}0.6 \times 1.2 \mathrm{t} \\
\text { Min length }=0.127 \mathrm{~cm} \\
(0.050 \text { in. })\end{array}$ \\
\hline
\end{tabular}

E. Safety factors

Recommended values (NASA SP-8057) for application to mechanically induced loads and pressure (i.e., not thermally induced). Limit load is defined as the maximum load expected to act on a structure in the expected operating environment. Limit pressure is the maximum differential pressure expected to occur in service.

a. General unpressurized structure

1.5 on limit load results in $\sigma$ (stresses) $<\sigma_{\text {tu }}$ (ultimate tensile strength). 1.0 on limit load results in $\sigma<\sigma_{\text {ty }}$ (yield strength)

b. Pressurized structure

1.5 on limit load applied at limit pressure results in $\sigma<\sigma_{t u}$. 
2 on limit pressure applied at zero load results in $\sigma<\sigma_{t u}$.

1.0 on limit load results in $\sigma<\sigma_{\text {ty }}$.

c. Main propellant tanks

1.4 on limit pressure results in $\sigma<\sigma_{t u}$

1.1 on limit pressure results in $\sigma<\sigma_{t y}$

d. Pressure vessels

2.0 on limit pressure results in $\sigma<\sigma_{t u}$.

e. Fatigue--factor of four on mission cycles

3. Materials and Process

A. Selection

a. A list of approved materials is maintained by the integration contractor (Rockwell International).

b. Selection of structural materials from this list is based on specified materials selection criteria (Rockwell International Shuttle Specification MF0004-003, September 20, 1974).

B. Properties

a. Sources: approved by NASA, such as MIL HDBK-5A or test data developed by the contractor

b. "A" allowables (99 percent nonexceedance with 95 percent confidence) used for single load path structure

c. "B" allowables (99 percent nonexceedance with 90 percent confidence) used for redundant structure

d. Fatigue and fracture mechanics data approved by NASA 


\section{Specifications \\ Developed by contractor. Approved by IIASA}

4. Design and Analysis

A. Design for damage tolerance

Fracture critical parts shall be designed using sound and established design procedures which include considerations for minimizing eccentricities and stress concentrations, providing access and clearance for in-service inspections and tests, and part documentation and identification requirements.

B. Joints

a. Design and analysis verified by test

b. The beneficial effects of interference fasteners, cold expanded holes and other K-reduction joint design and assembly procedures may be used in achieving compliance to the flaw growth requirements.

c. Welds--selection of materials and welding methods is based on consideration of the effect of welding on the operational capability of the parts concerned.

C. Stress analysis

a. Consists of the analytical determination of the structural response to the critical loads, environments, and temperatures anticipated during the service life of the vehicle.

b. Used for the following:

1) To define the critical combination of loads, conditions, material properties, and interactions which determine the stress levels and margins of safety for all structural components,

2) To show that deformations do not cause degradation of vehicle performance,

3) To establish vehicle strength and operating restrictions, and

4) To determine stresses for the fatigue and fracture mechanics analyses.

D. Fatigue analysis

A conventional fatigue analysis (i.e., no assumed initial flaw) is conducted to determine by analysis and subsequently verify by test that all structure vital to the integrity of the vehicle or the safety of personnel has a safe life that exceeds by at least four times the specified service life. 
E. Fracture mechanics analysis

A11 primary structural parts are analyzed to verify that the assumed initial flaws do not propagate to critical length during a minimum of four service lifetimes. Ilominal part dimensions, fatigue crack growth rates, minimum fracture toughness values, and semiempirical retardation models are used in the analysis. If the crack-growth life with standard IIDE flaw sizes does not exceed four lives, the part is fracture critical and special NDE is required and smaller initial flaw sizes may be assumed (section 2.0.d). If the part stil1 does not exceed four lives by analysis, the part must be redesigned or the analysis modified to reduce conservatism on the basis of directly applicable test results. If the part cannot be redesigned or successfully reanalyzed, the design life of the component riay be reduced below that of the system and mandatory inspection intervals established.

\section{Quality Assurance}

A. Materials and processes

a. General specification (IIASA requirements)

b. Material specifications. prepared by contractor and approved by NASA

c. Process specifications: required for fabriction activities such as welding, bonding, chemical processing, and heat treatment.

B. Inspection

a. NIDE demenstration program: Special NDE flaw sizes (2.D.d) require an IDE demonstration program to determine the minimum flaw size that can be detected 90 percent of the time with a 95 percent confidence.

b. Part specific NDE. A specific inspection procedure must be established for cach fracture-critical part.

c. Other quality assurance responsibilitics

a. Receiving inspection

b. Quality review and reporting

c. Failure documentation

d. Traceability

c. Personnel certification

D. Proof testing

a. Mandatory for all pressure vessels

b. Optional for establishing initial flaw sizes. In practice, this option is not too attractive because of the high toughness and thin section sizes of most of the structural members. 


\section{Qualification Tests}

Extensive qualification testing is required to verify the analysis procedures used in design and to demonstrate the capability of the structure to withstand the design loads and environment.

A. Static tests

a. Limit conditions. to demonstrate that detrimental defornation does not occur at limit loads and pressures

b. Ultimate conditions: to demonstrate that rupture or collapse does not occur at ultimate load and pressure

c. Combined conditions -

Loads and pressure

Loads and thermal effects

B. Life tests

a. Fatigue tests: to demonstrate safe life for four service lives

b. Fail-safe tests. to demonstrate damage tolerance and residual strength where applicable

c. Flight and ground tests

a. Static elasticity--divergence

b. Dynamic acroclasticity--flutter

c. Vibration

d. Shock

e. Thernal 


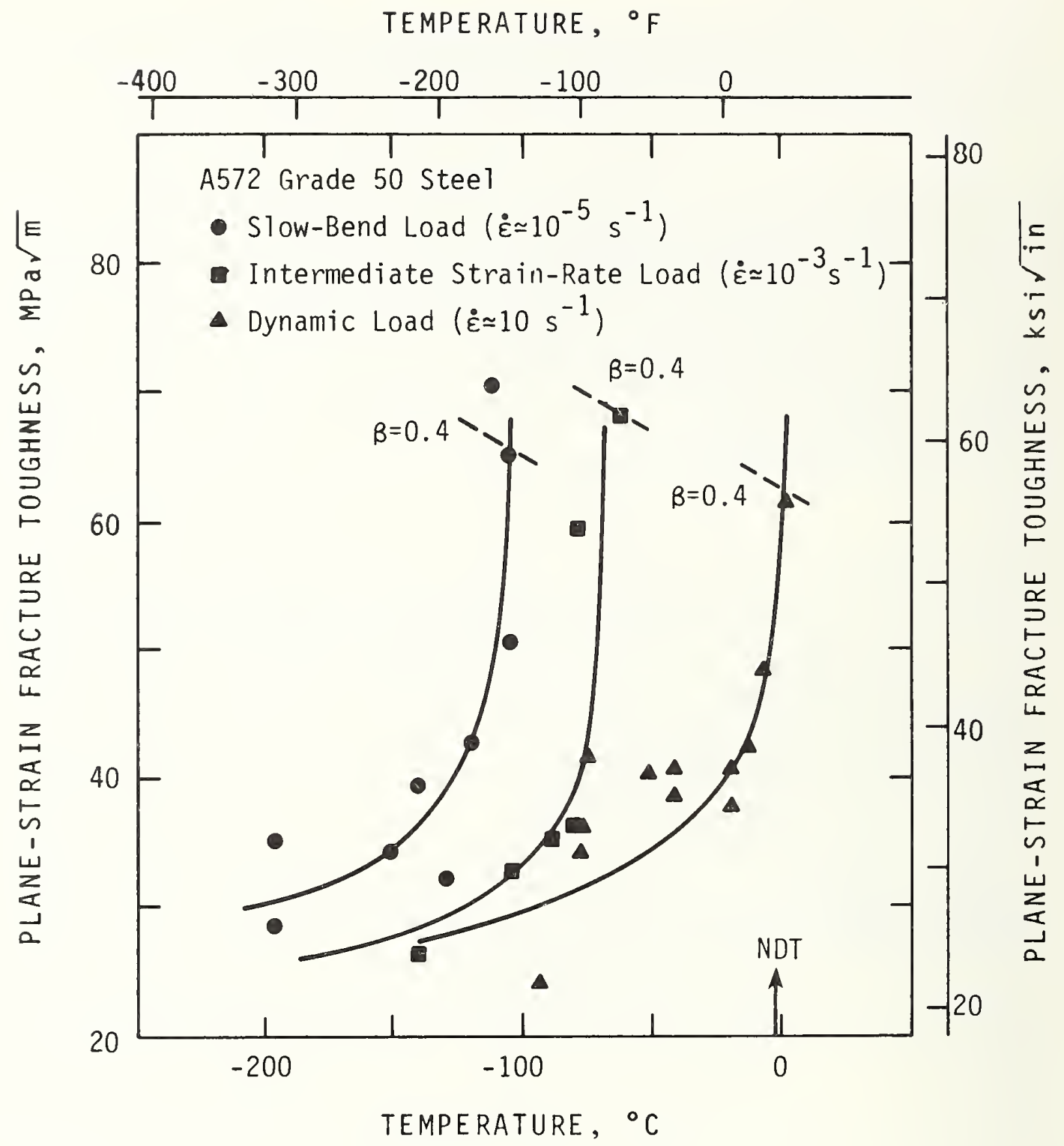

Fig. 1 The Effect of Strain Rate on the Fracture Toughness of a Structural Steel 
CHARPY V-NOTCH ENERGY, ft. Ibs.

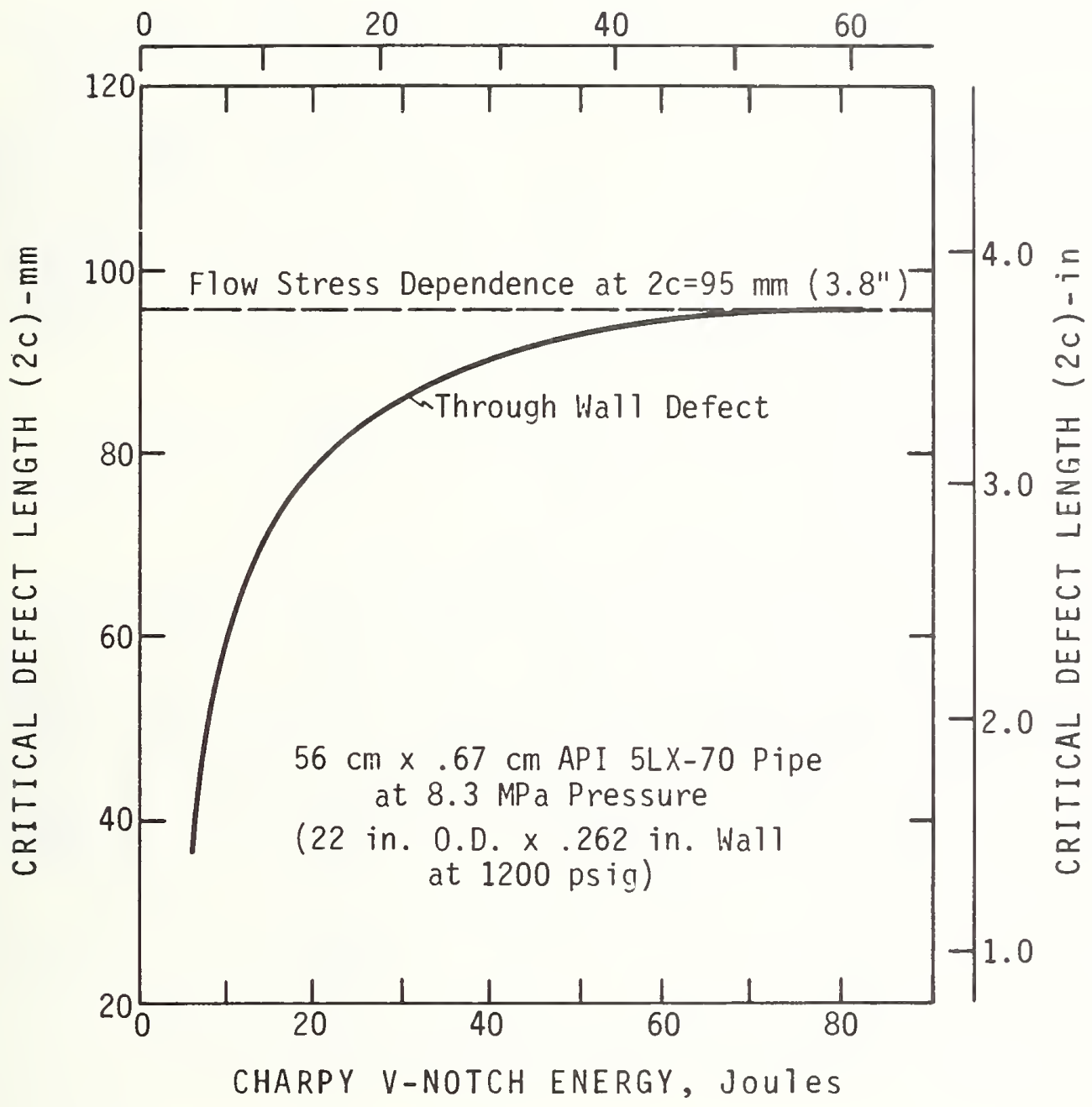

Fig. 2 Critical Crack Length as a Function of Charpy V-ilotch Toughness for a Specific Type of Size of Line Pipe 


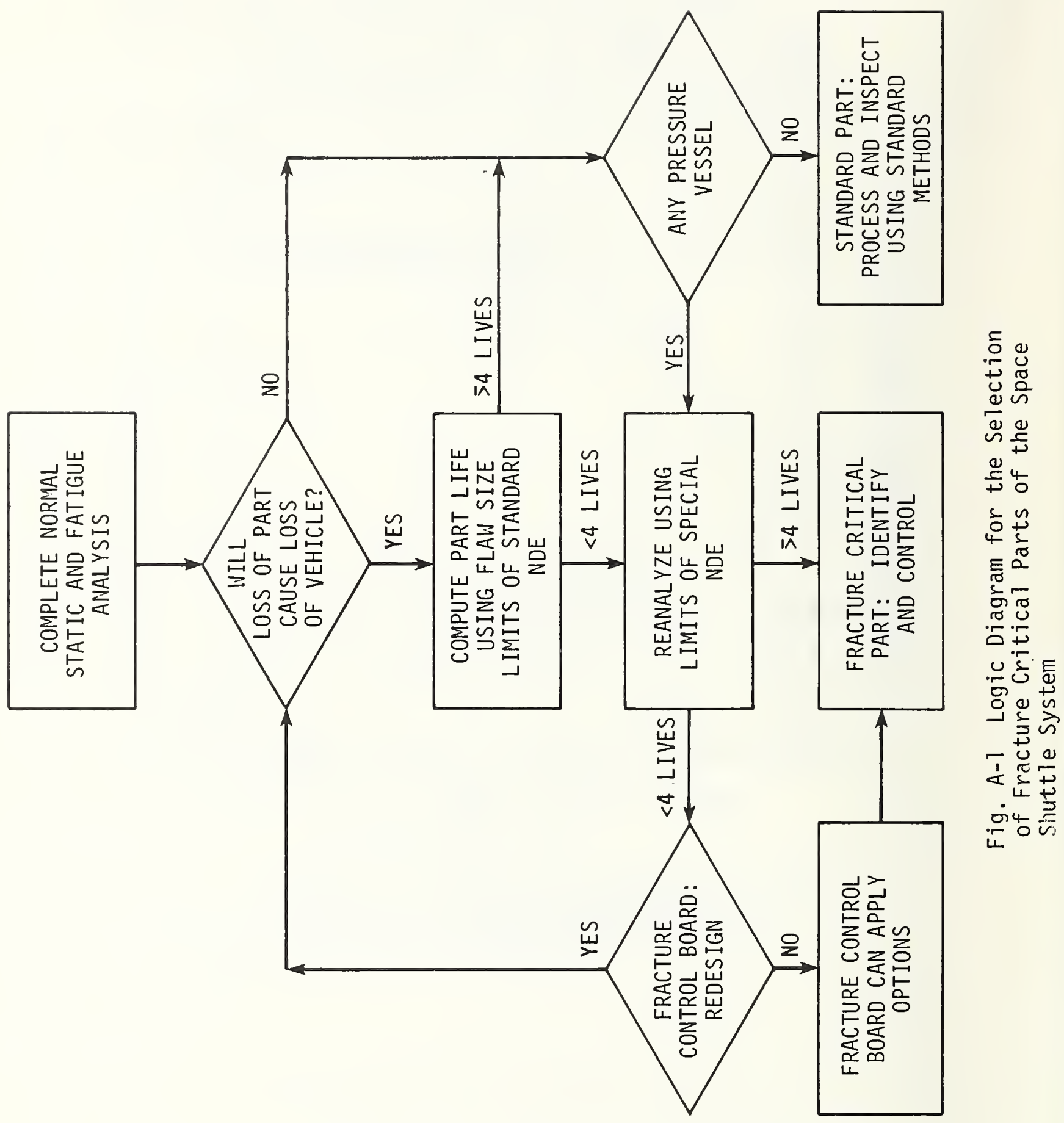


NBS. II AA (REV.0.78)

\begin{tabular}{|c|c|c|}
\hline $\begin{array}{l}\text { U.S. DEPT. OF COMM. } \\
\text { BIBLIOGRAPHIC DATA } \\
\text { SHEET }\end{array}$ & $\begin{array}{l}\text { 1. PUBLICATION OR REPORT NO. } \\
\text { NBSIR } 79-1623\end{array}$ & 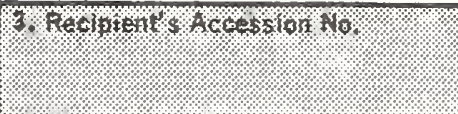 \\
\hline \multirow{2}{*}{\multicolumn{2}{|c|}{ 4. TITLE AND SUBTITLE }} & $\begin{array}{l}\text { 5. Publication Date } \\
\text { January } 1980\end{array}$ \\
\hline & & 6. Performing Organization Code \\
\hline \multicolumn{2}{|l|}{ 7. $A U T H O R(S)$} & 8. Performing Organ. Report No. \\
\hline \multicolumn{2}{|c|}{ 9. PERFORMING ORGANIZATION NAME AND ADDRESS } & 16. Prolect/Task/Notk Unit No. \\
\hline \multicolumn{2}{|c|}{$\begin{array}{l}\text { NATIONAL BUREAU OF STANDARDS } \\
\text { DEPARTMENT OF COMMERCE } \\
\text { WASHINGTON, DC } 20234\end{array}$} & 11. Contract/Grant No. \\
\hline \multirow{2}{*}{\multicolumn{2}{|c|}{ 12. SPONSORING ORGANIZATION NAME AND COMPLETE ADDRESS (Street, City, state, ZIP) }} & 13. Type of Report \& Period Covered \\
\hline & & 14. Sponsoring Agency Code \\
\hline
\end{tabular}

15. SUPPLEMENTARY NOTES

Document describes a computer program; SF-185, FIPS Software Summary, is attached.

16. ABSTRACT (A 200-word or less factual summary of most significant information. If document includes a significant bibliography or literatura survey, mantion it here.)

Fracture control practices are the engineering procedures and requirements that contribute to the prevention of fracture in metal structures. These practices are identified as the elements of fracture control and each element is defined and described. The systematic application of these practices to the prevention of fracture in a particular structure is accomplished by either the code approach or the performance specification approach to fracture control. In these two approaches, the consideration given to each of the elements of fracture control is discussed and illustrated with examples for specific types of structures. Selected practices that may be of use in Naval systems are discussed. An Appendix contains detailed summaries of the fracture control practices used in each of thirteen classes of metal structures, including ships, offshore structures, bridges, cryogenic tanks, pressure vessels, piping, power generation equipment, and aerospace structures.

17. KEY WORDS (six to twelva entries; alphabetical order; capitalize only the first letter of the first key word unlaas a proper name; saparated by semicolons)

Fracture Control, Fracture Mechanics, Mechanical Properties, Quality Assurance, Stress Analysis, Structural Safety.

\begin{tabular}{|c|c|c|}
\hline 18. AVAILABILITY & $\begin{array}{l}\text { 19. SECURITY CLASS } \\
\text { (THIS REPORT) }\end{array}$ & $\begin{array}{l}\text { 21. NO. OF } \\
\text { PRINTED PAGES }\end{array}$ \\
\hline$\square$ For Official Distribution. Do Not Release to NTIS & UNCLASSIFIED & 114 \\
\hline $\begin{array}{l}\square \text { Order From Sup. of Doc., U.S. Government Printing Office, Washington, DC } \\
20402 \text {, SD Stock No. SNO03-003- }\end{array}$ & $\begin{array}{l}\text { 20. SECURITY CLASS } \\
\text { (THIS PAGE) }\end{array}$ & 22. Price \\
\hline $\begin{array}{l}X \text { Order From National Technical Information Service (NTIS), Springfield, } \\
\text { VA. } 22161\end{array}$ & UNCLASSIFIED & \\
\hline
\end{tabular}





$$
-
$$


